\title{
QNVTLC STATES
}

DEPAETMENT OF THE INTERIOF

\section{GEOLOGICAL SURVEY}

\section{$9-136$}

\section{7}




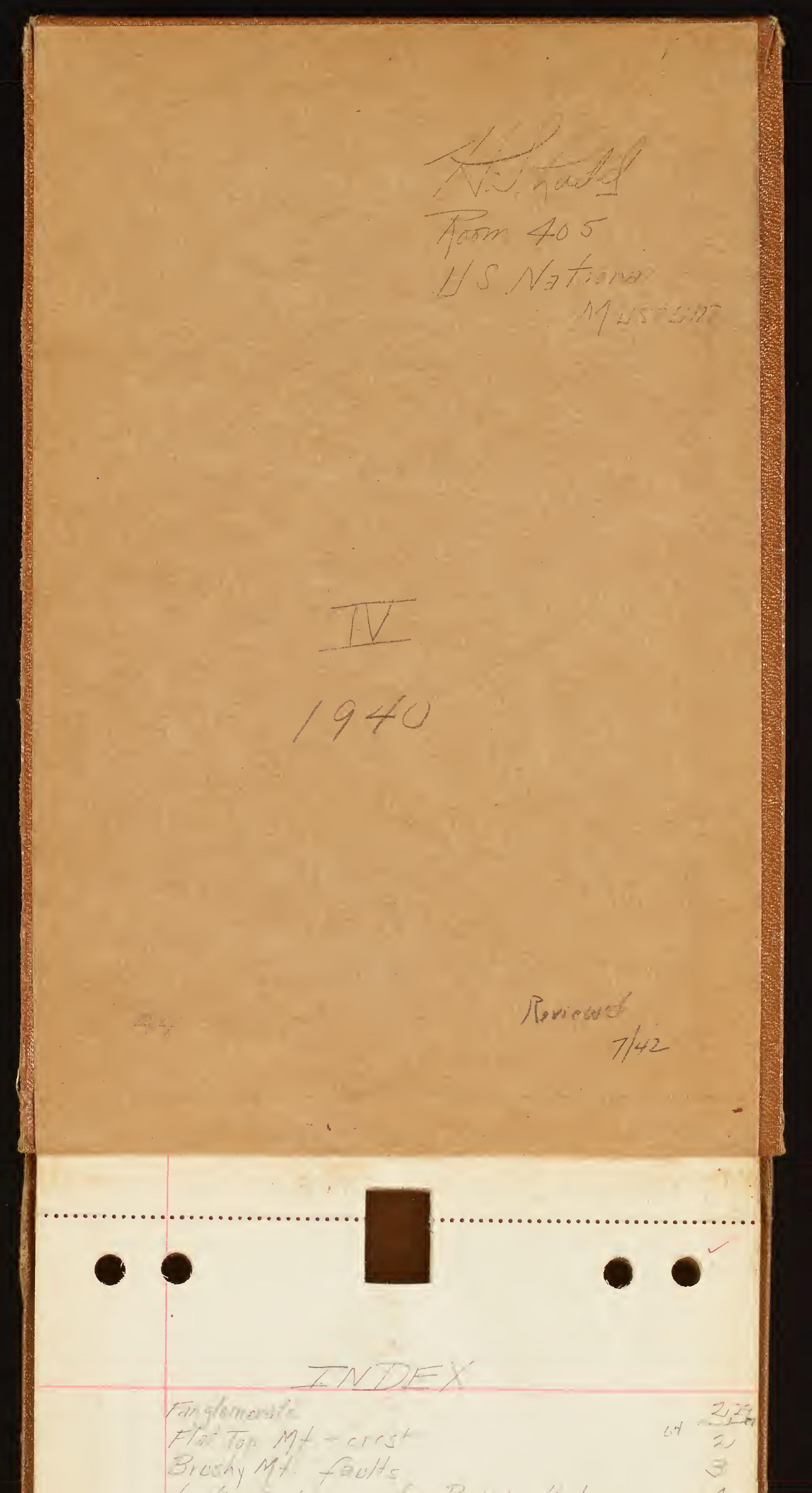




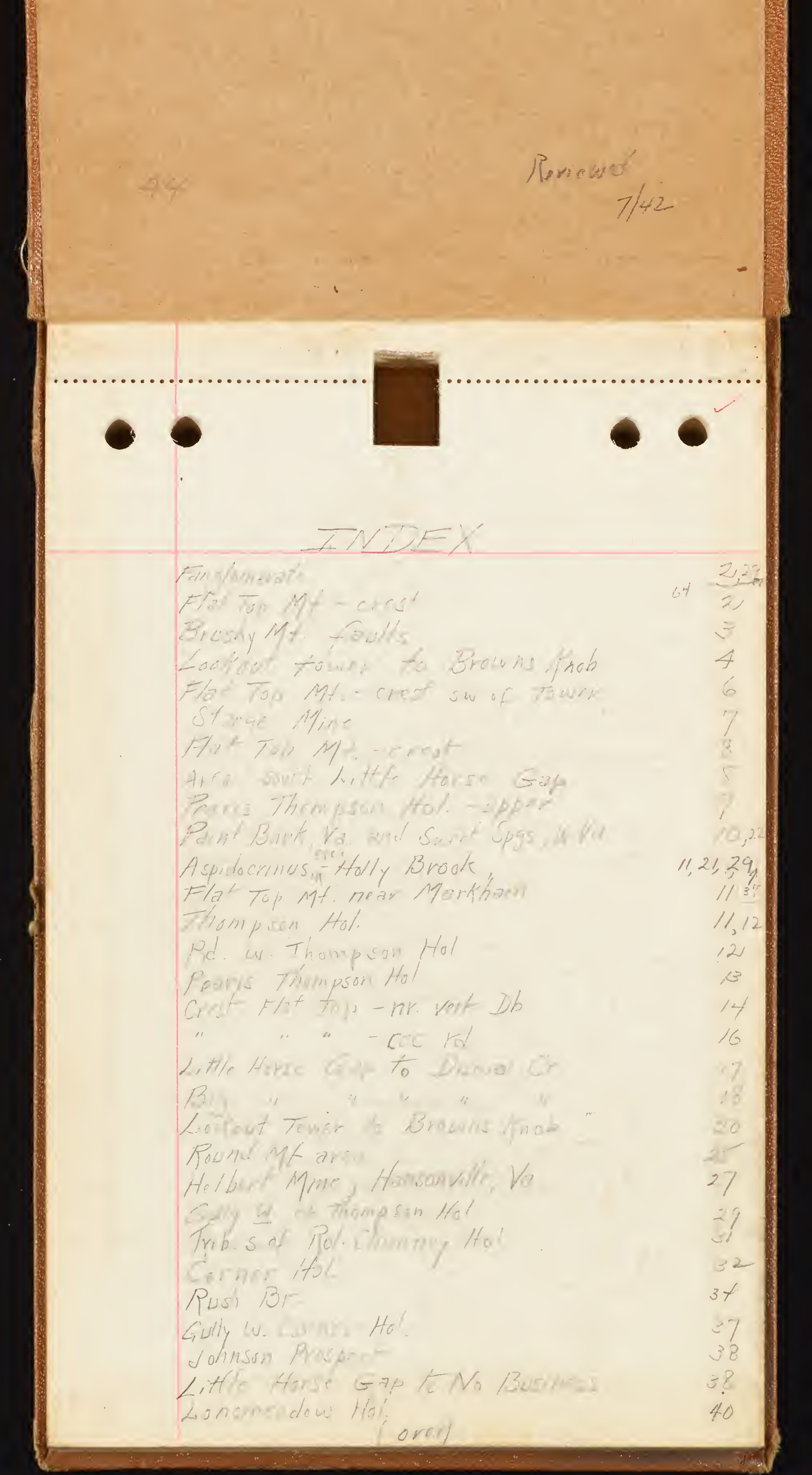


Brushy Mt _. _ _ _ _ $\ldots 41,54$ Round Mt - -8 - $\quad 45.55$. " "Switer Mine - - - -47 Big Harse Gap to SE - - W - 59 Round $M$, cCC Rd. Dismal Basin
Stange "Prospects" - _ _ - $-6 /$ Senny Cábin Hollow Rocky gap section — — $\quad 67$ Traynham Prospect, _. _ _ - 68 


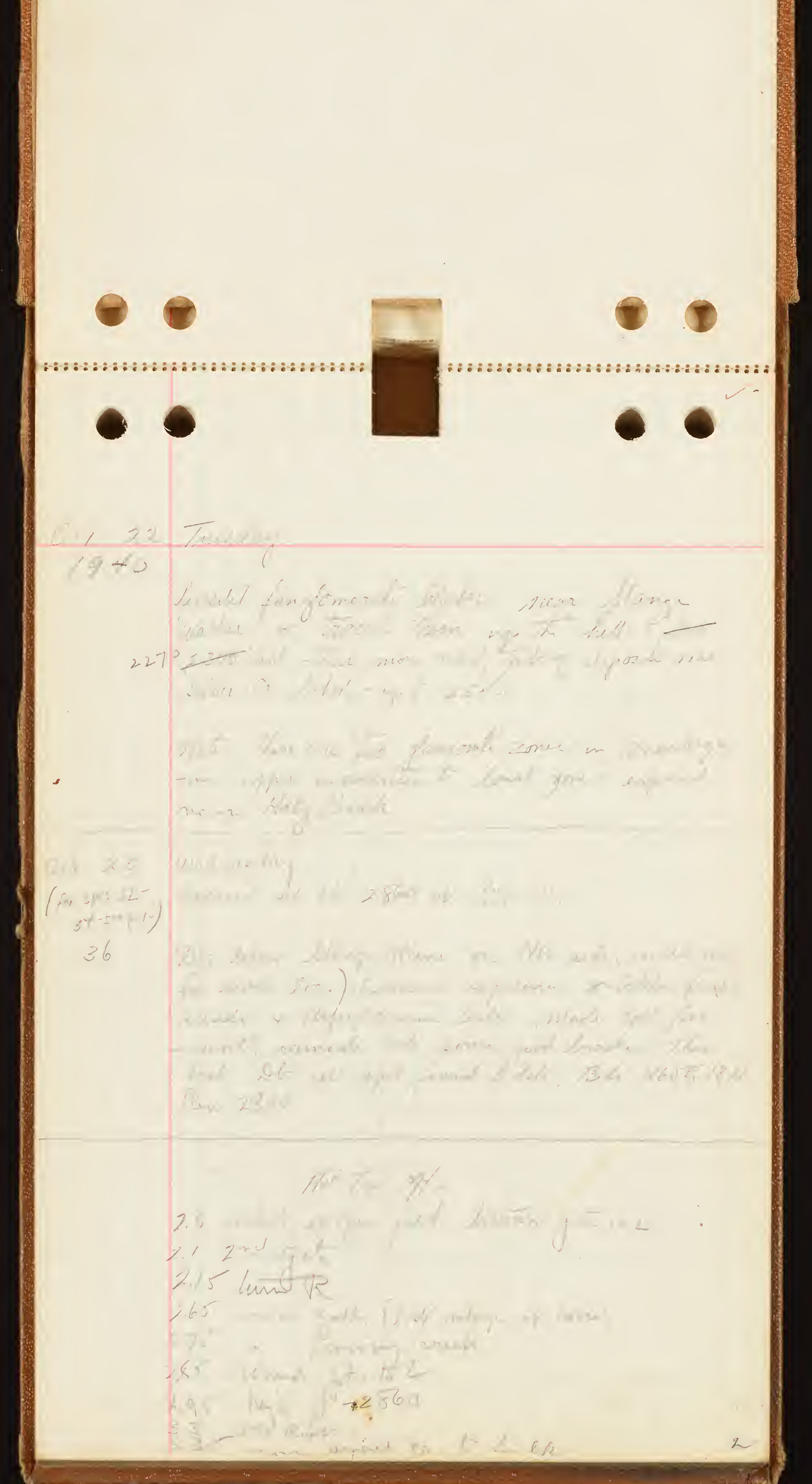




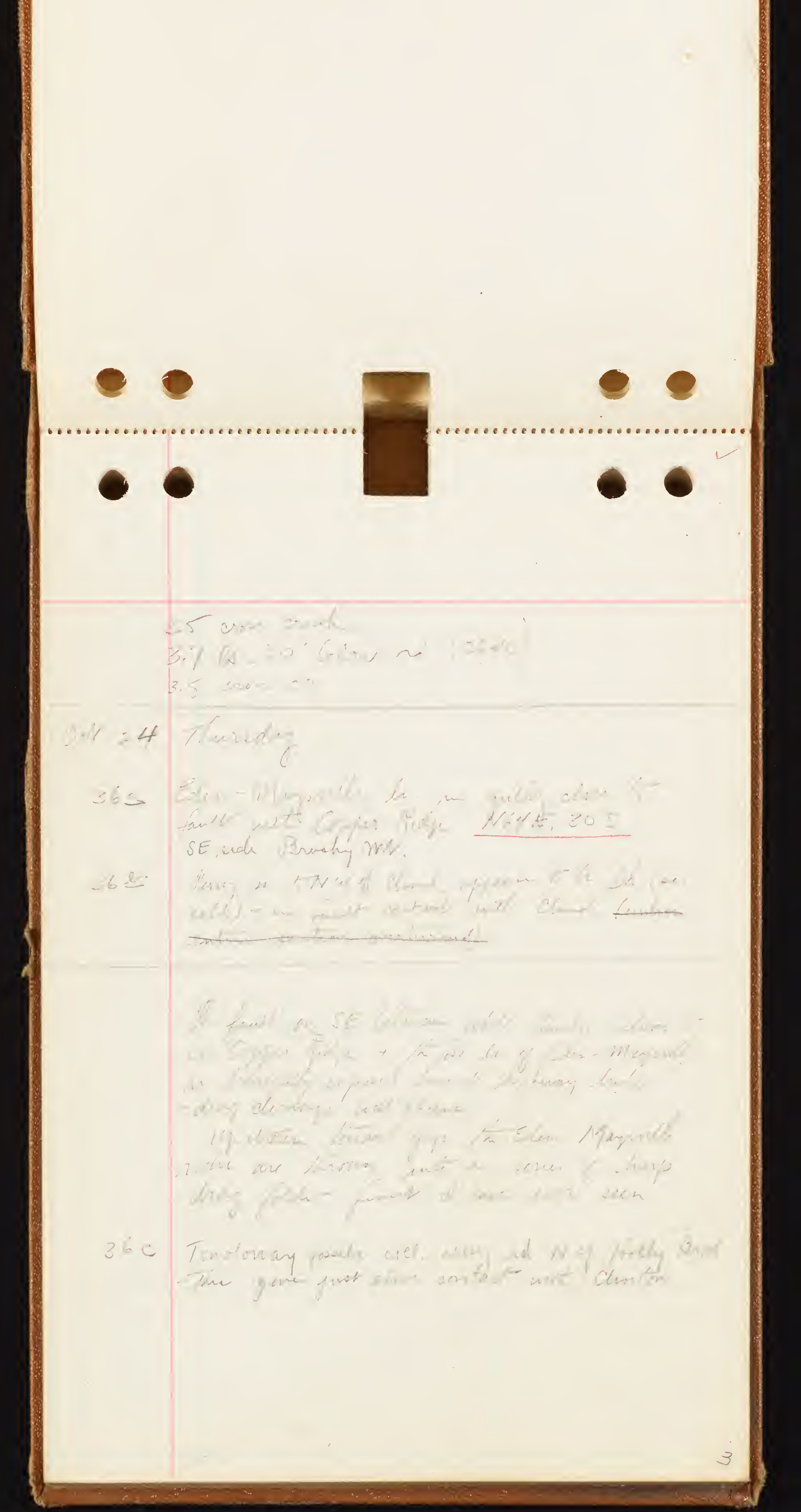




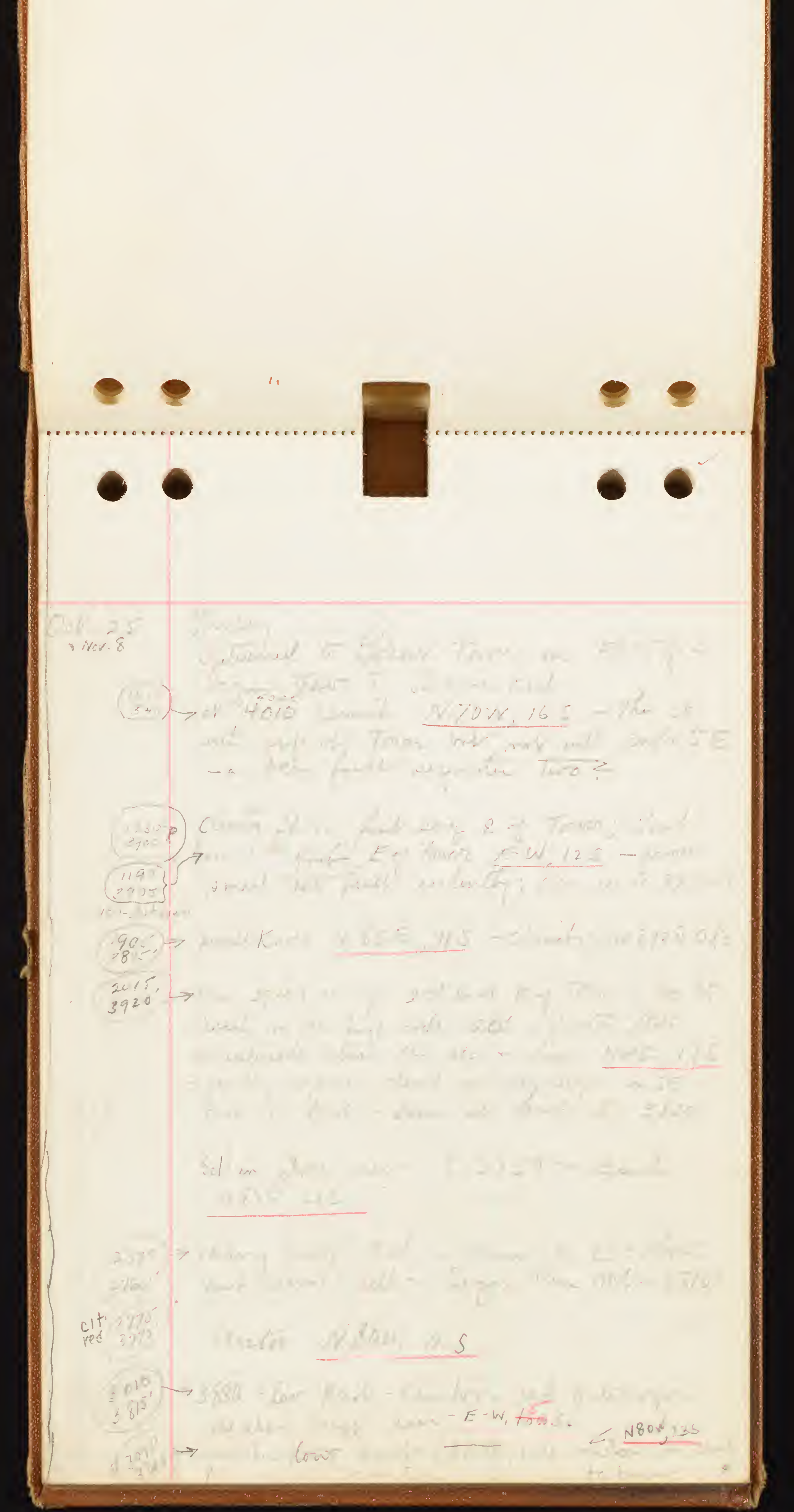




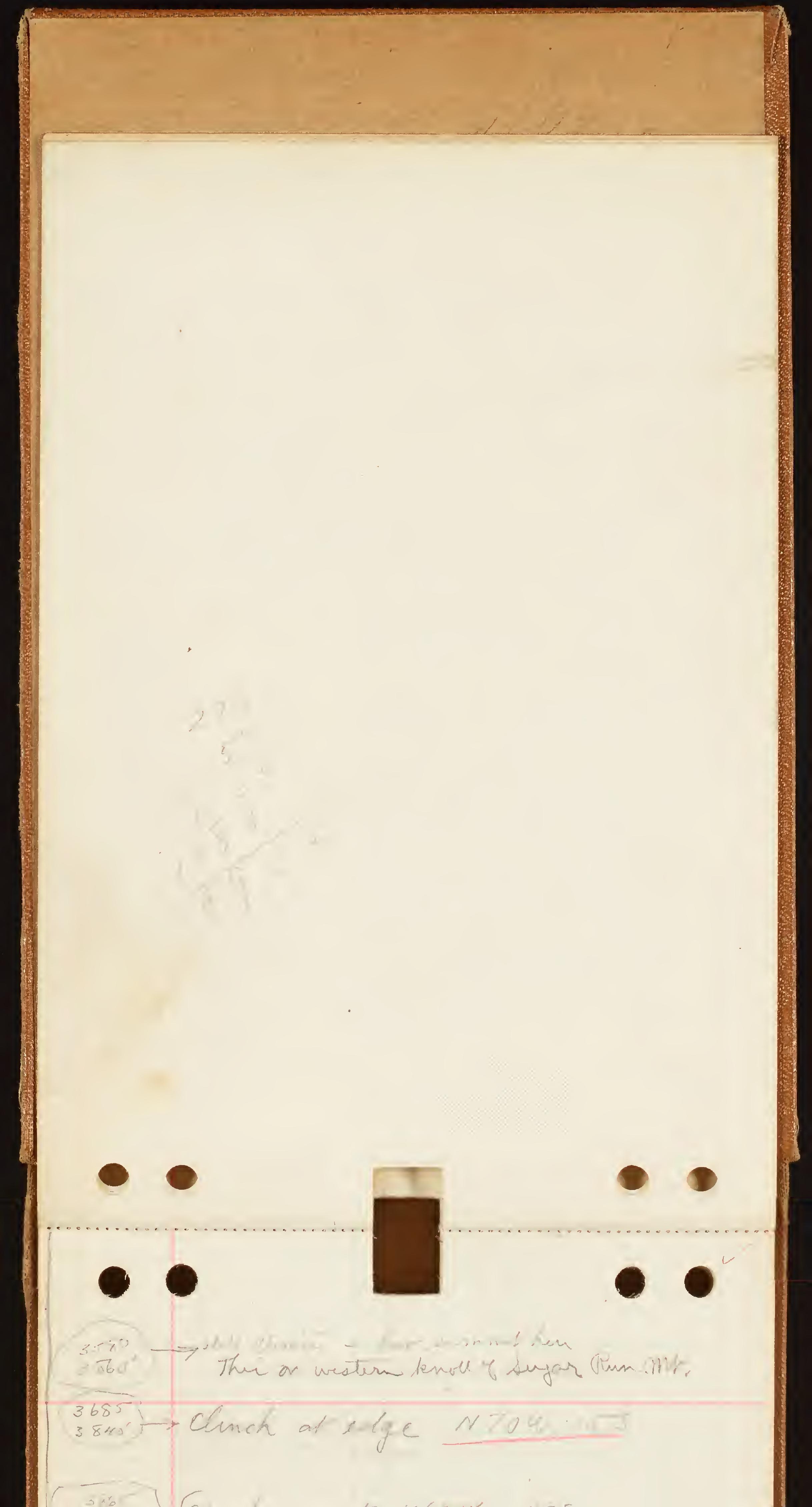




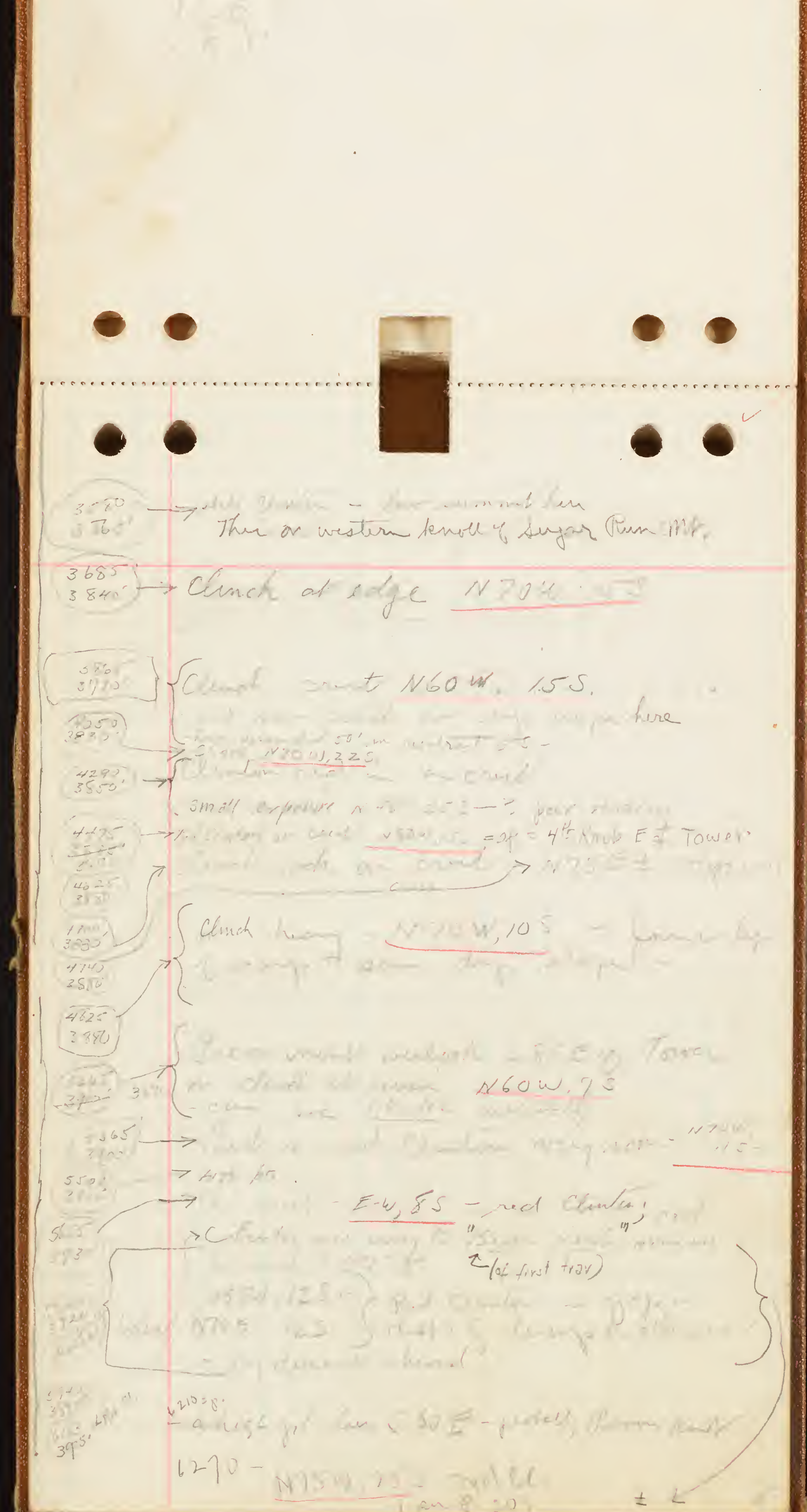




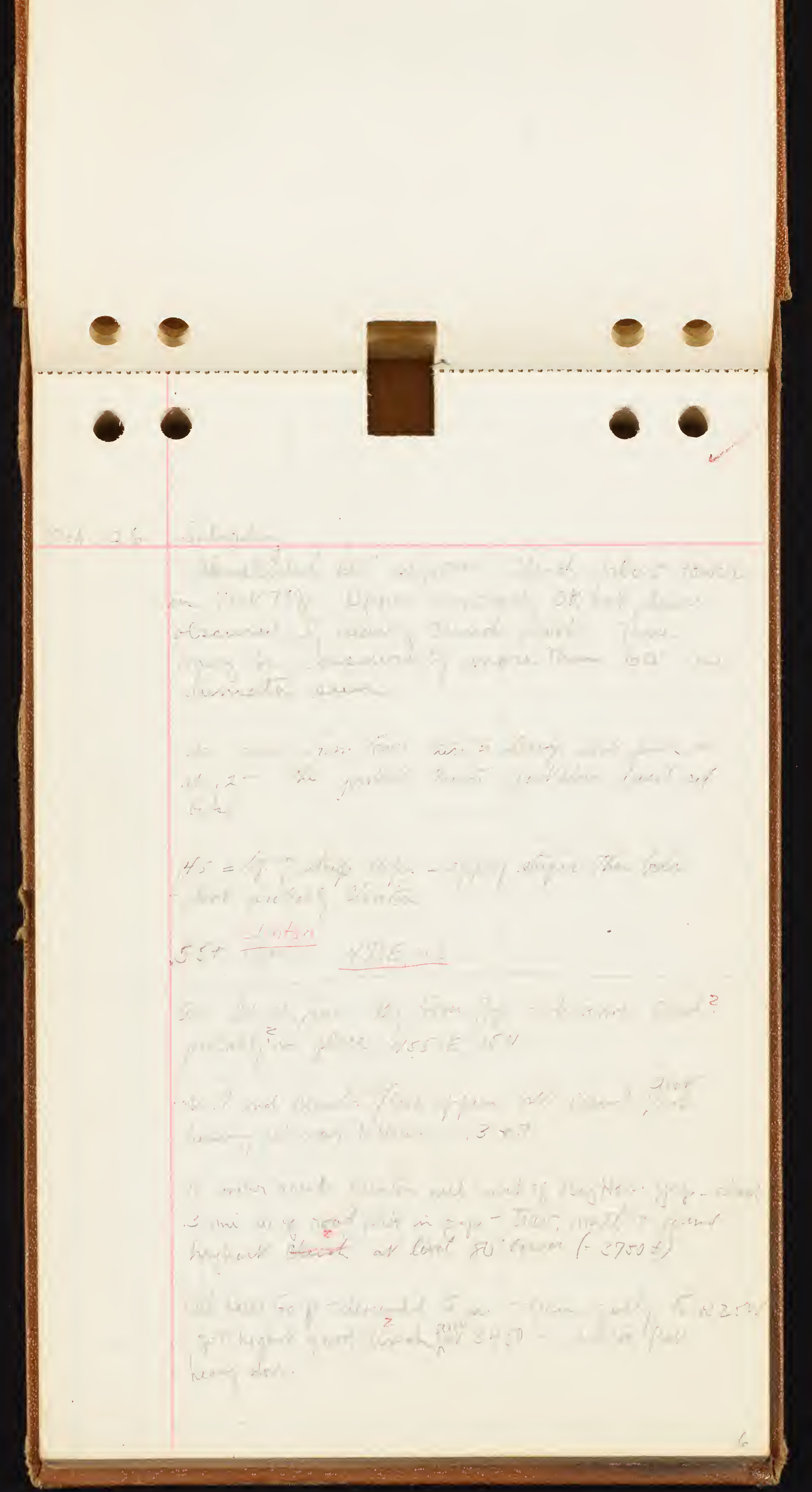




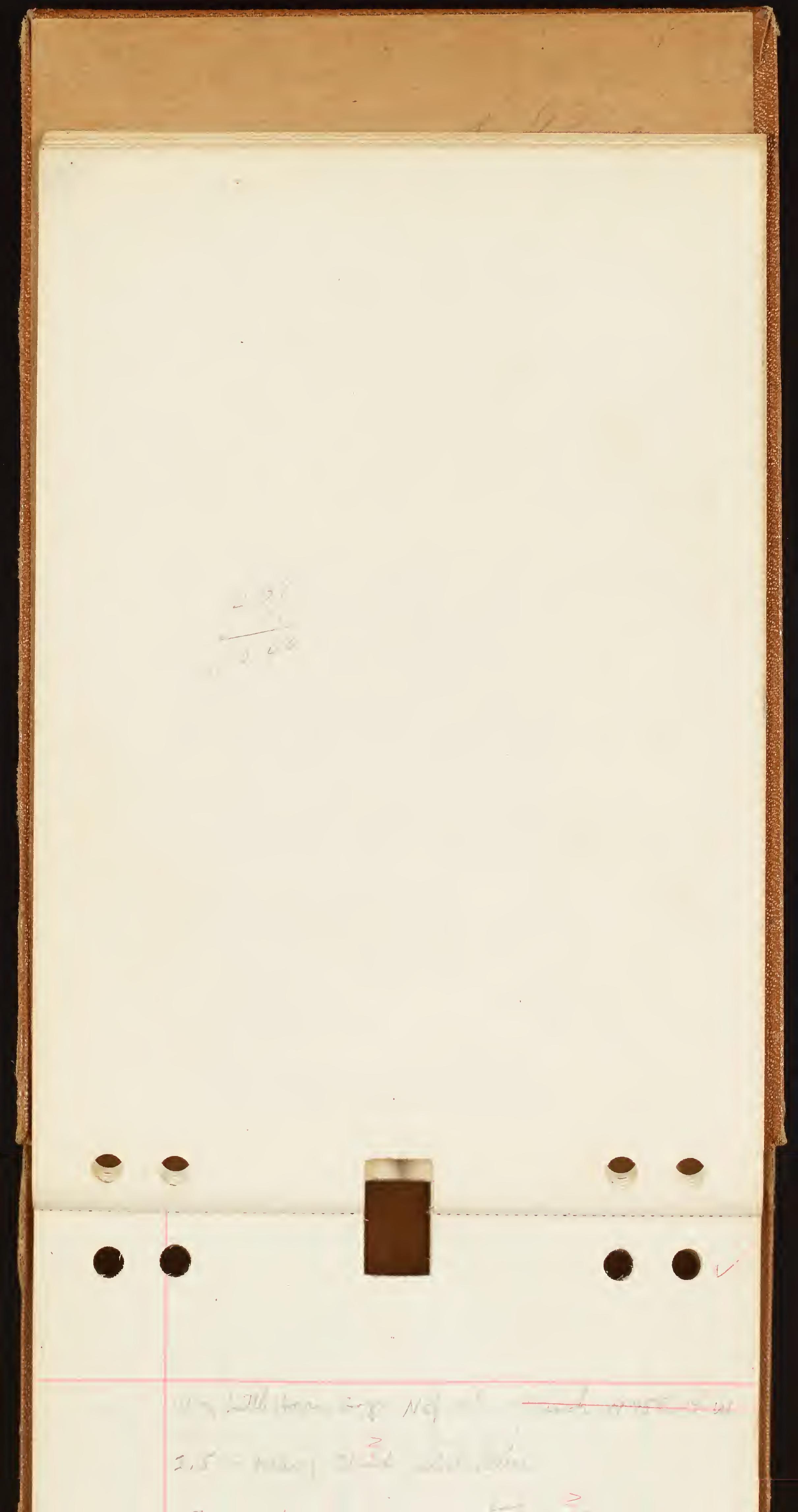




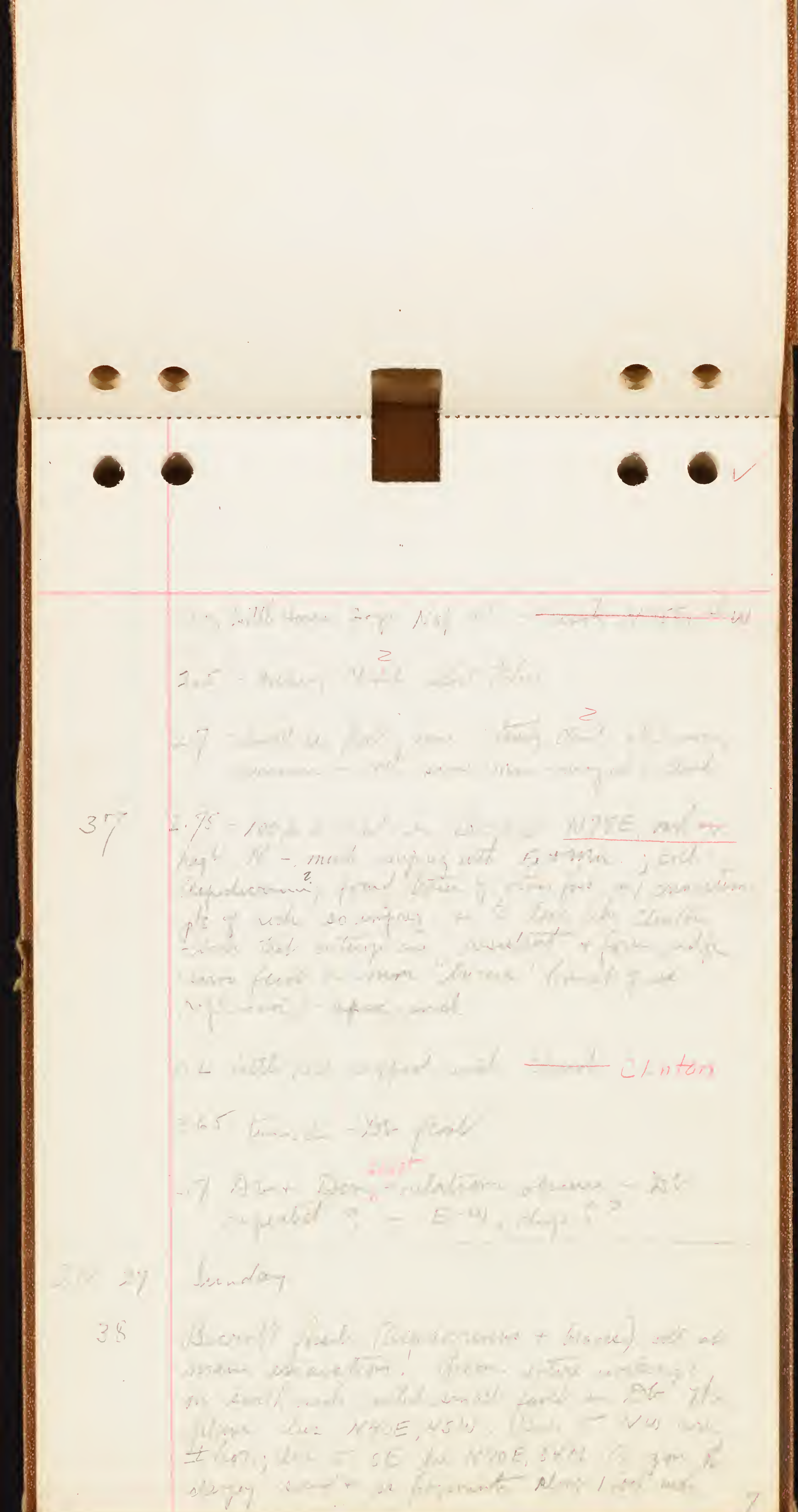



$?$

.

- $\bullet$

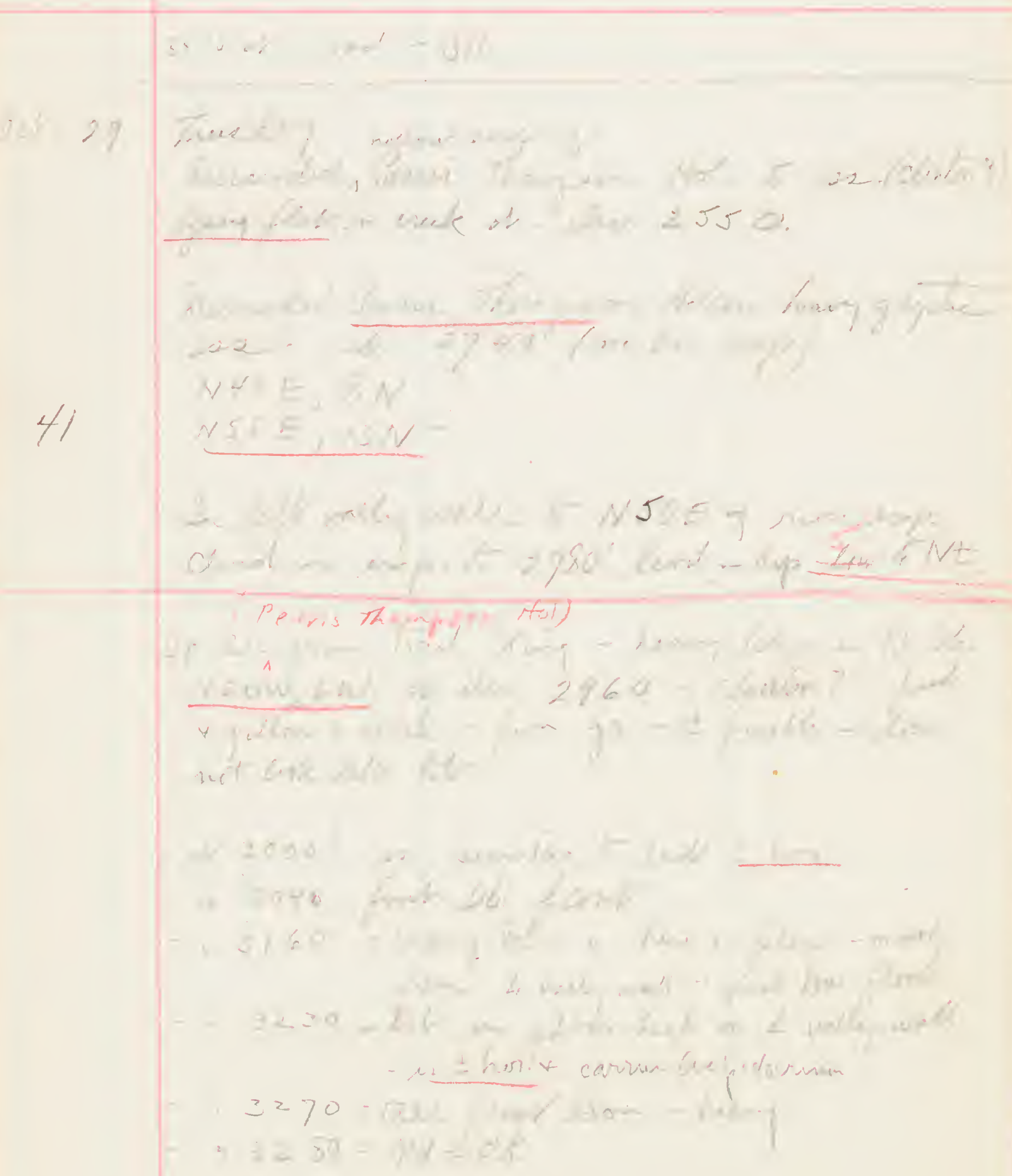


$+$

-

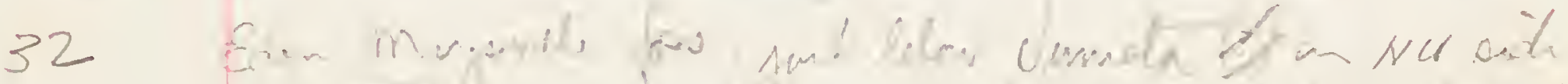

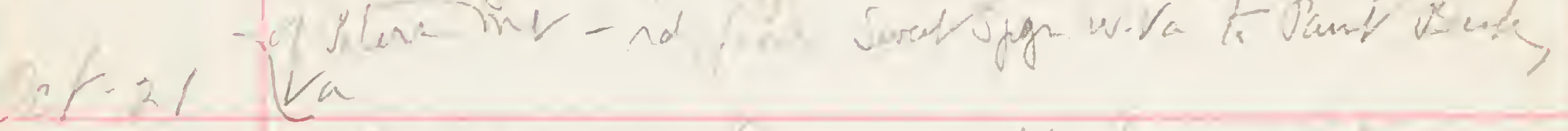

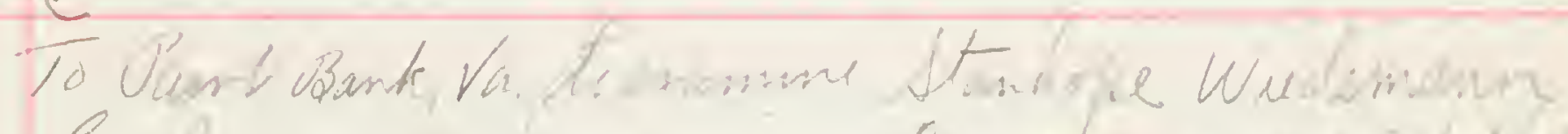

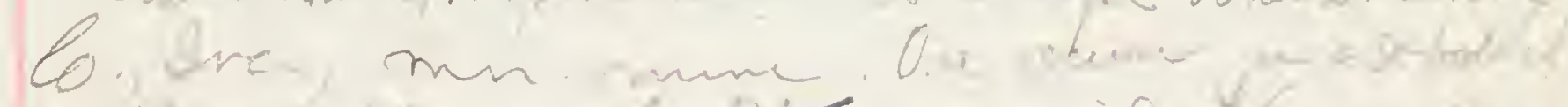

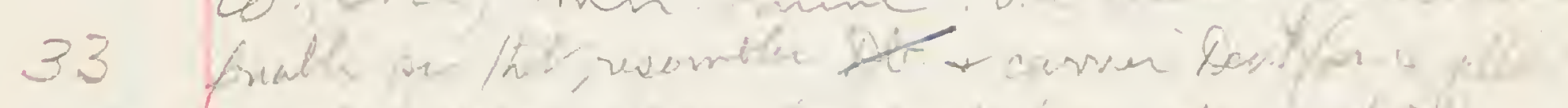

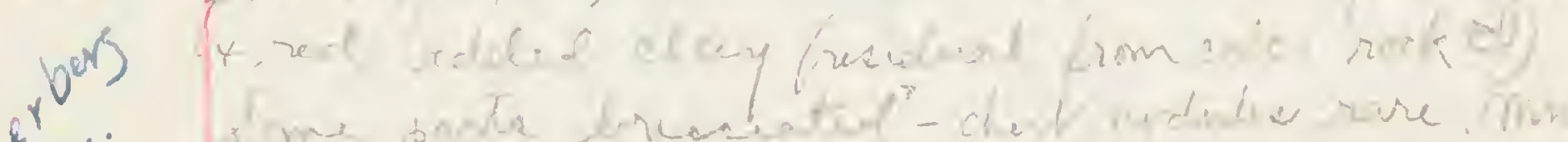

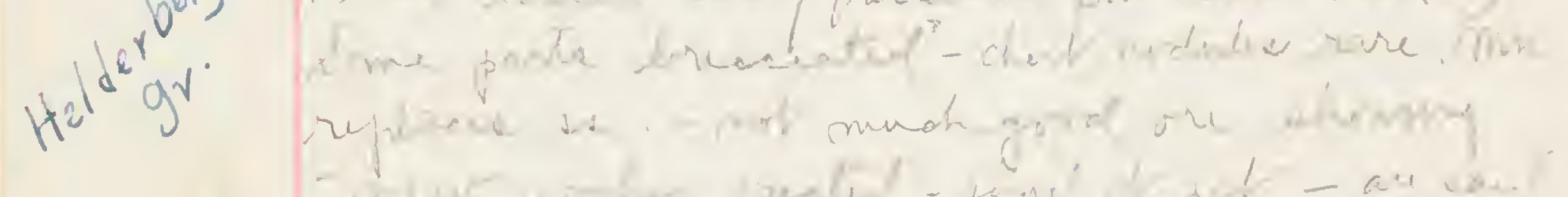

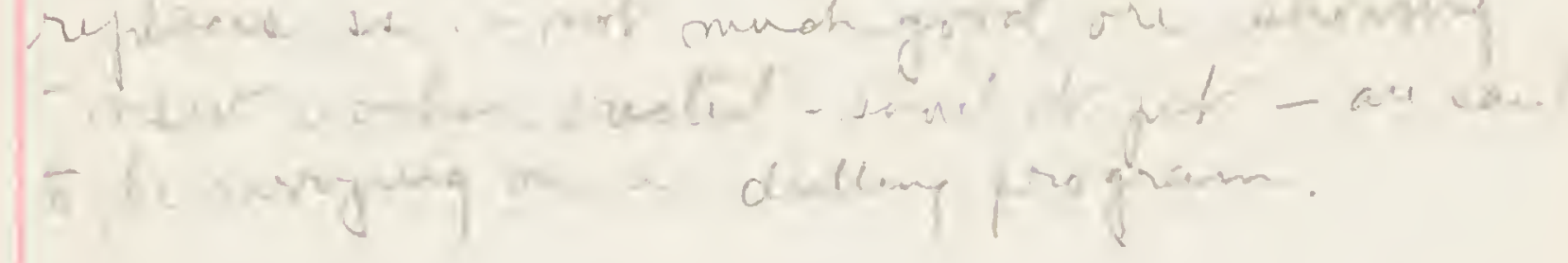

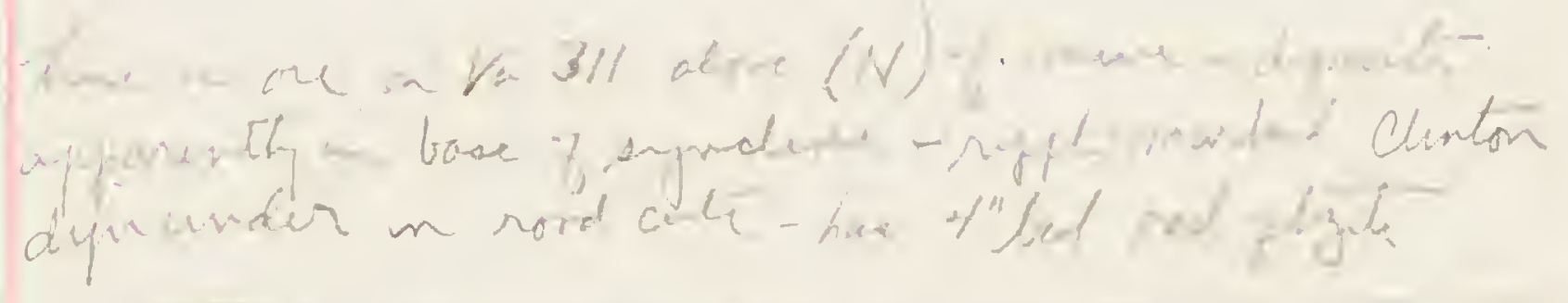
Tipparaciun the Go. Lemen Morke.

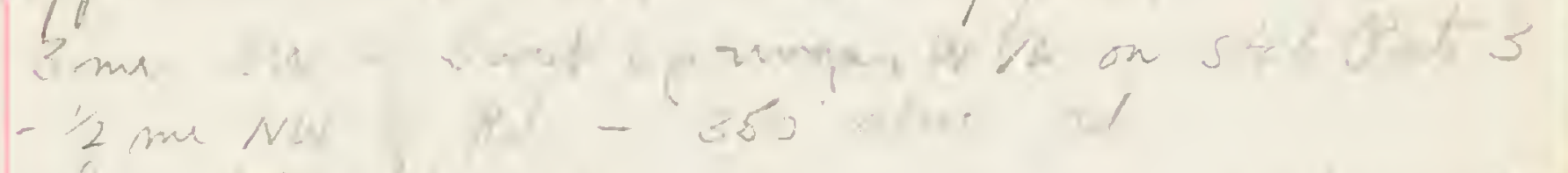

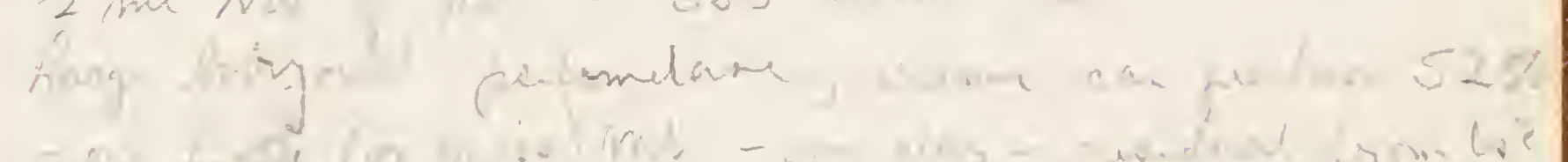

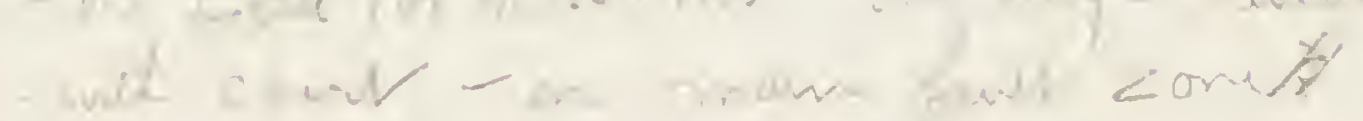

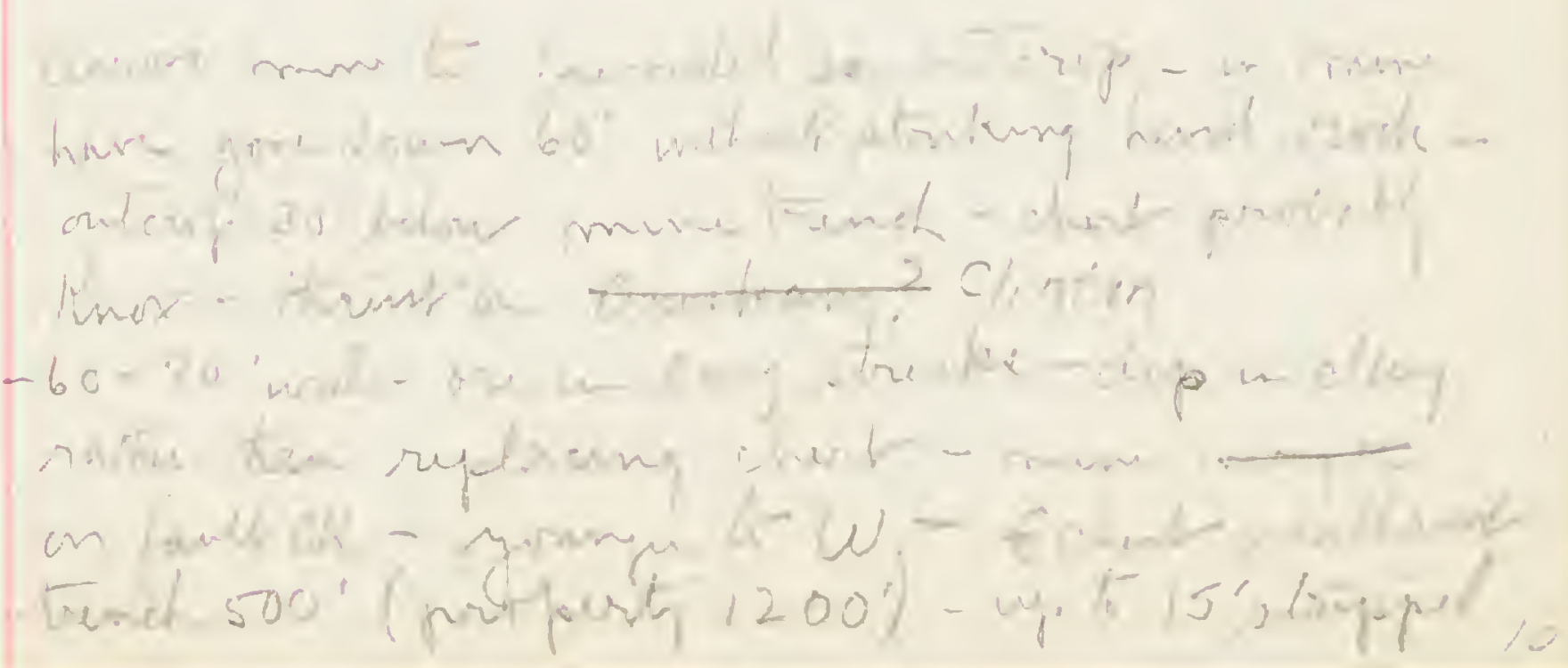




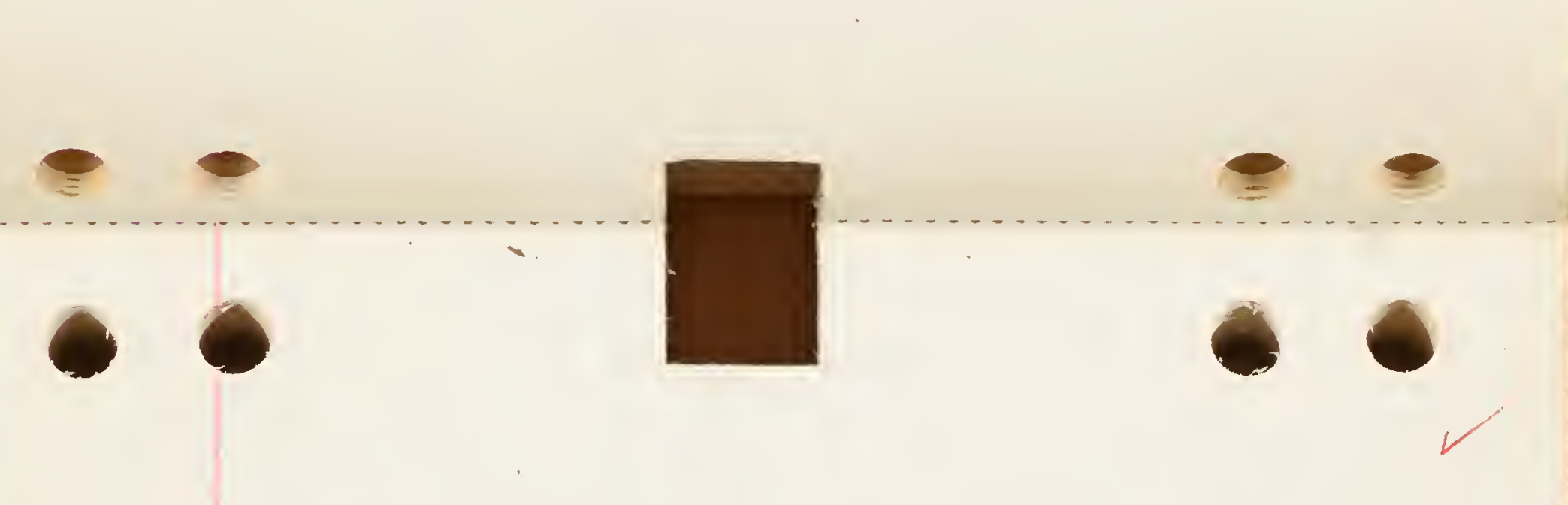



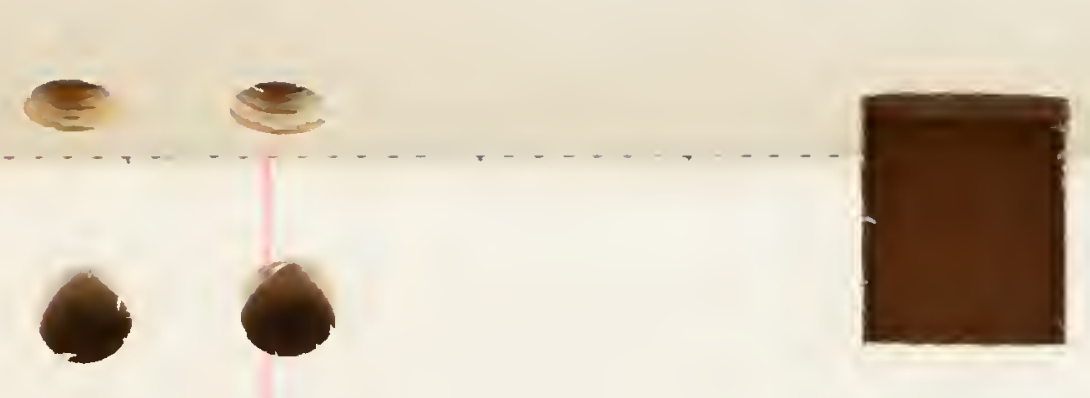

$-$

-

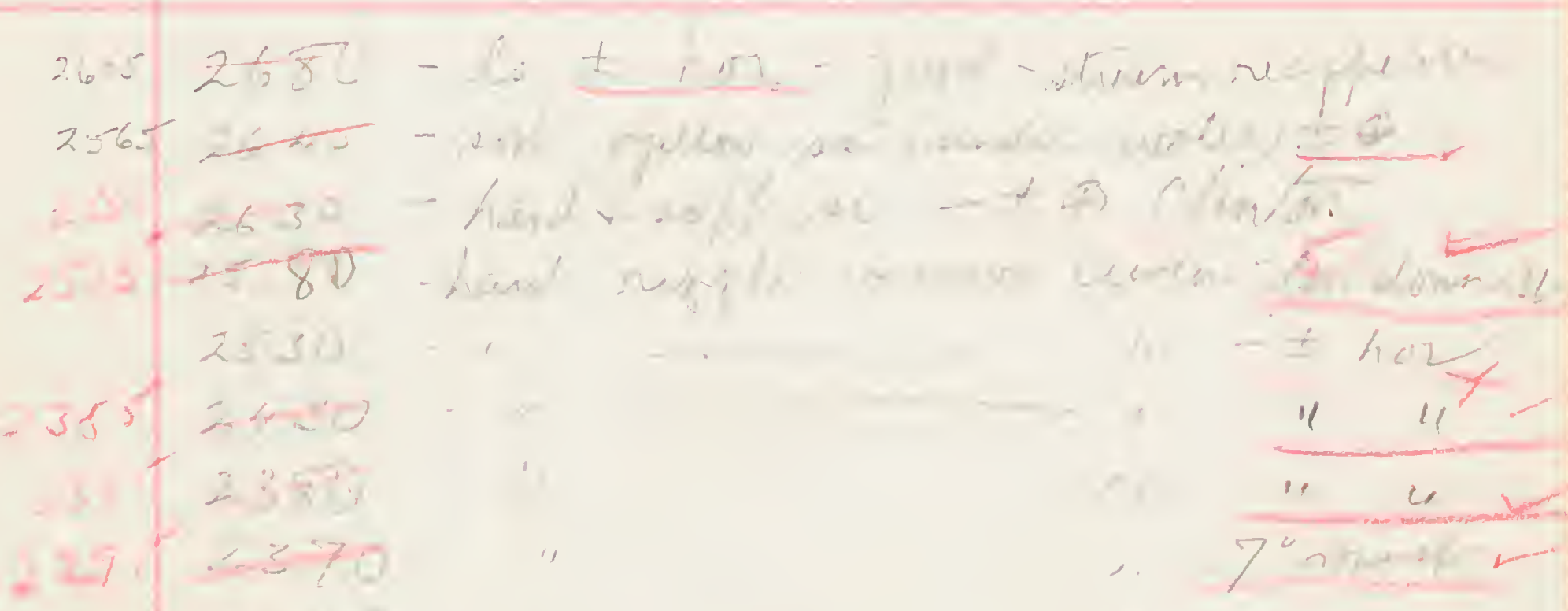

$23=0$
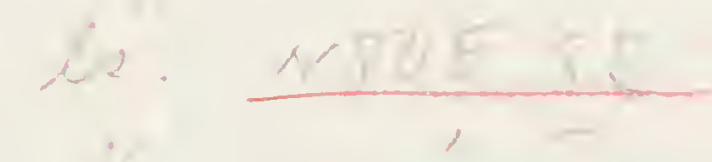

(2) 57

$210^{\circ} 2160$

$-\div \div \div$
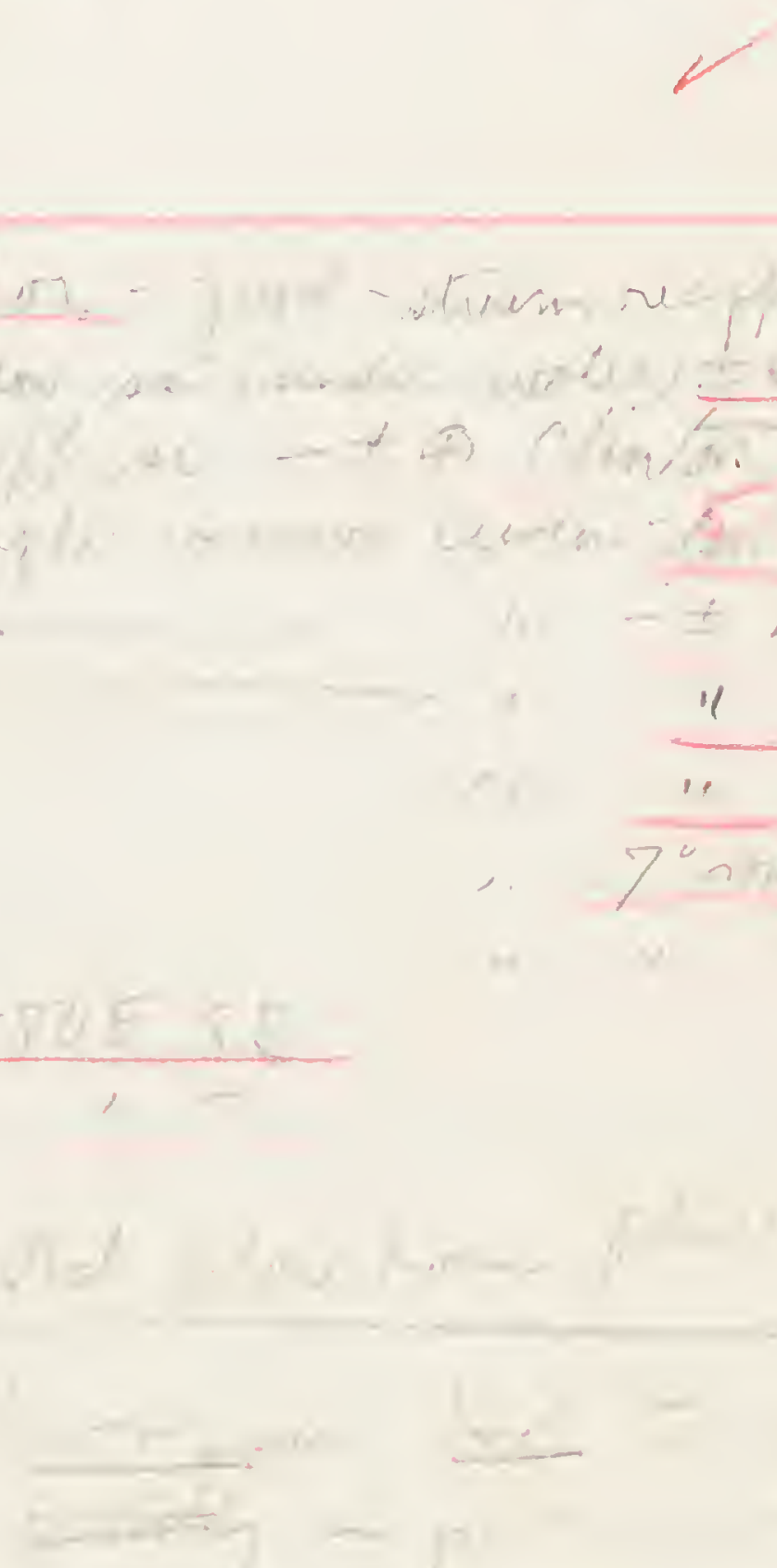


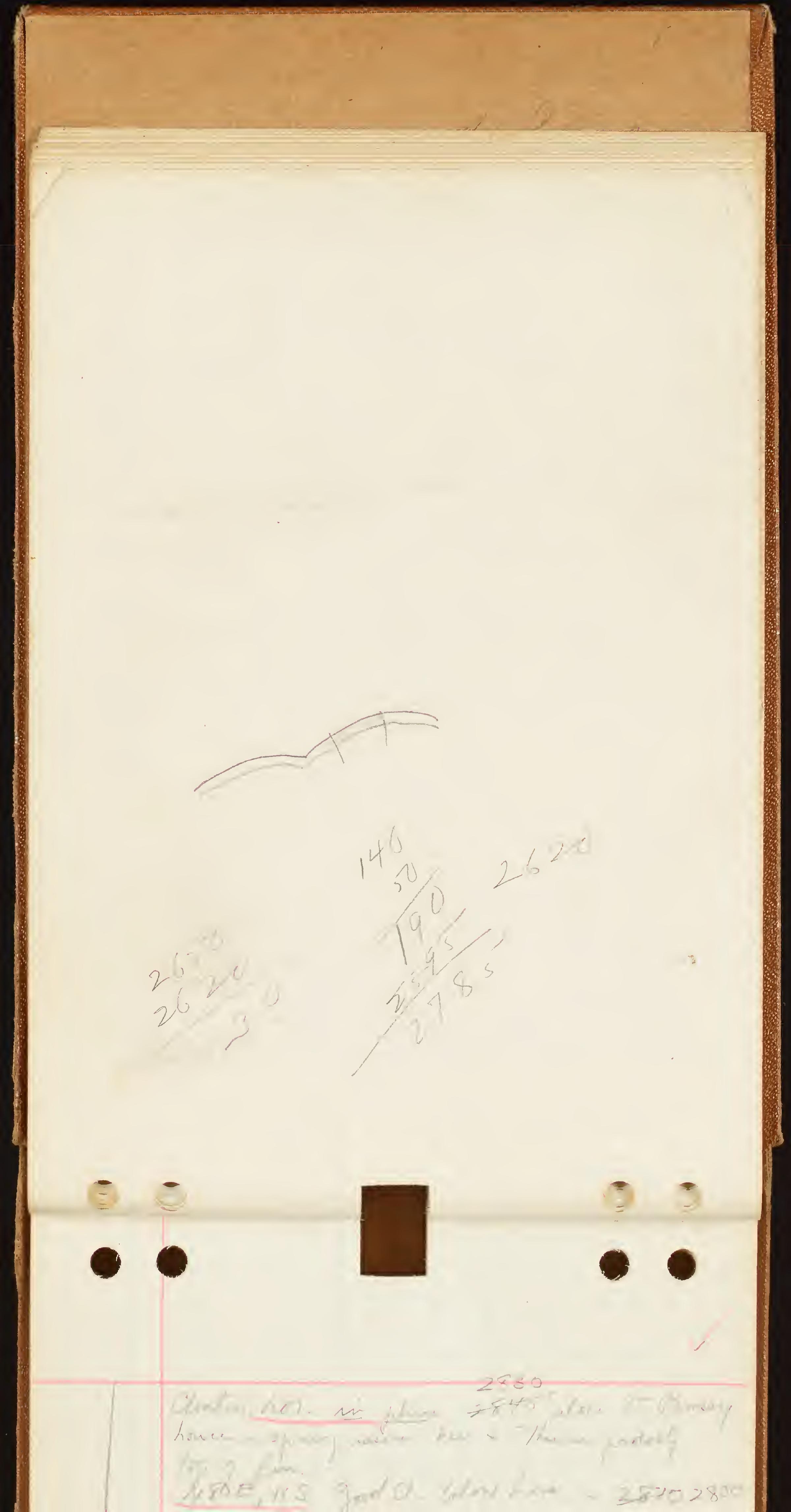




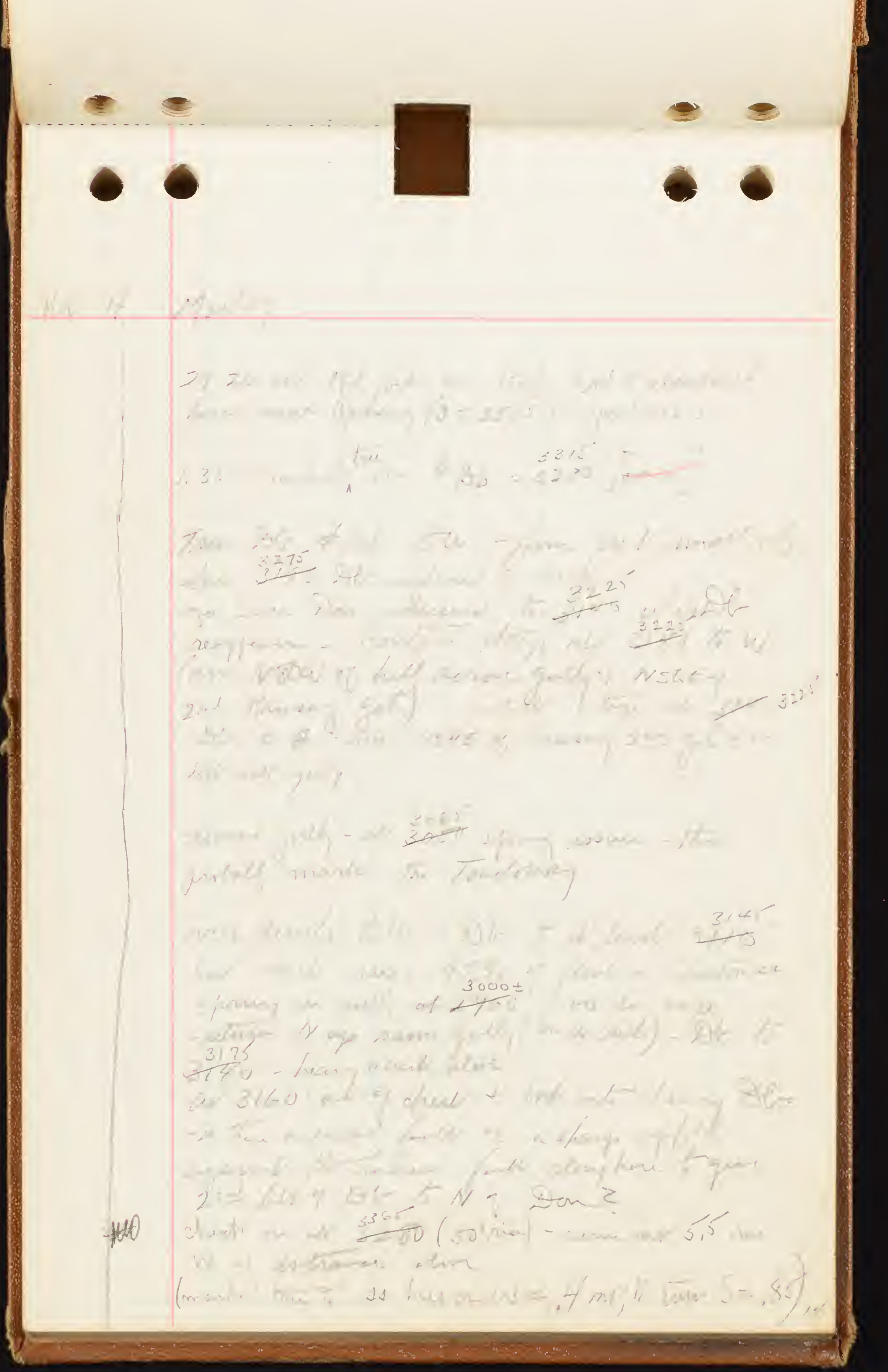




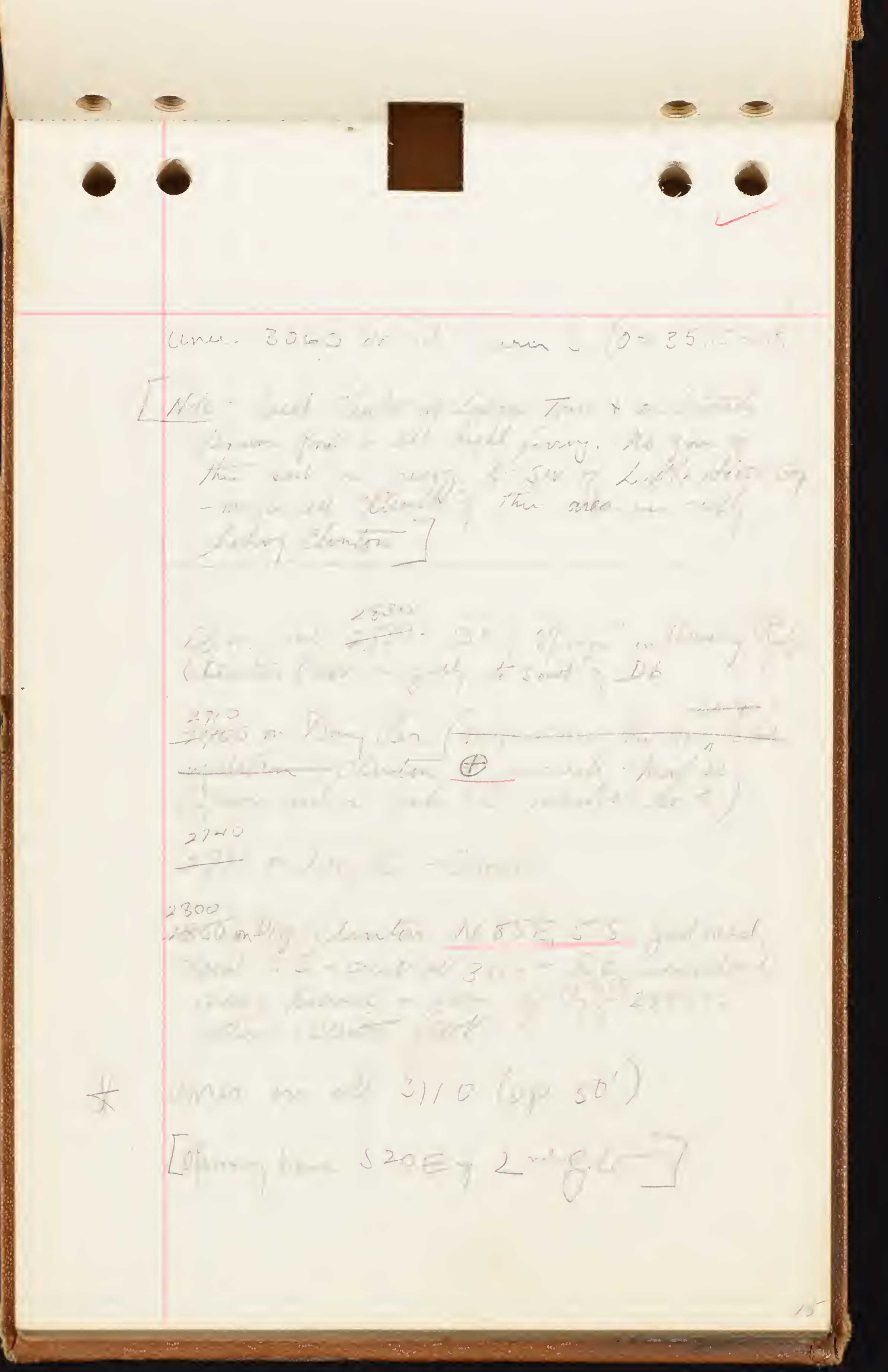




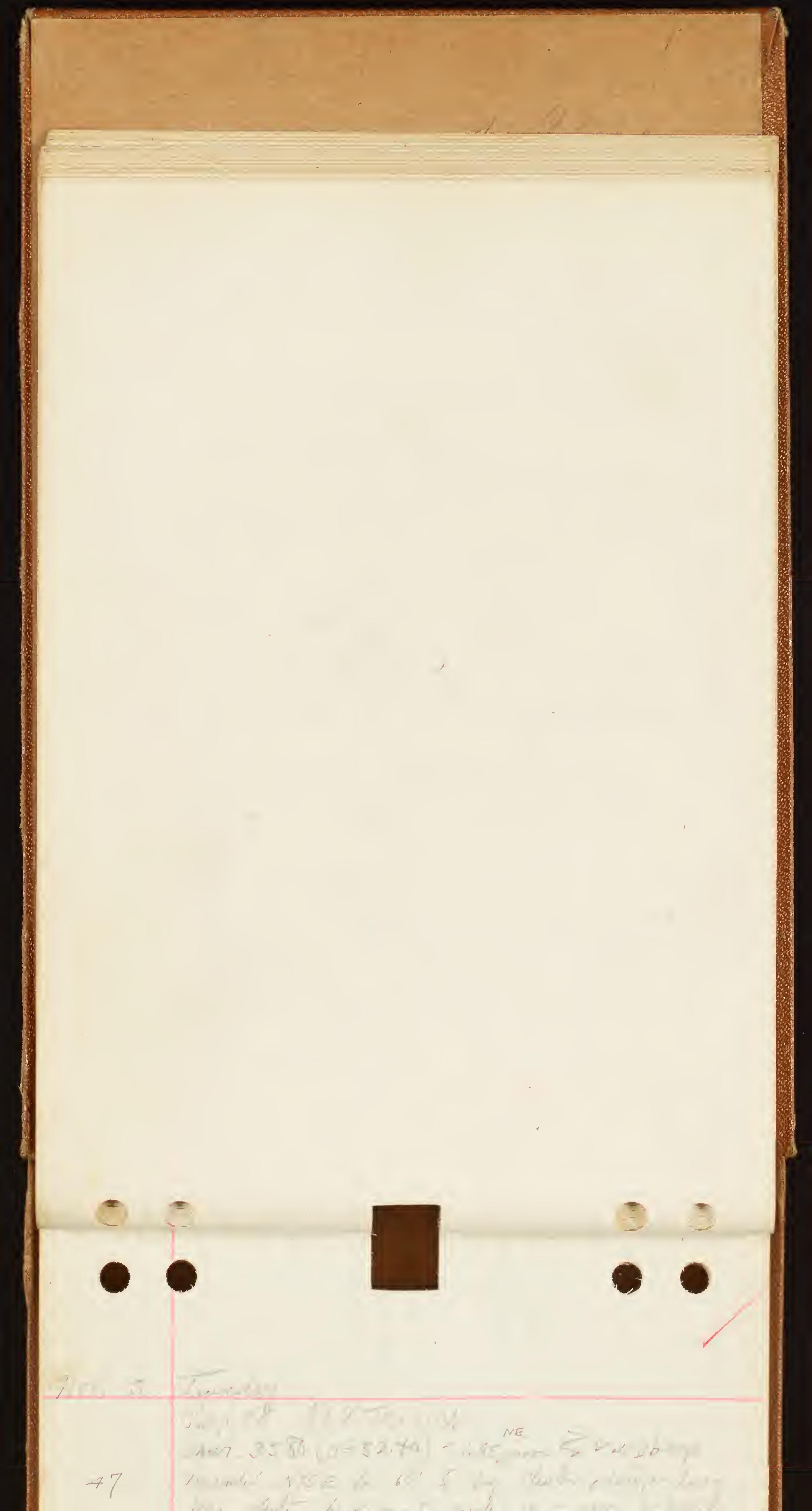


$-\bullet$
$-\bullet$

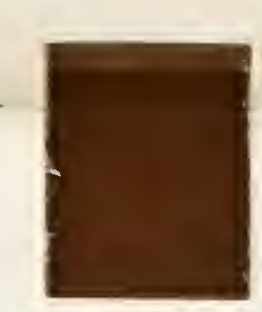

$-2$

-

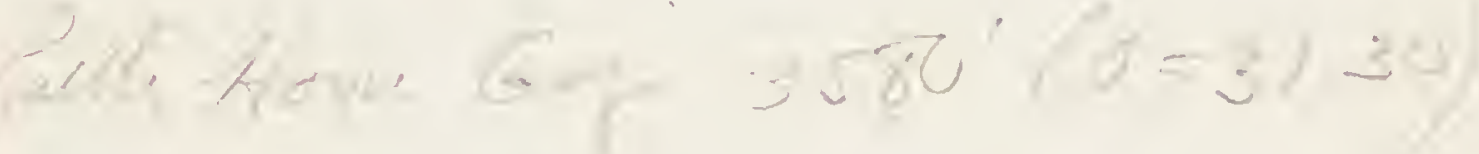
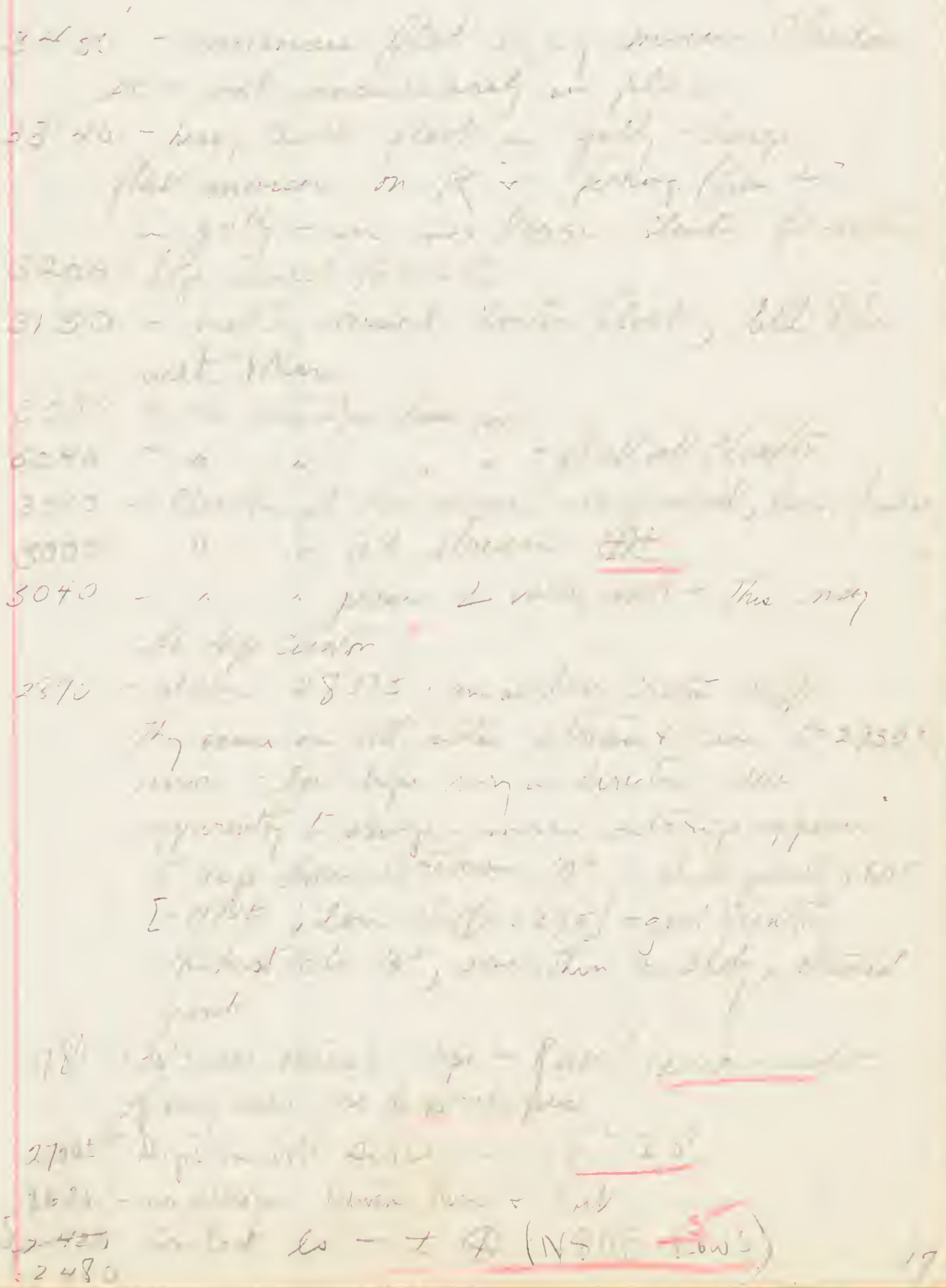



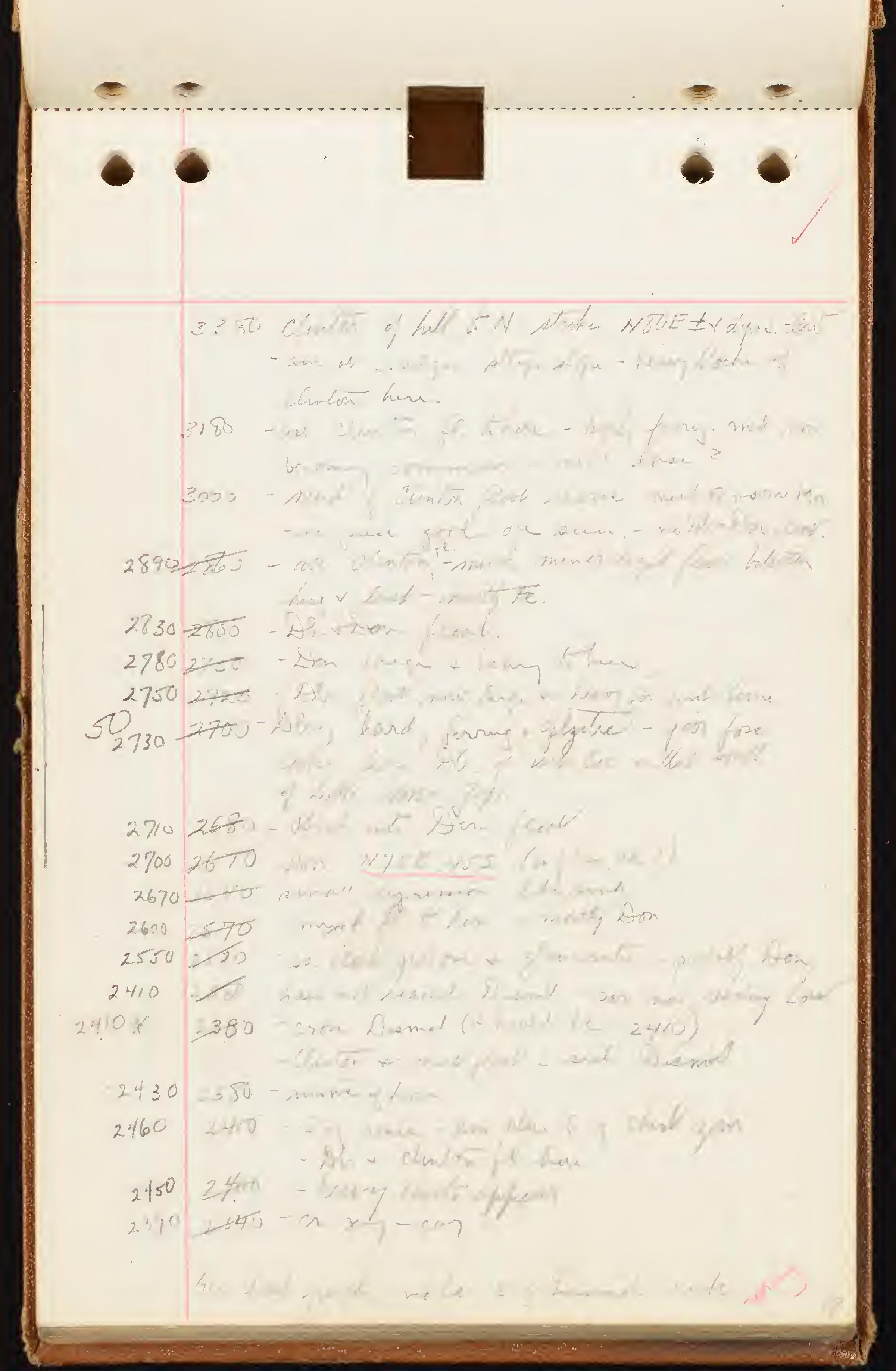



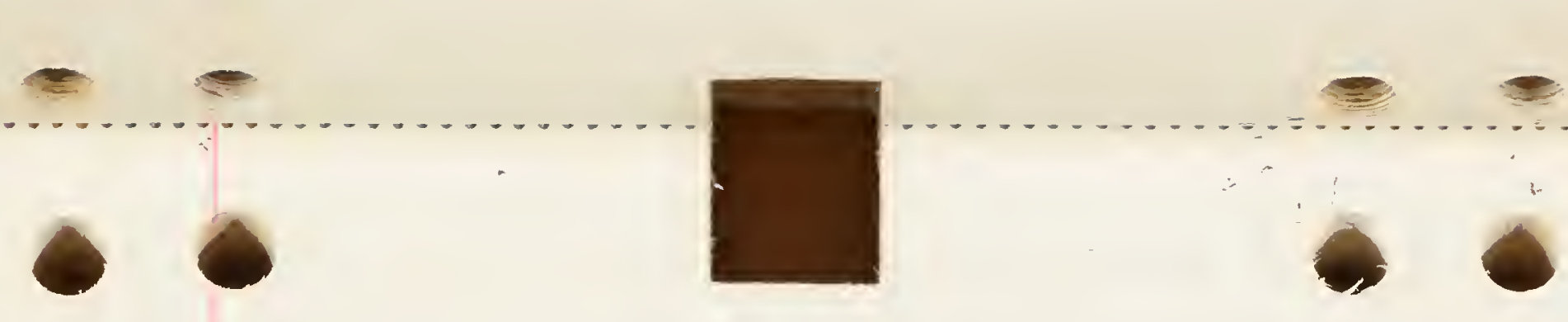

$q-\frac{\text { Salurelt? }}{2}$

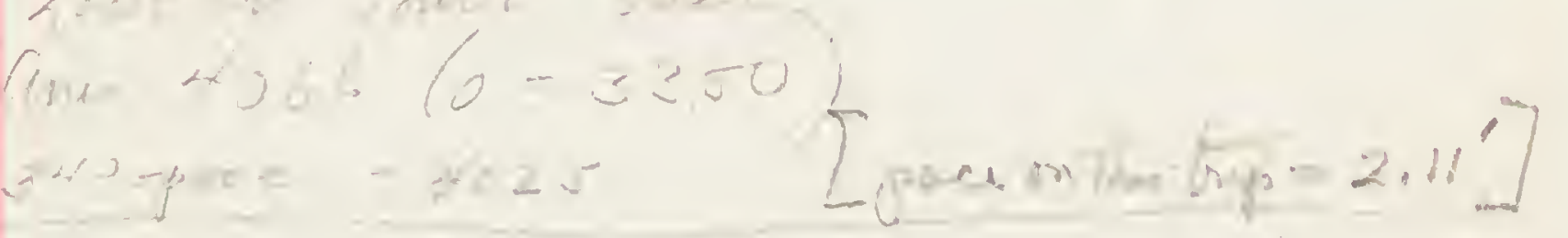

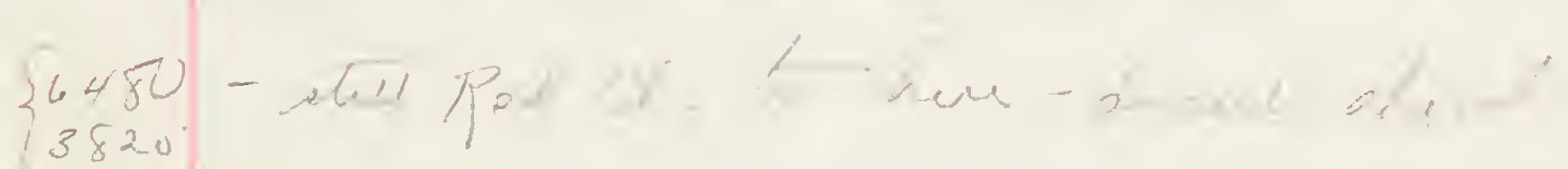

-

.560

$y \rightarrow 5 \cdot 10 \div 5$

372

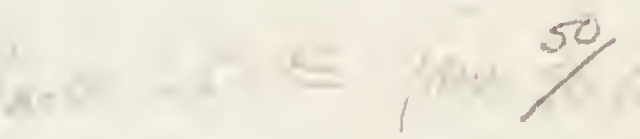

37

7296

1\%\% Cluch? \&

$2-7 / 4$

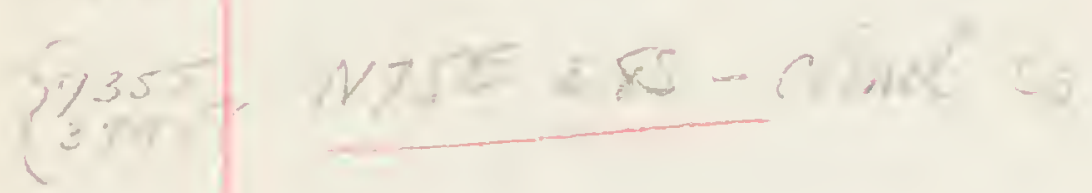

57

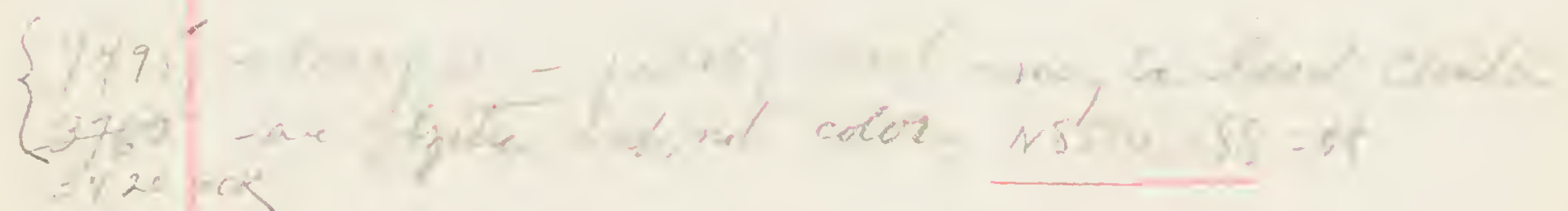

52

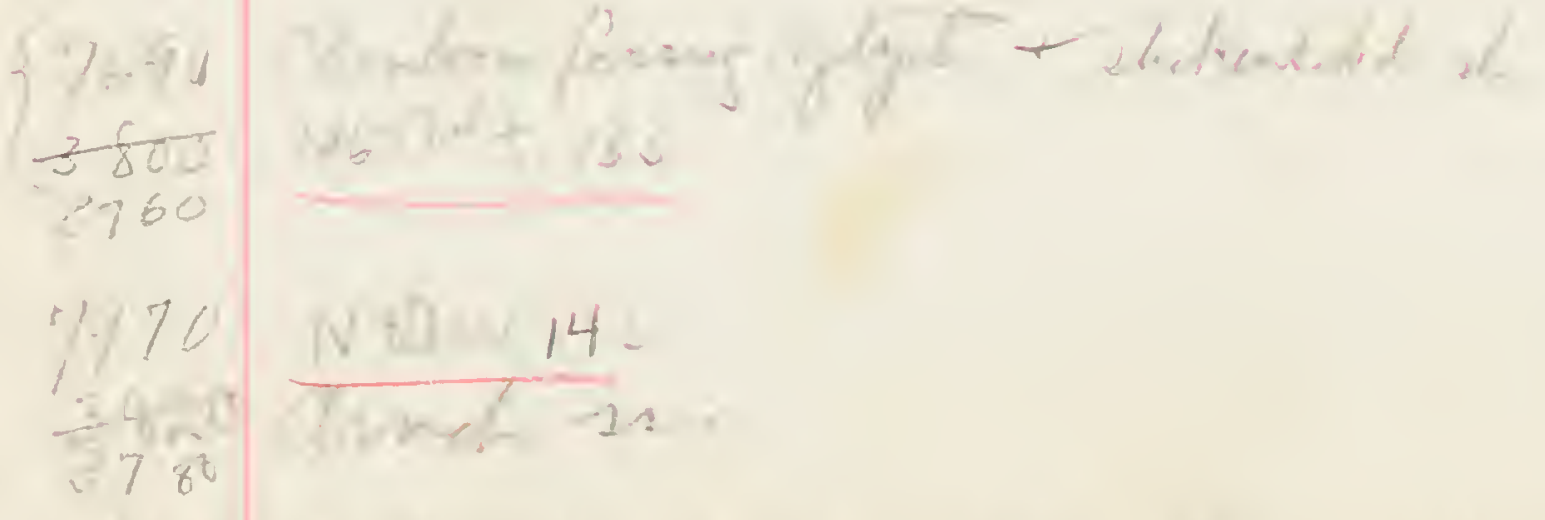

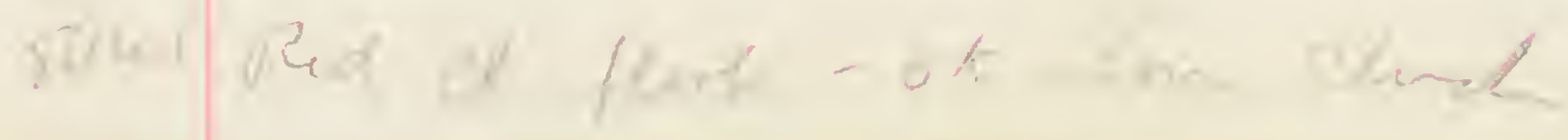



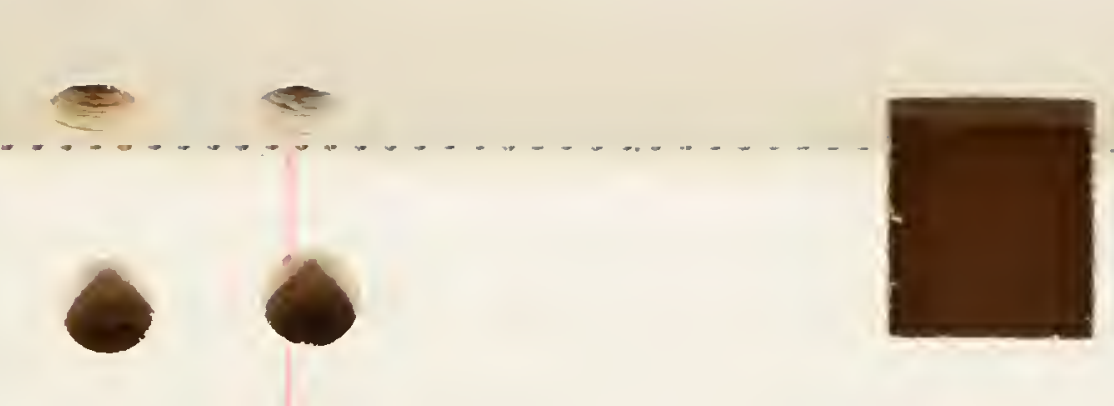

$\because \ldots$

(2)

1
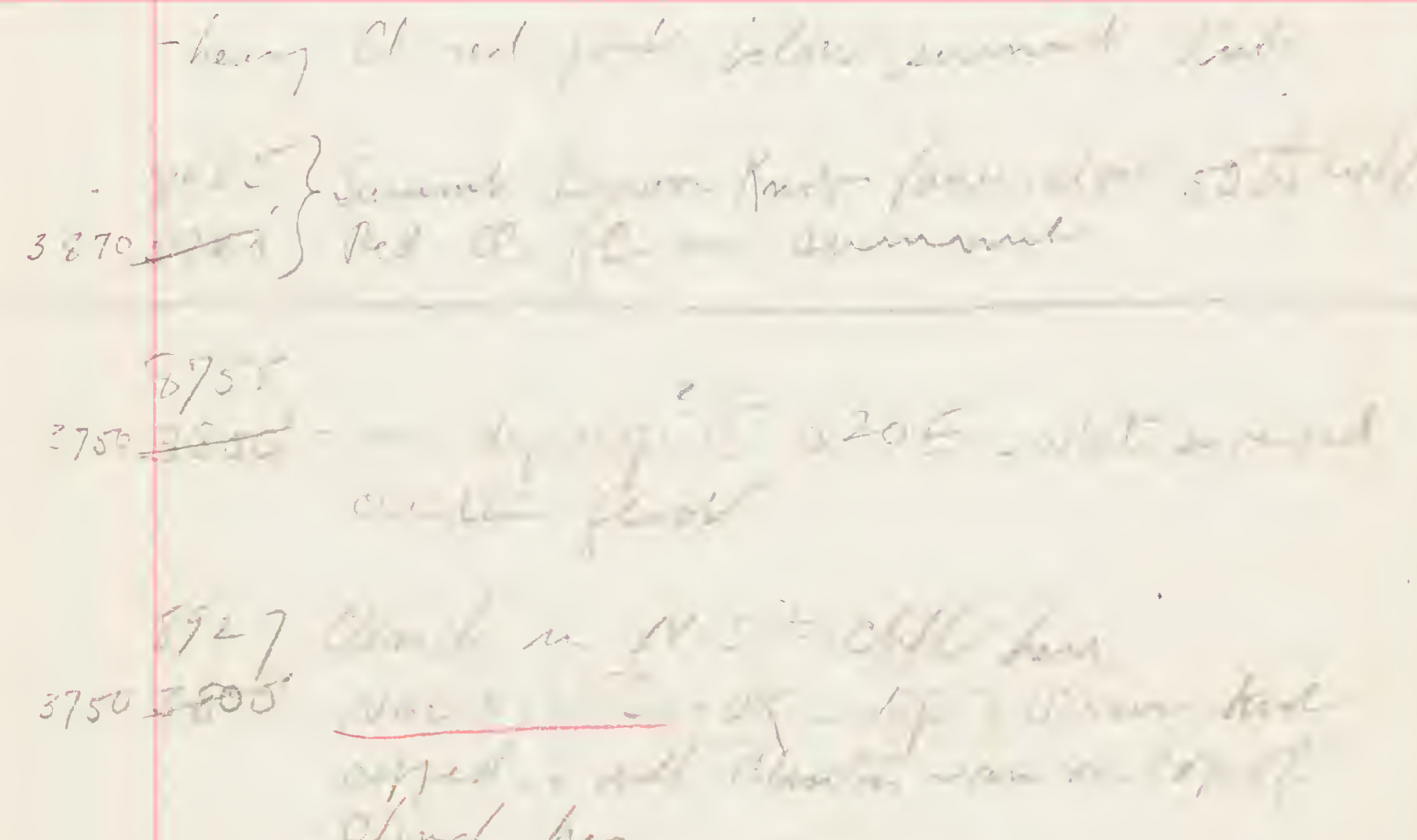
Lisingl bere.
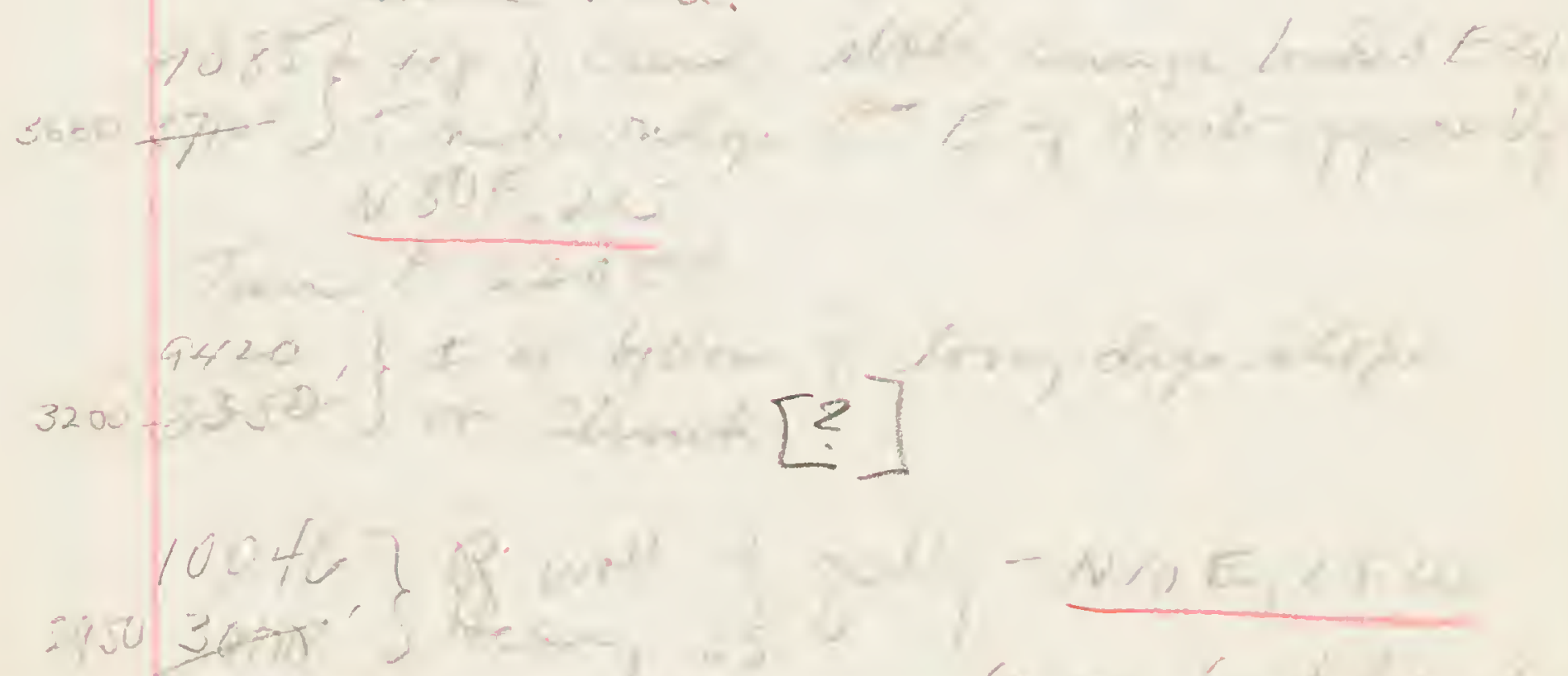

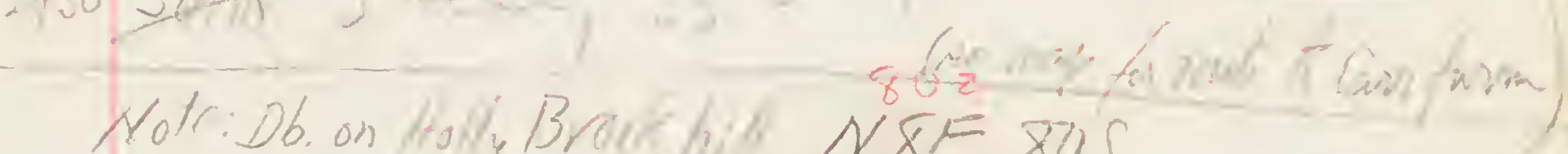
53

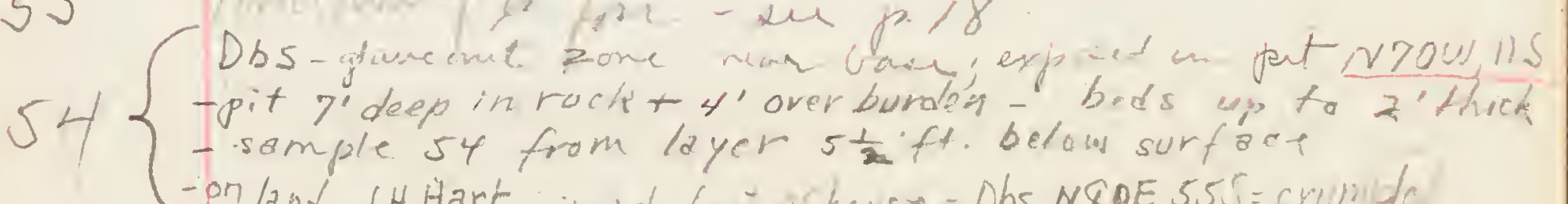

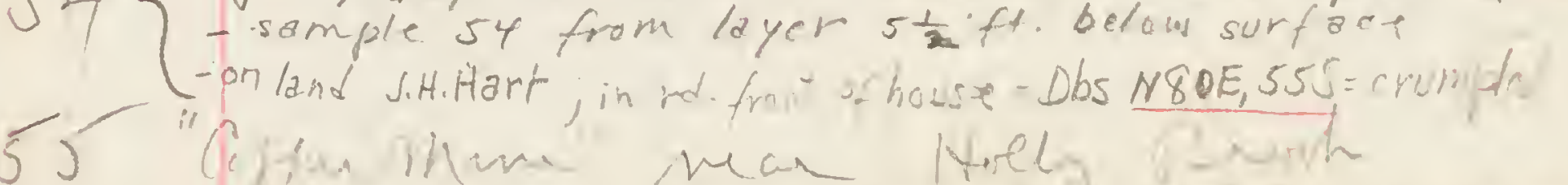

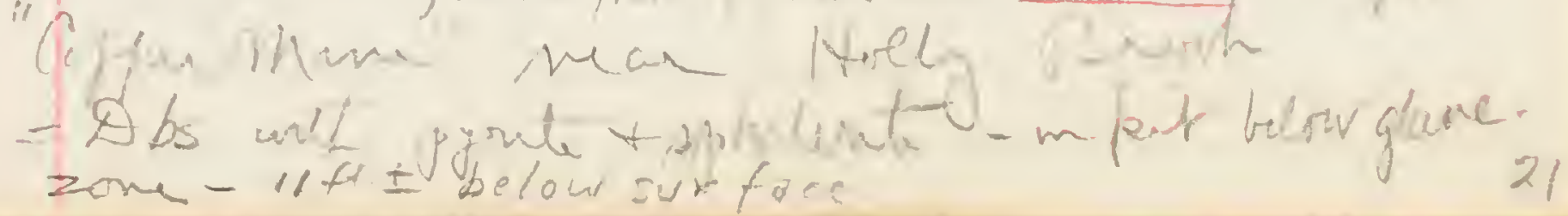



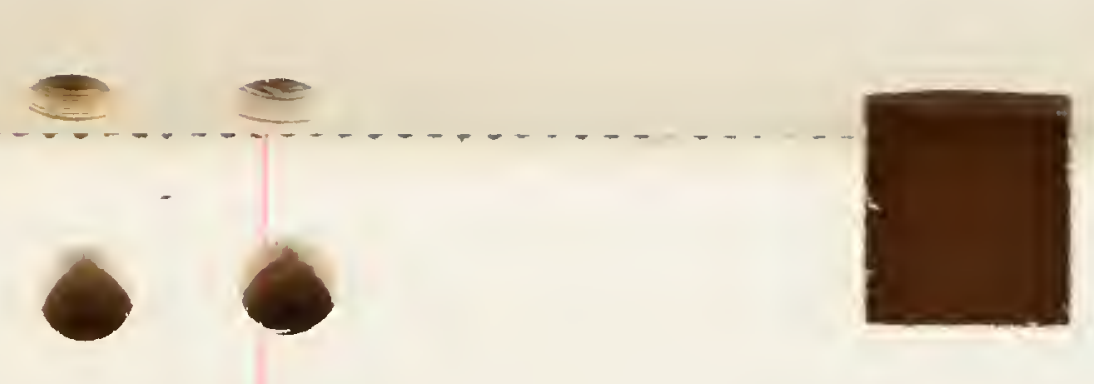

$\therefore$

14s.12-Twerdaty

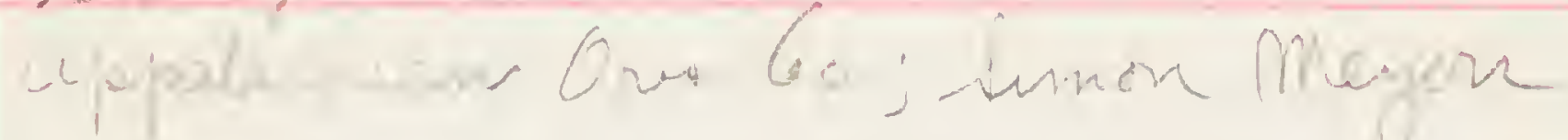

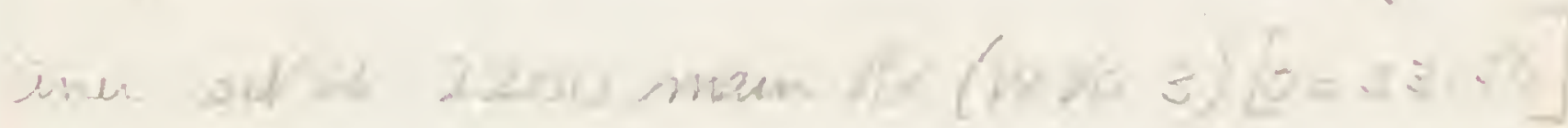

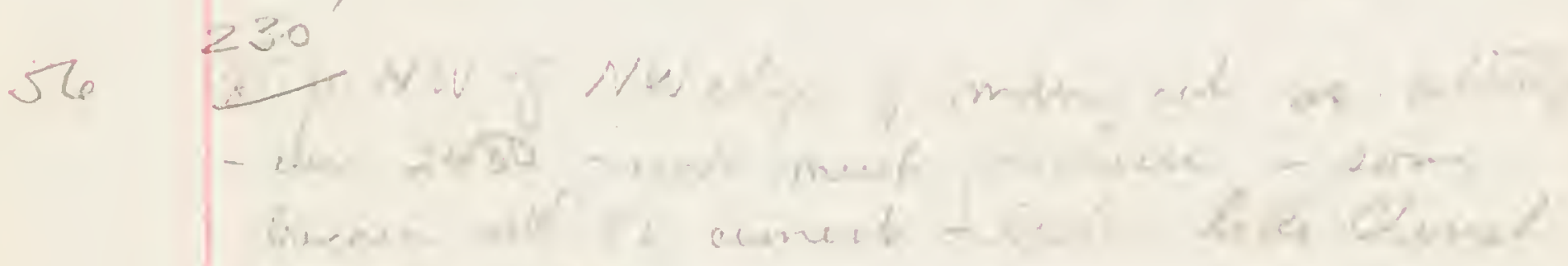
W2AE WIE

57

58

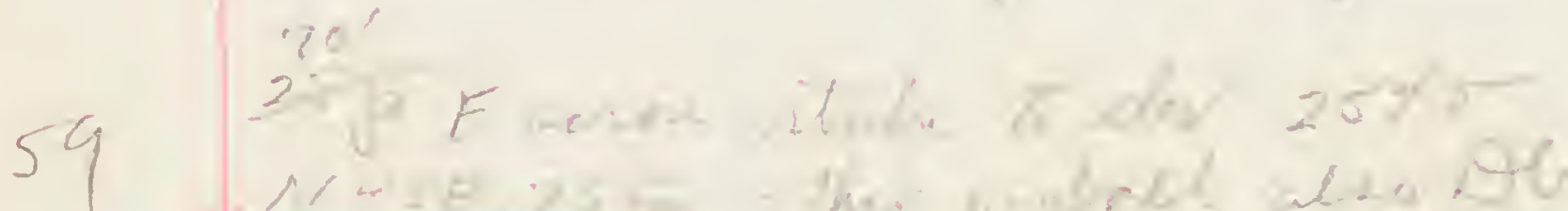
WRE, RUE

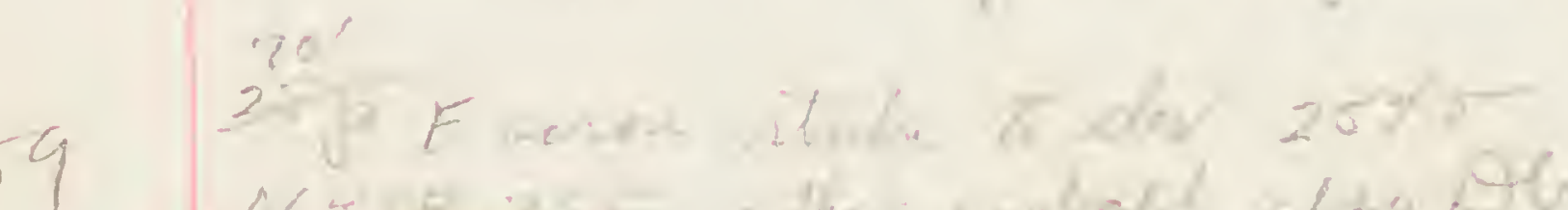

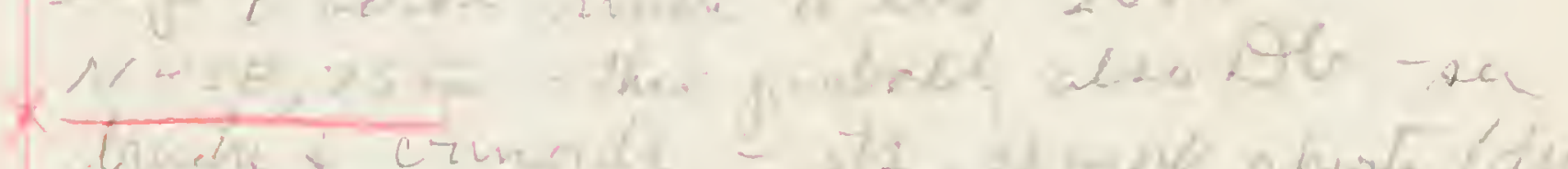

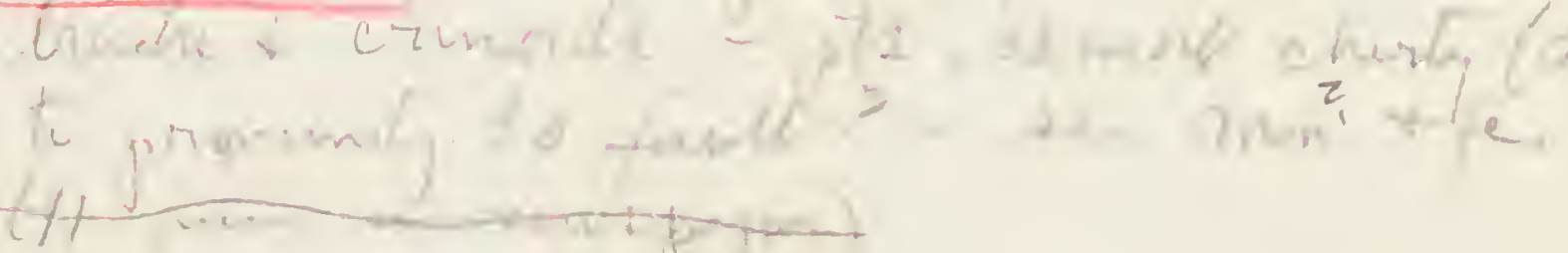

6

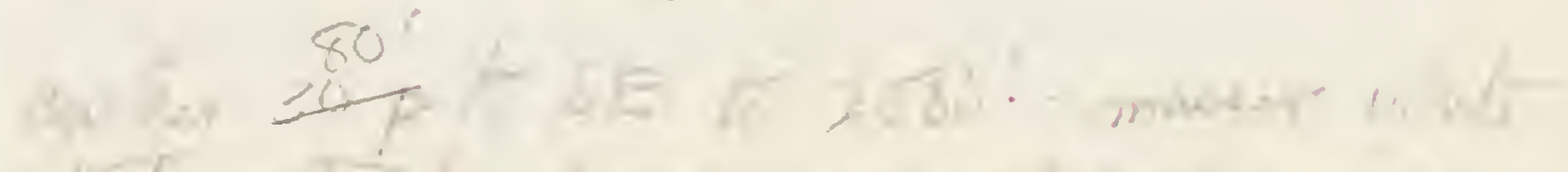

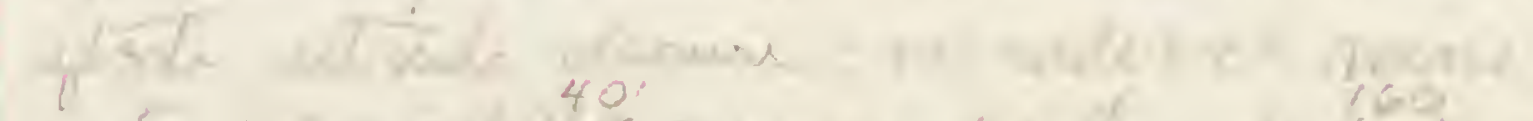

$$
\begin{aligned}
& \text { - TS SE- TS } 40
\end{aligned}
$$

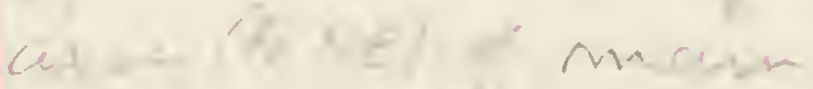

$$
\begin{aligned}
& \text { wh whe } 254 \text { ह }
\end{aligned}
$$




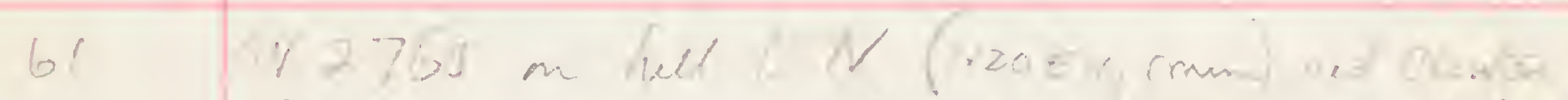

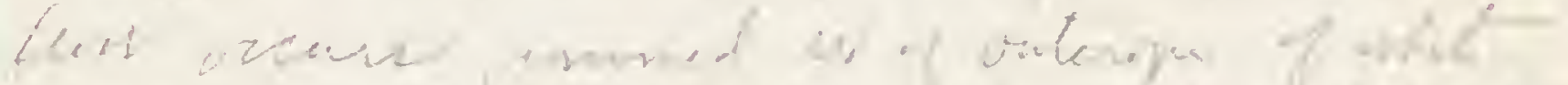

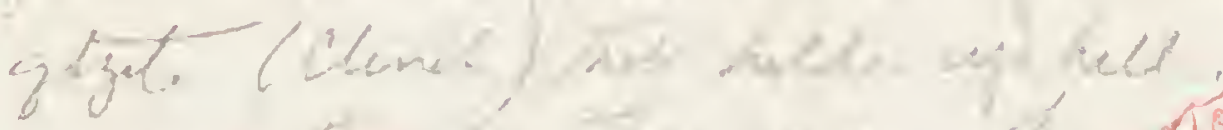

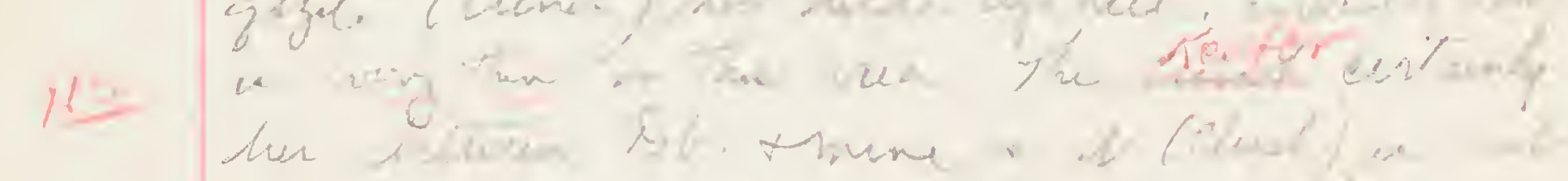

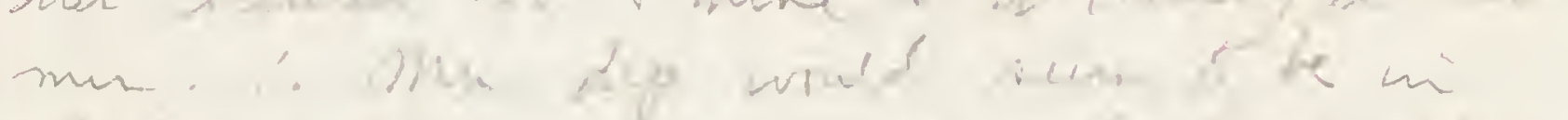

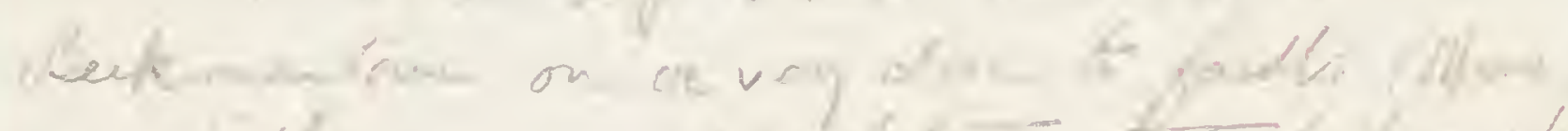

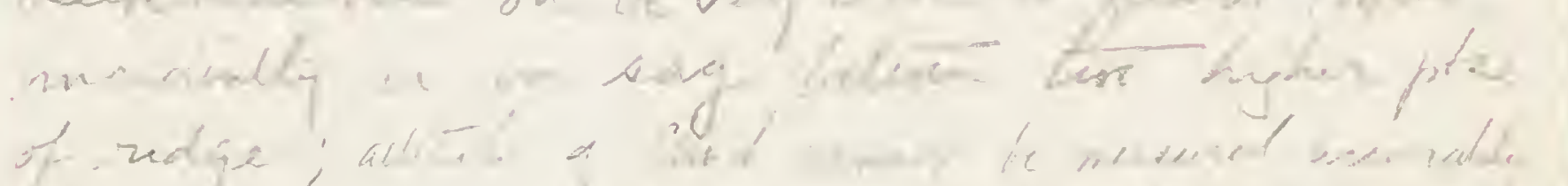
tain

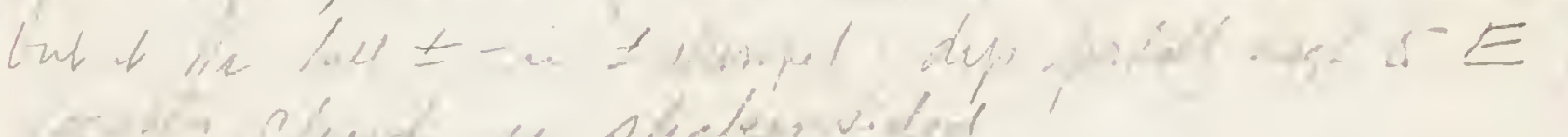

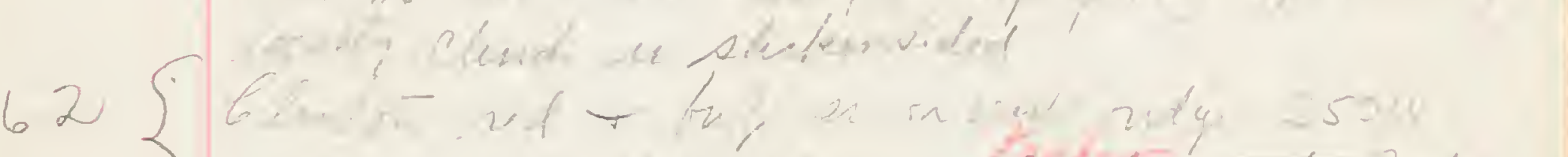

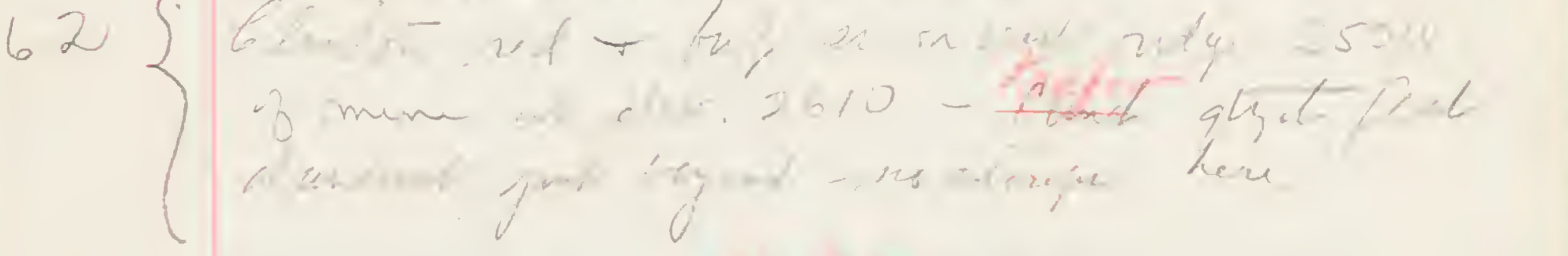

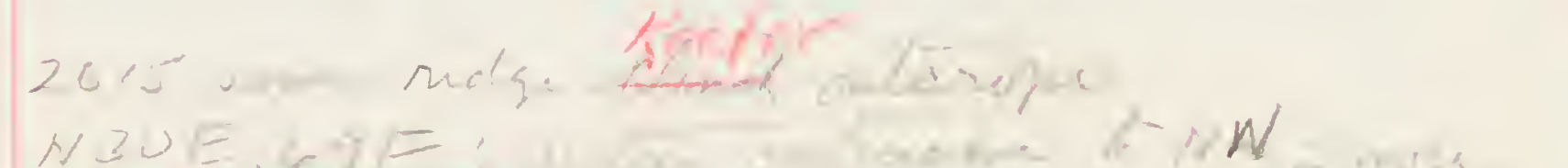

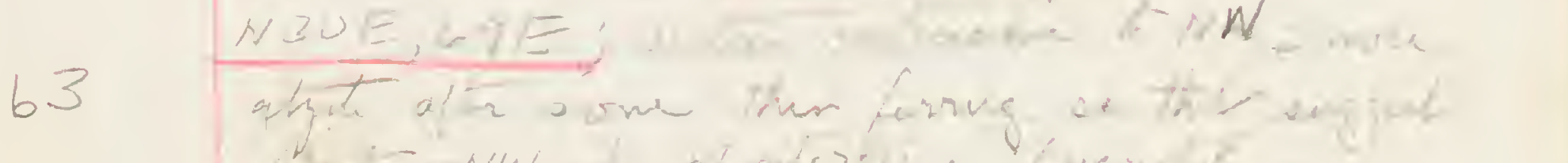

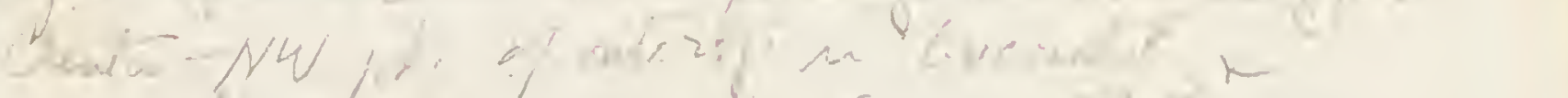

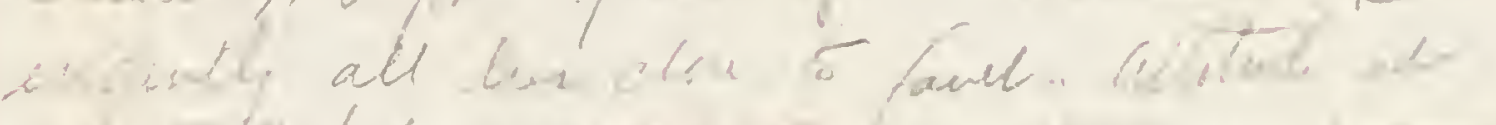

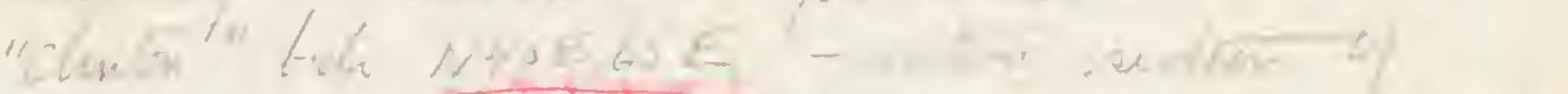

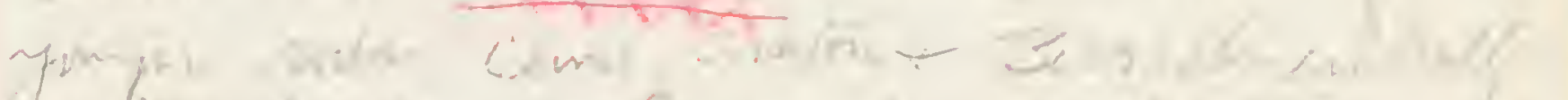

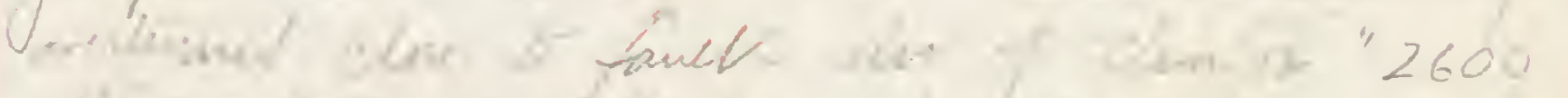

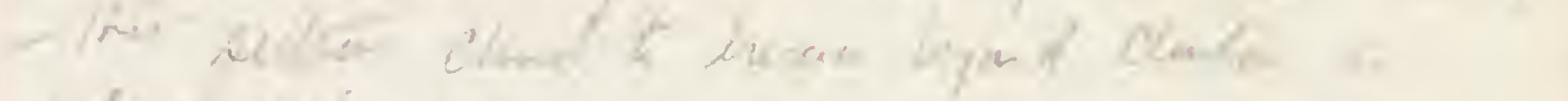
What 2is $+212:$

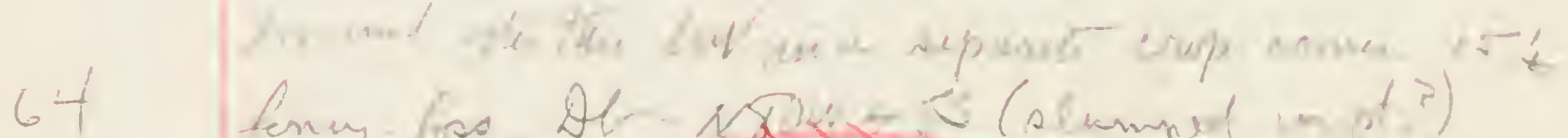

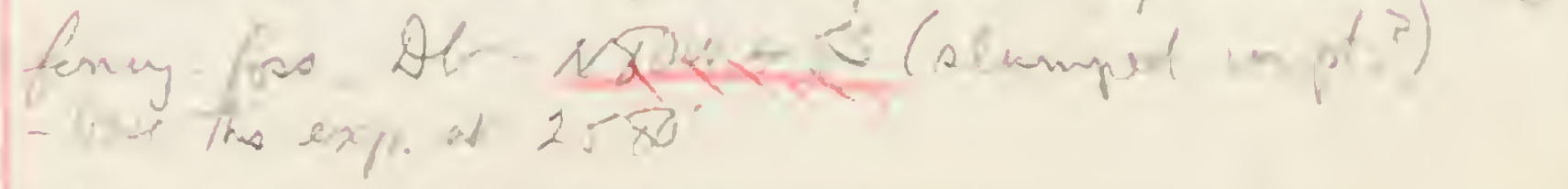



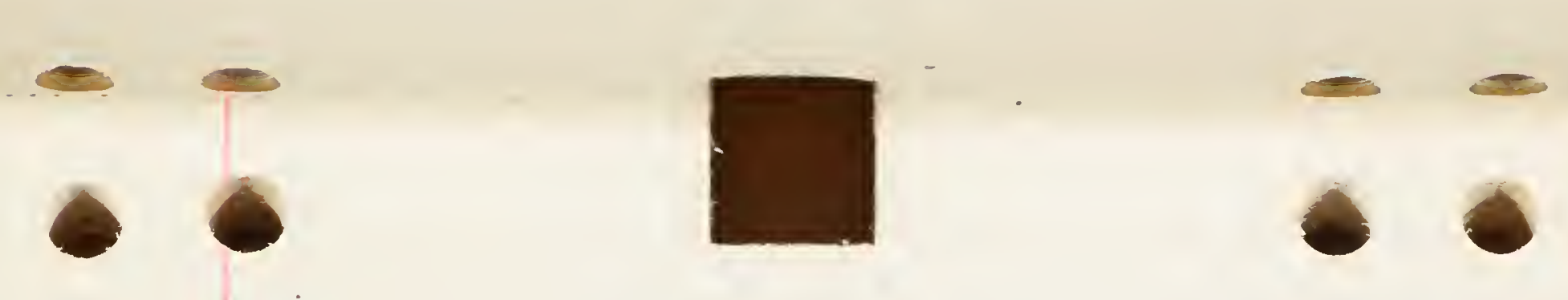

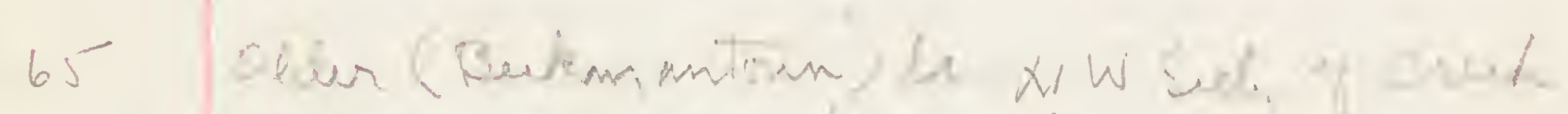
N5OE,4EE - ihe $22 / 5-25-$

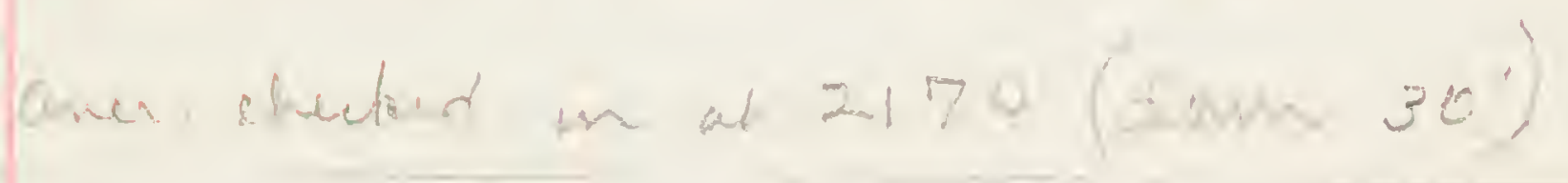

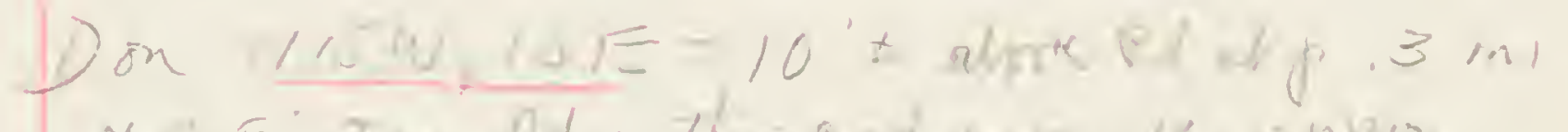

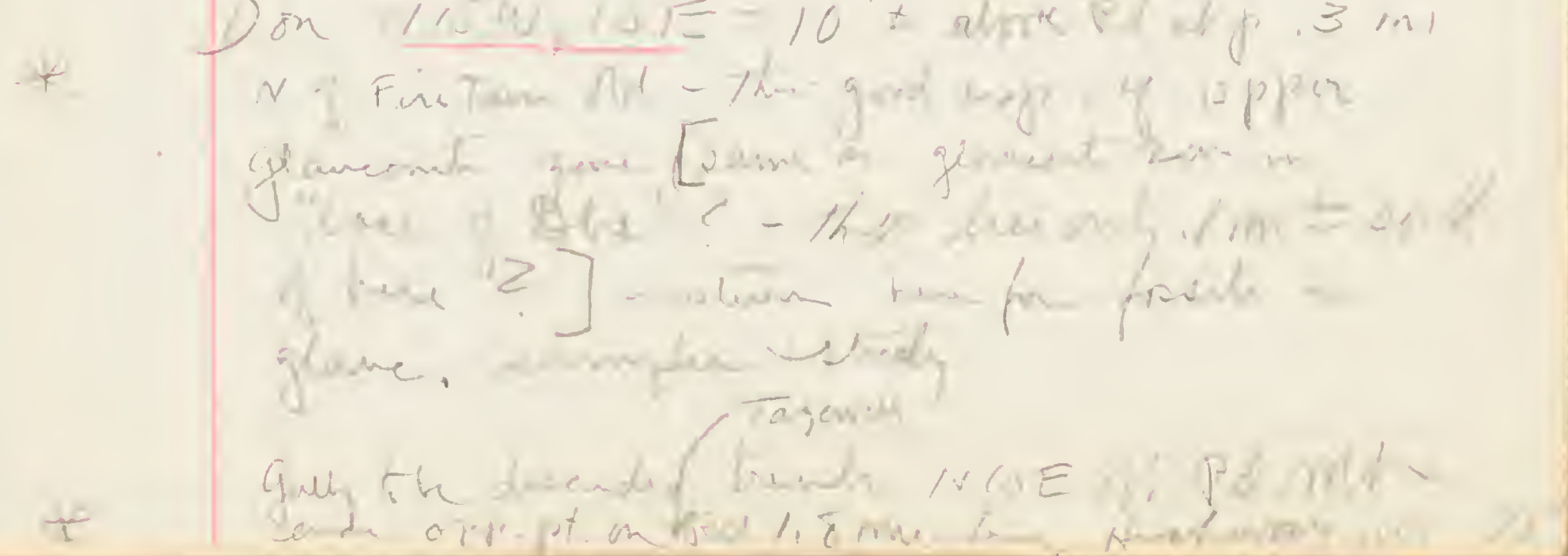




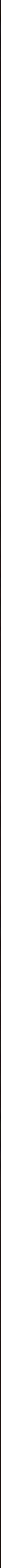


-
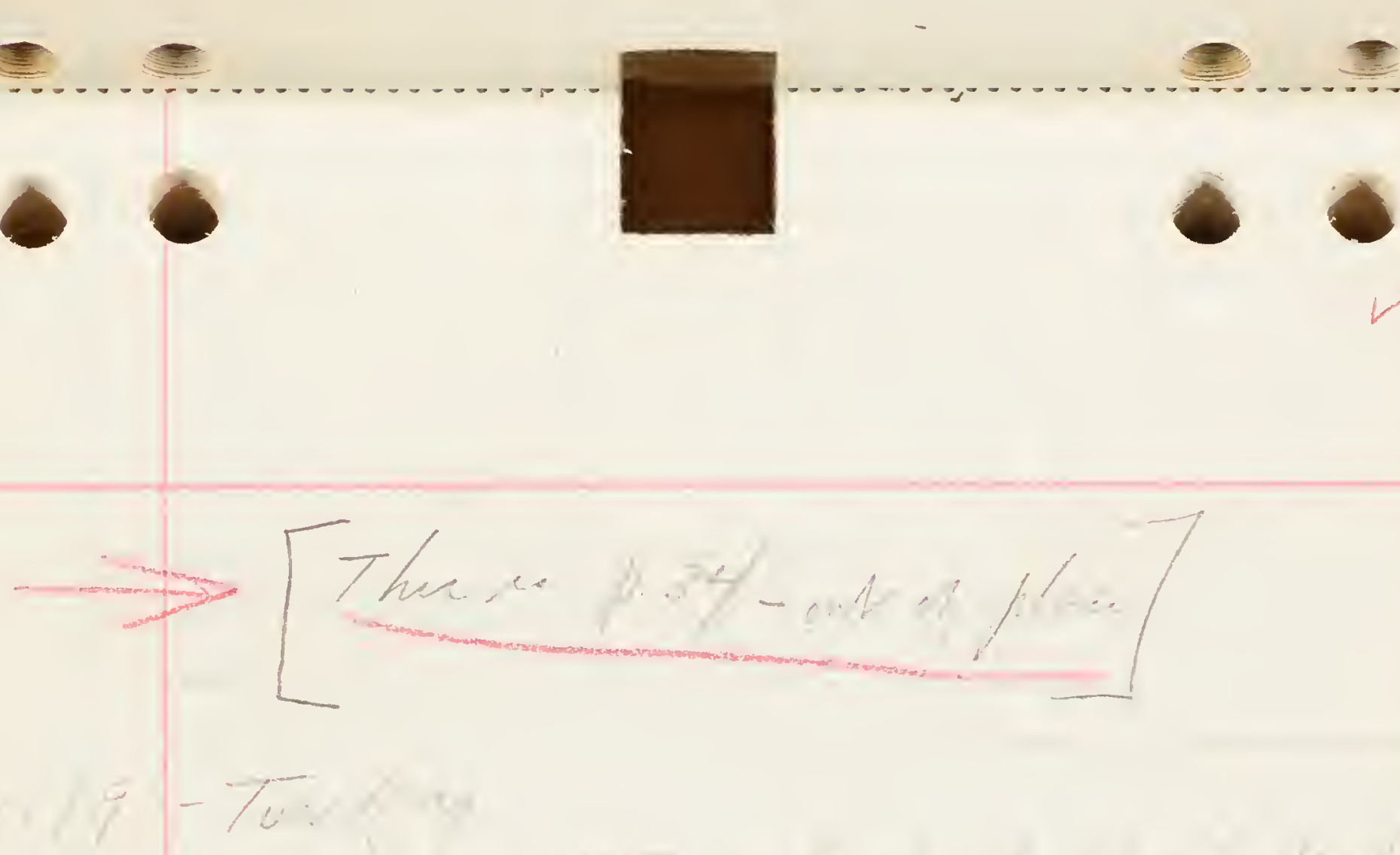

249

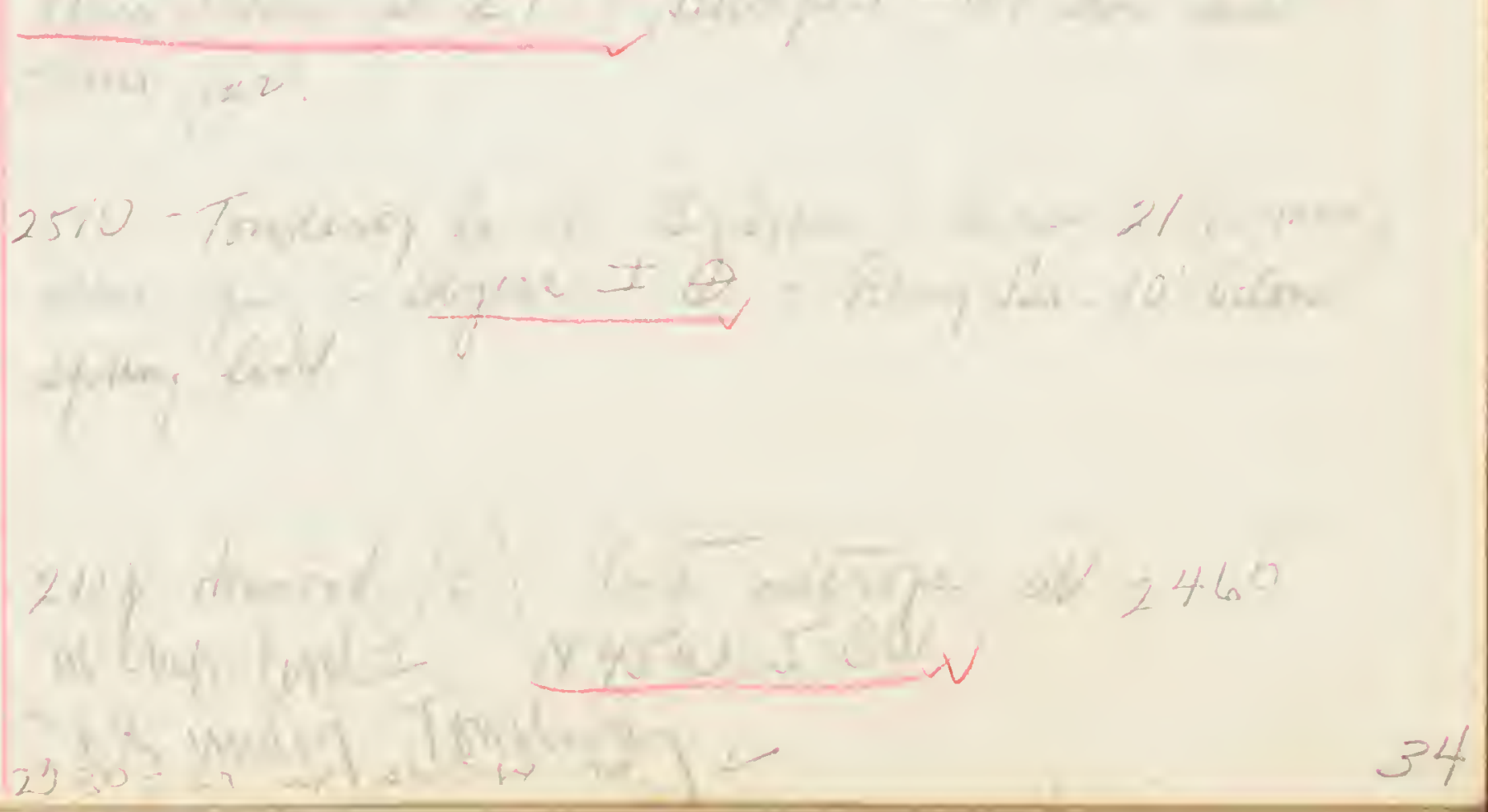



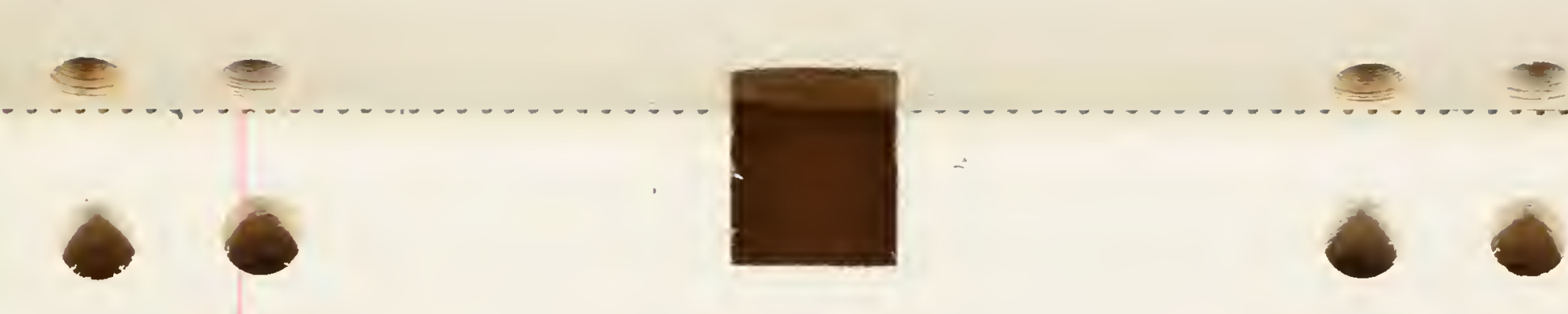

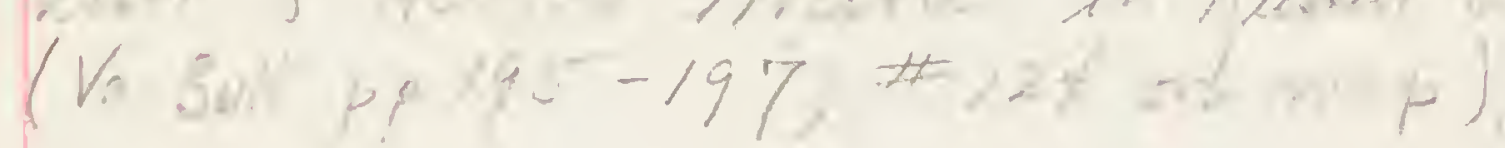

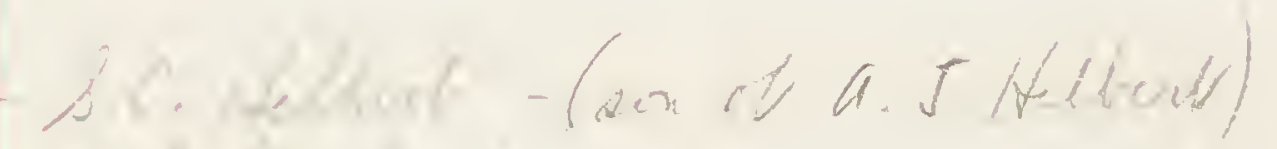

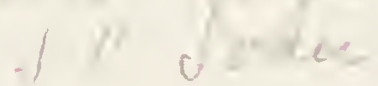

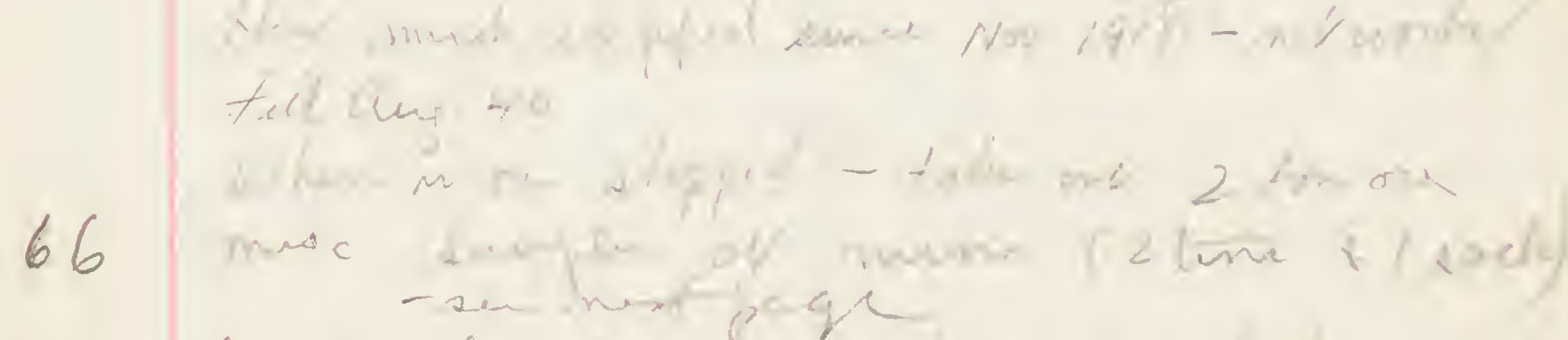

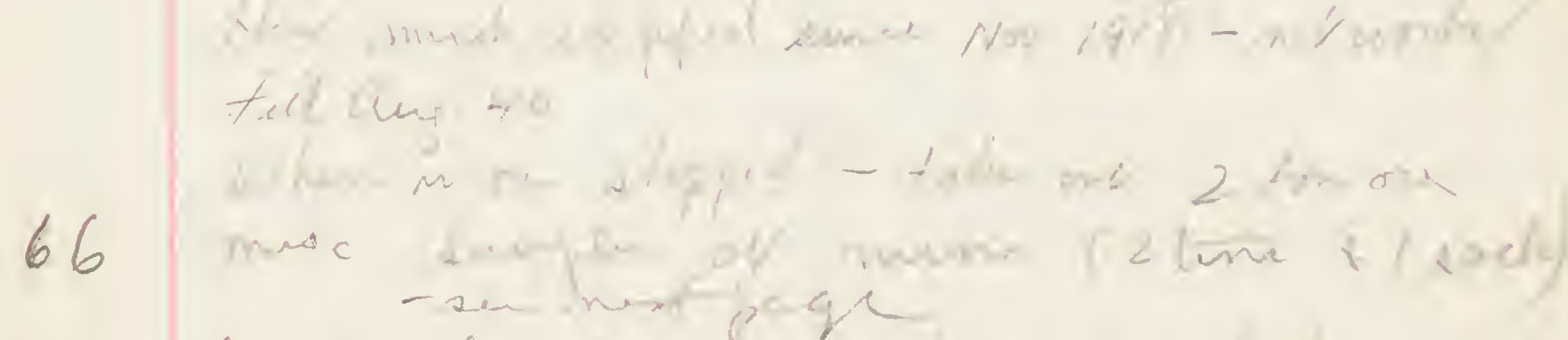

67

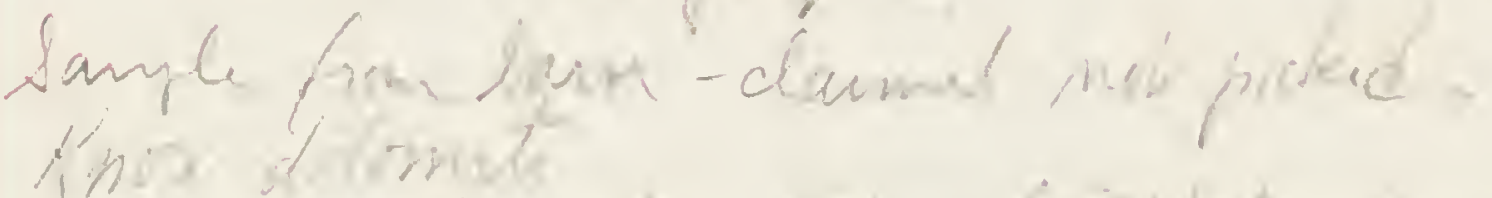

$67 a$

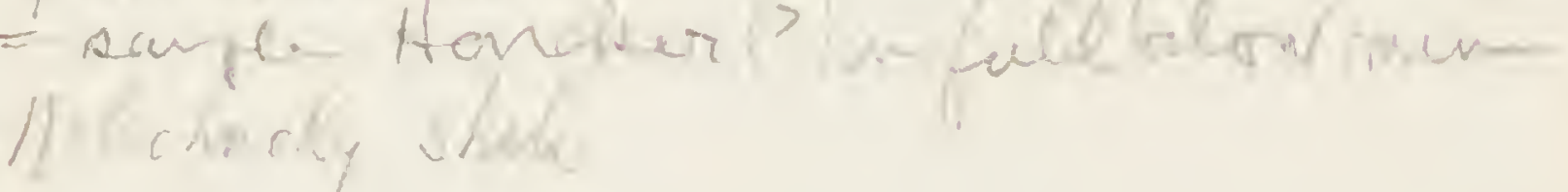

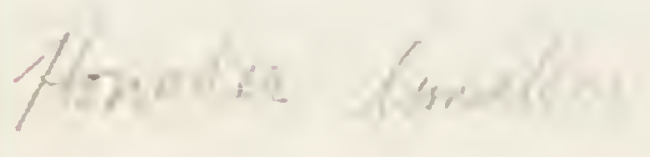




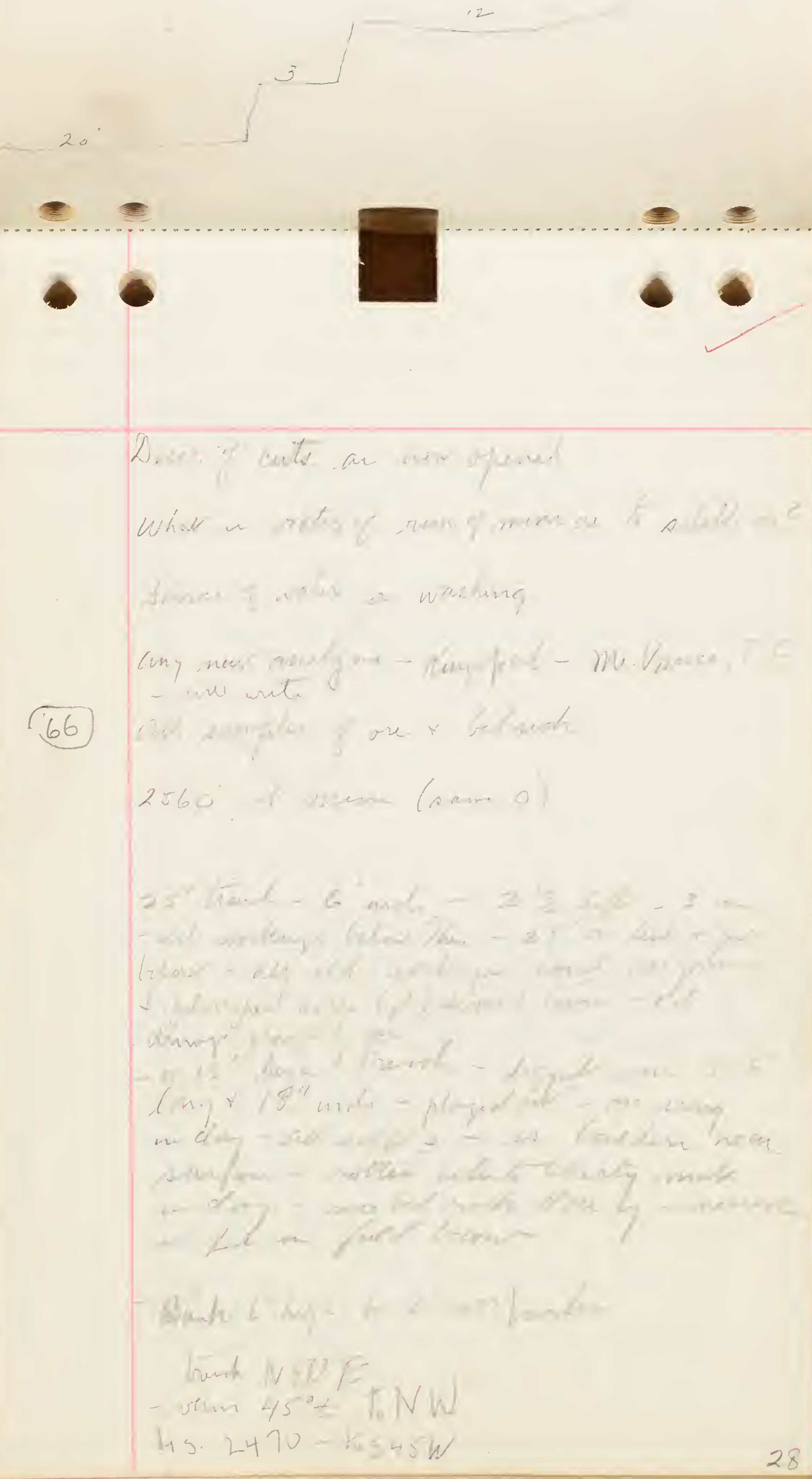




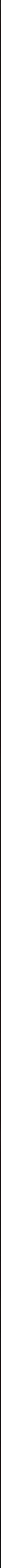




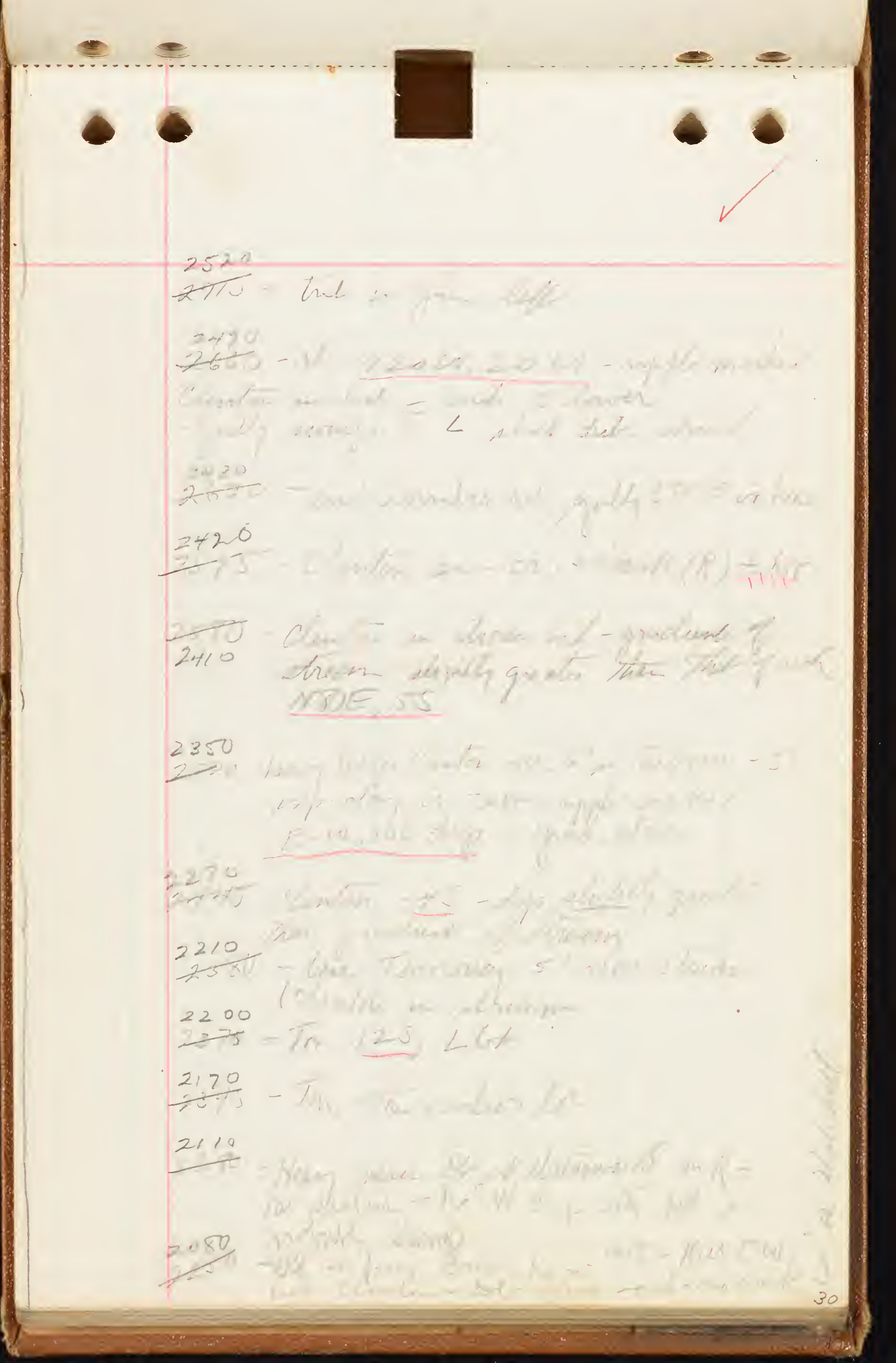




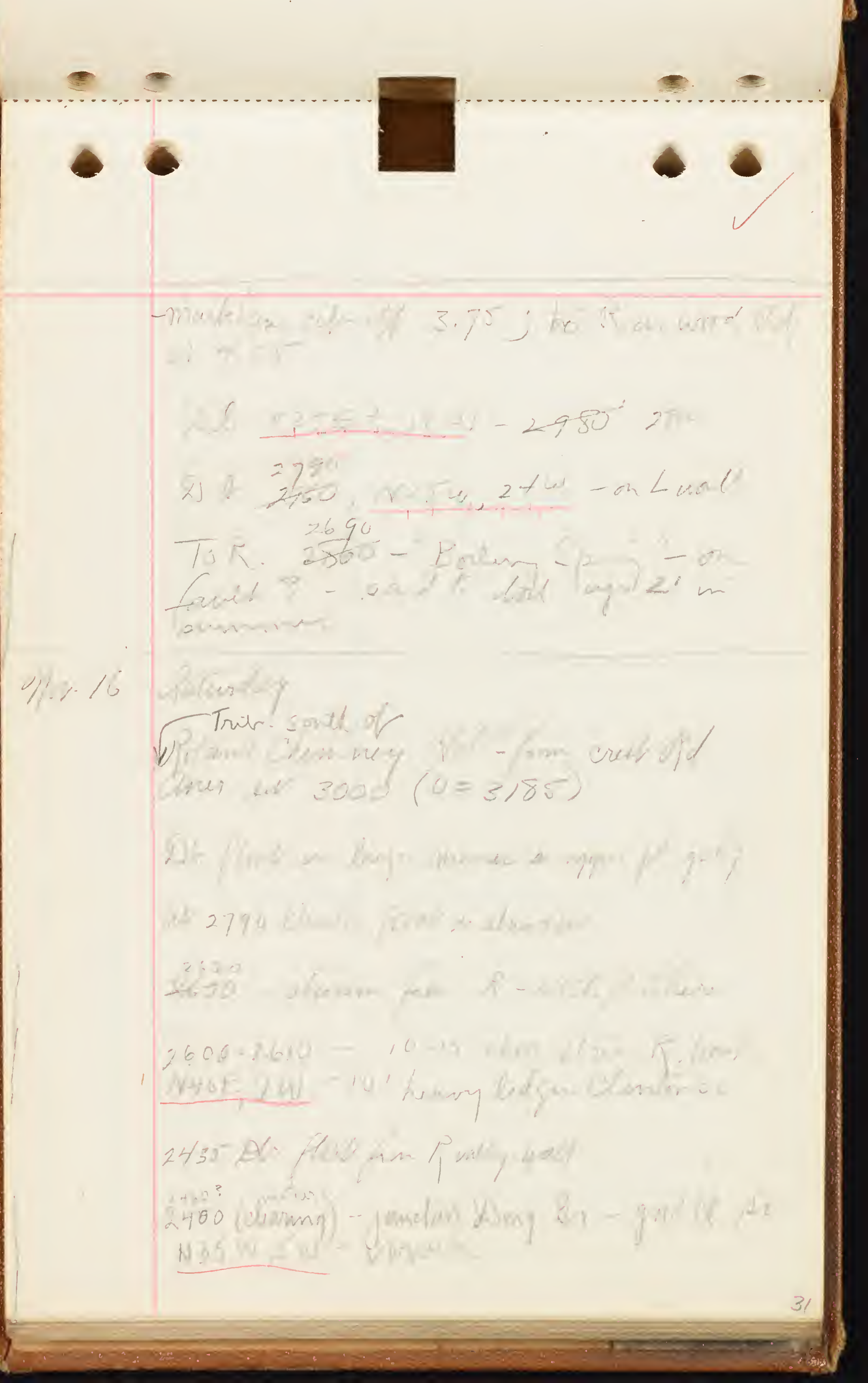




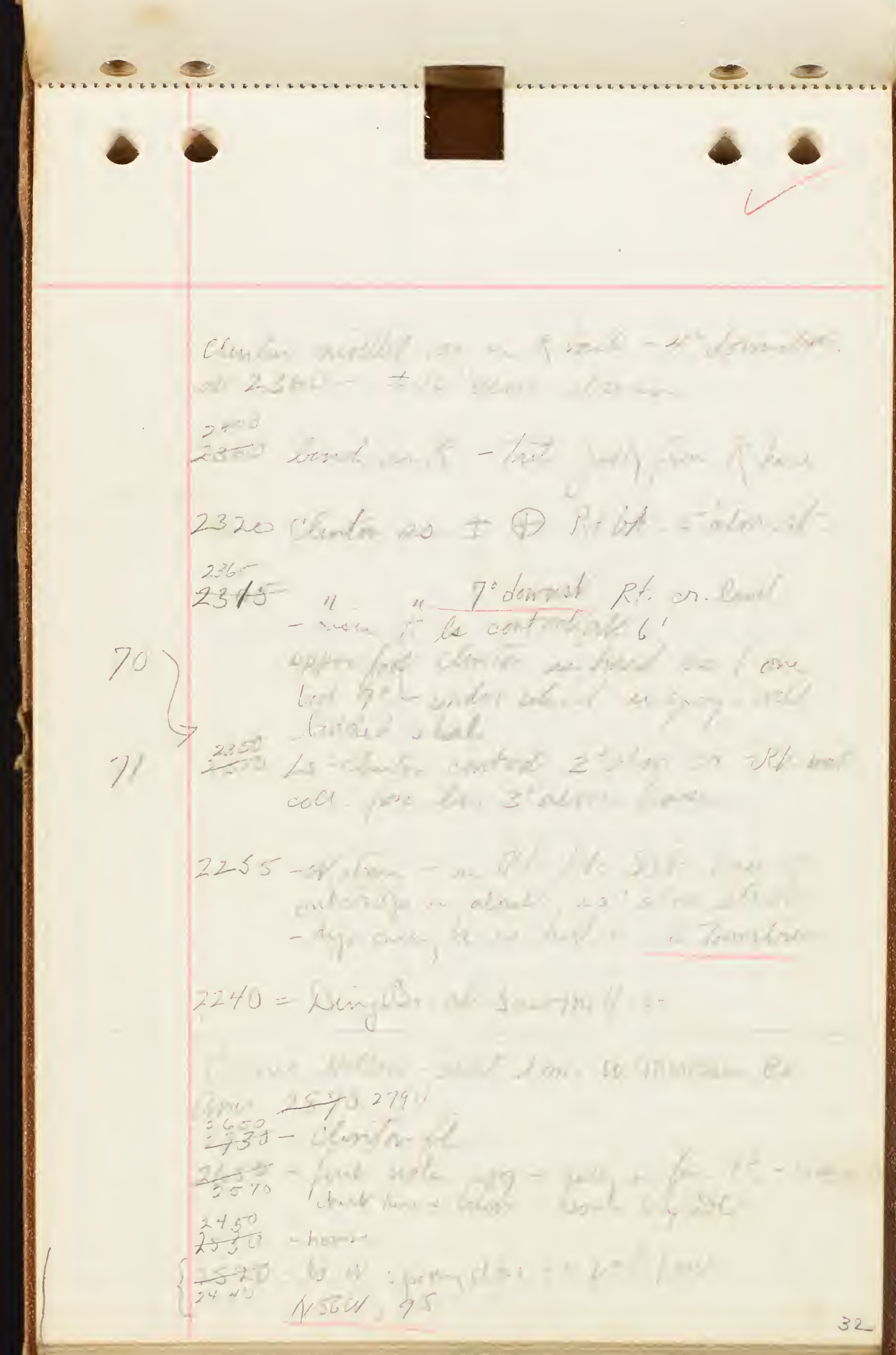




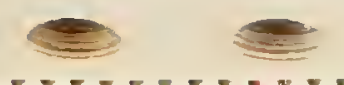

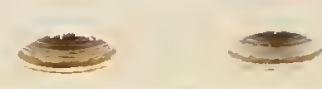

- $\bullet$

$\bullet \bullet$

2430-hasy Clunín fe

$2300-80077^{2}-0$

s.m. Man

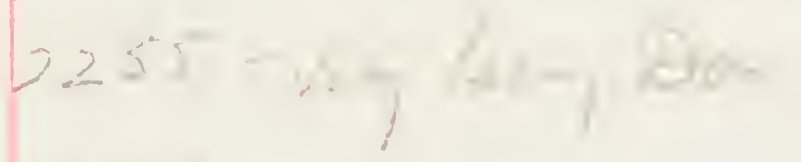

$=2200$

Q. W. Whe laid ad

$2 \geq 20$

2260

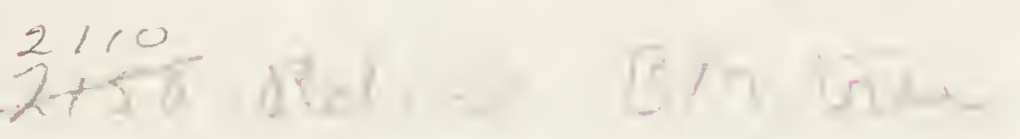

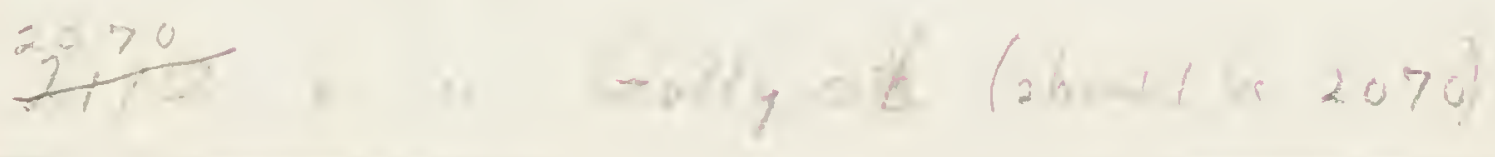




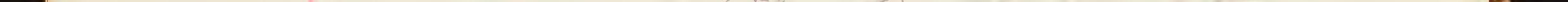




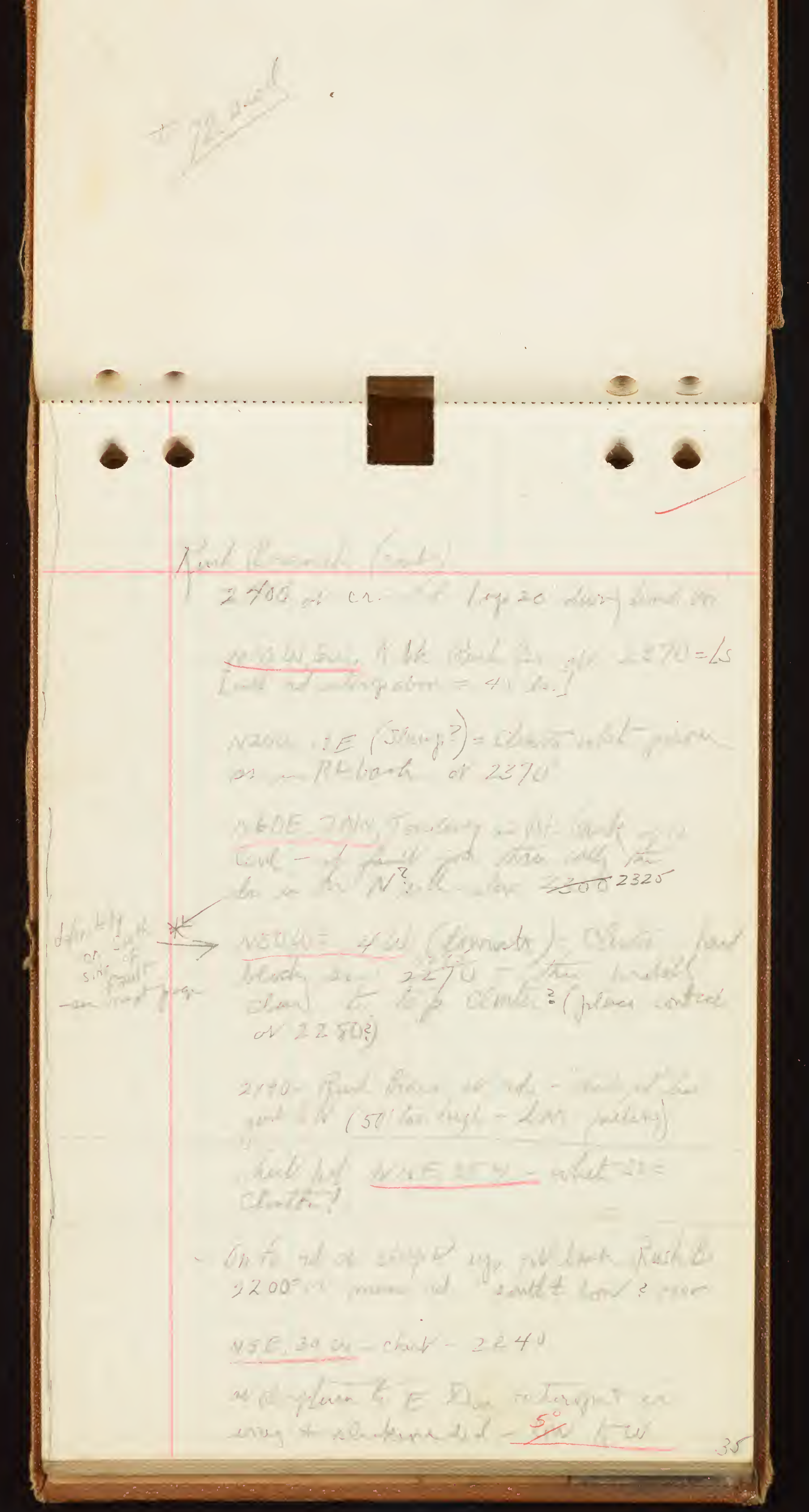




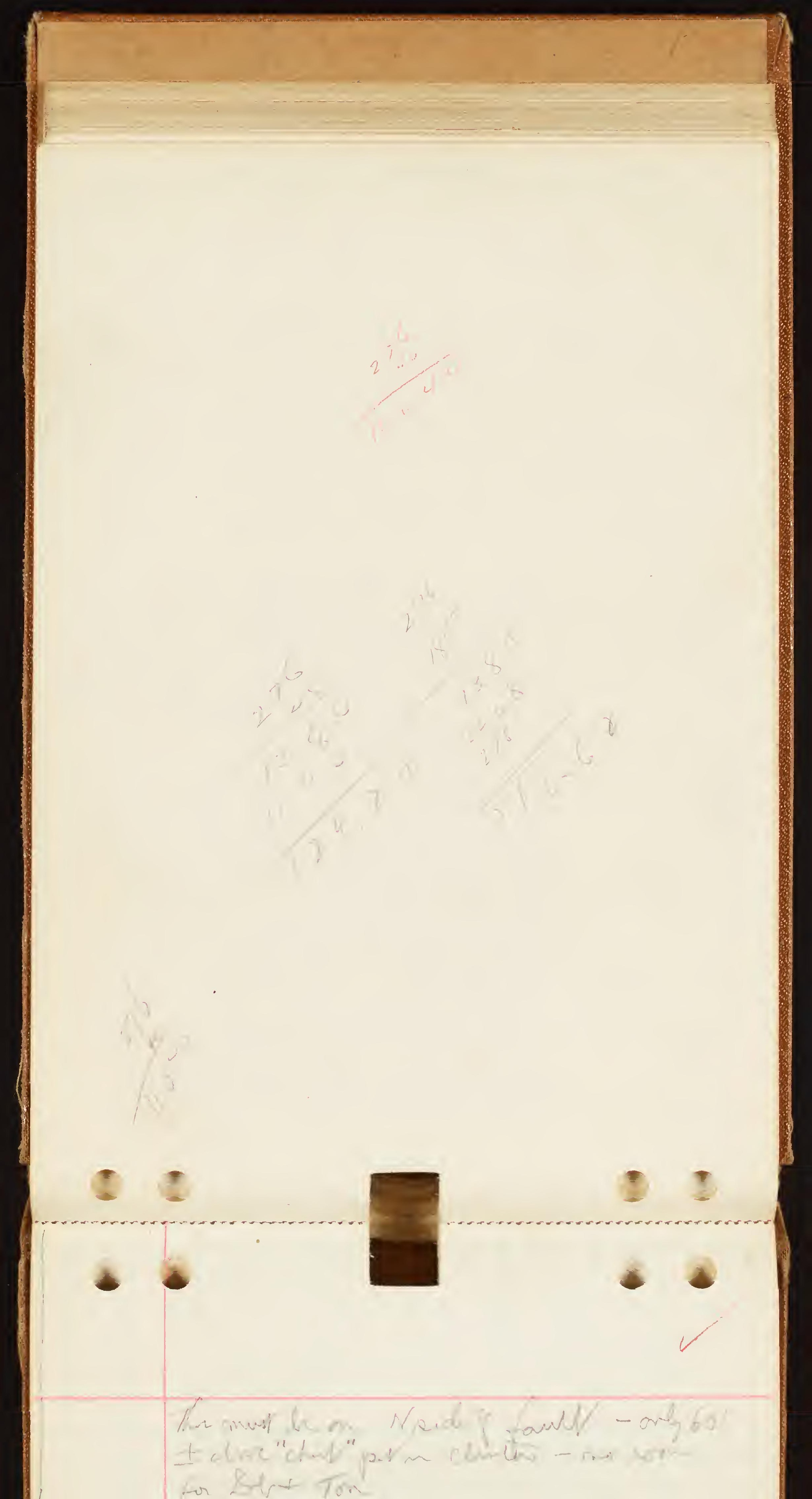




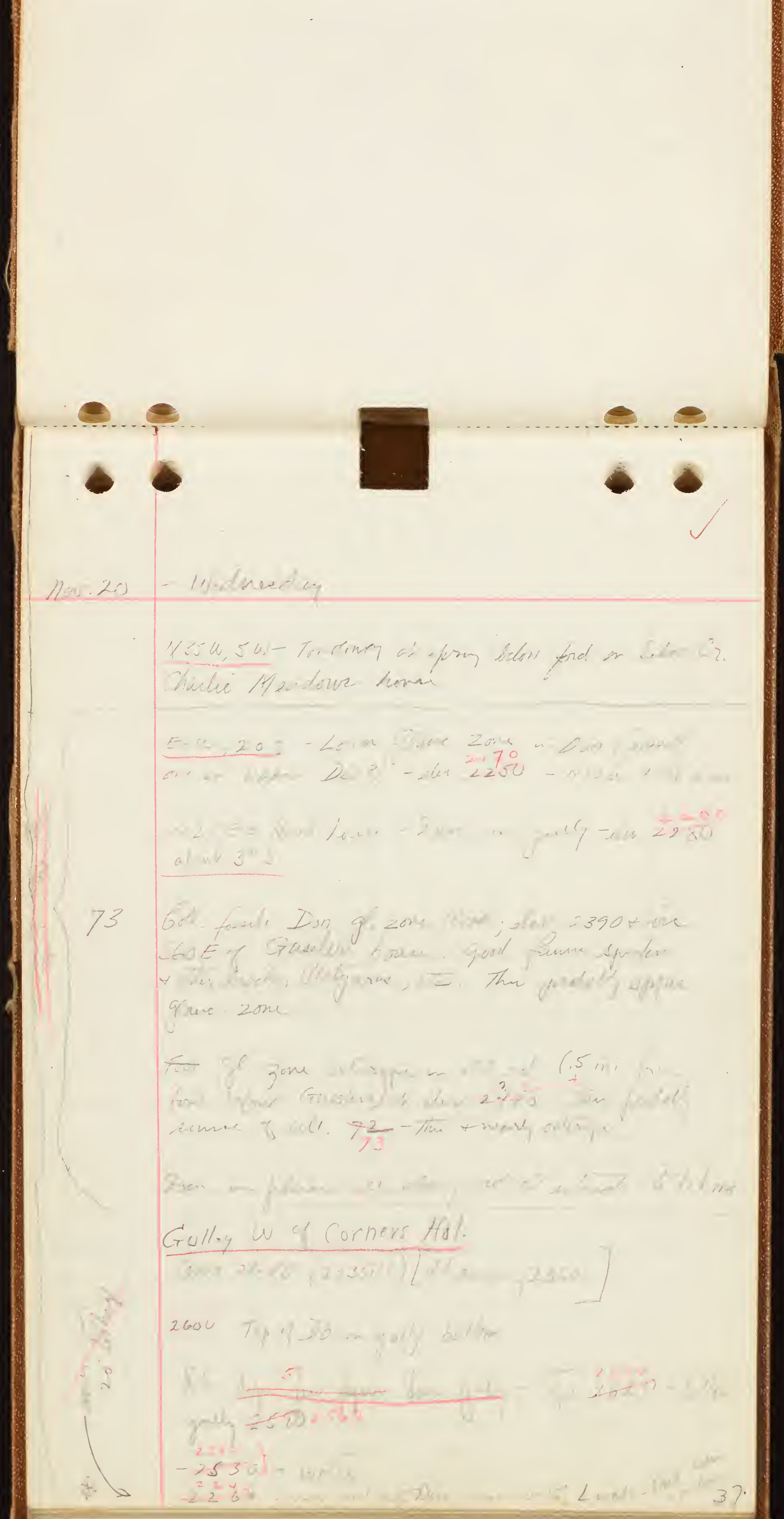




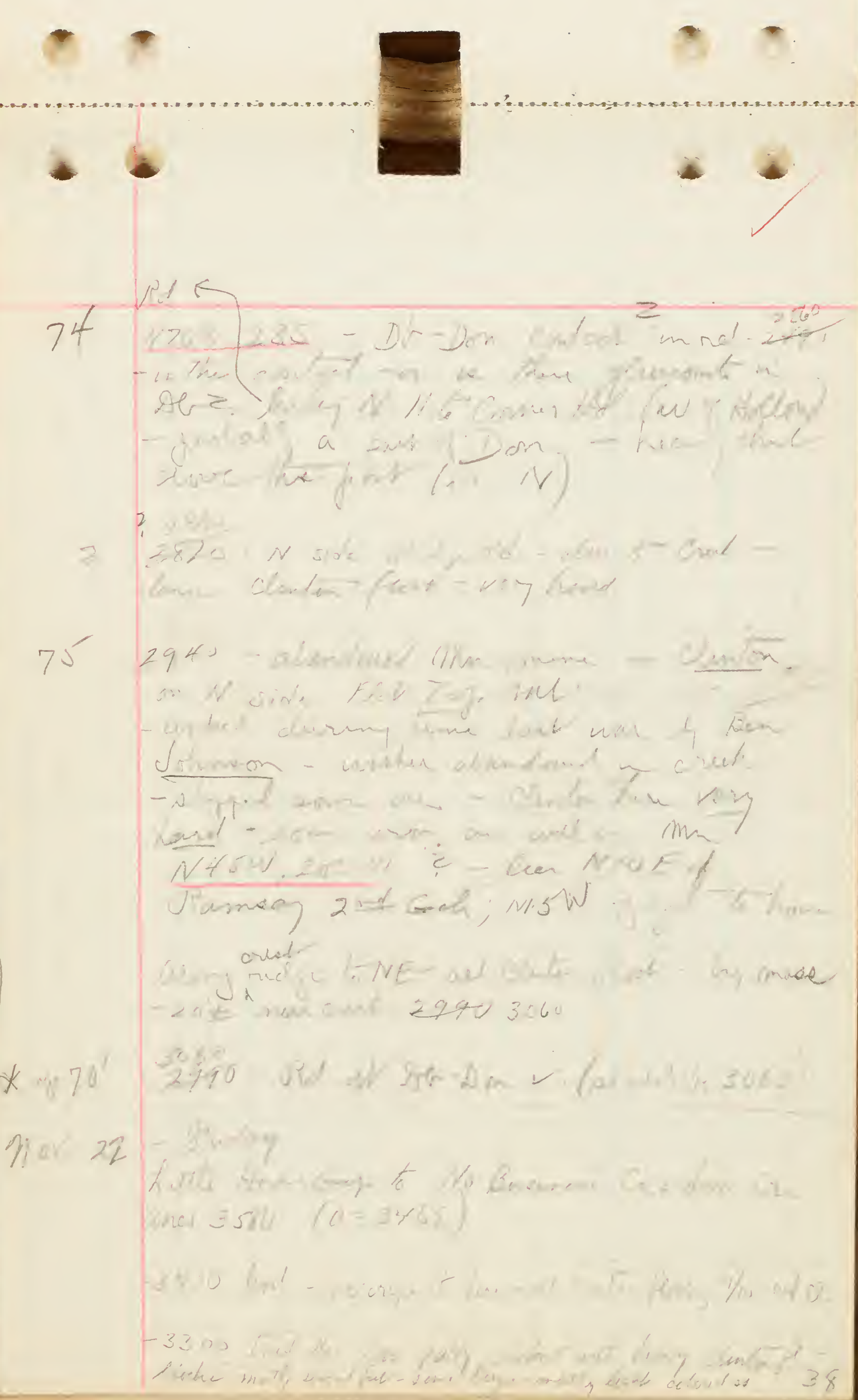




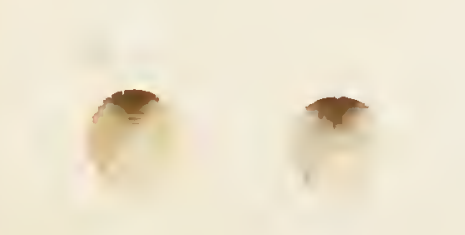

$+$
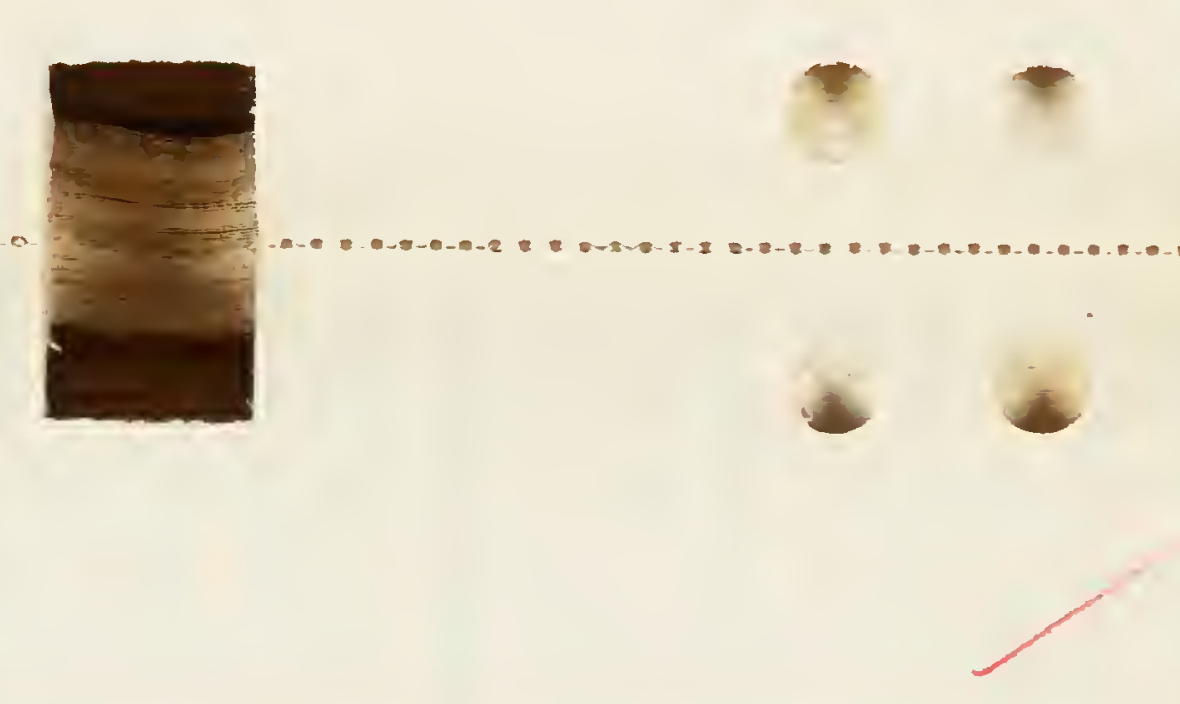

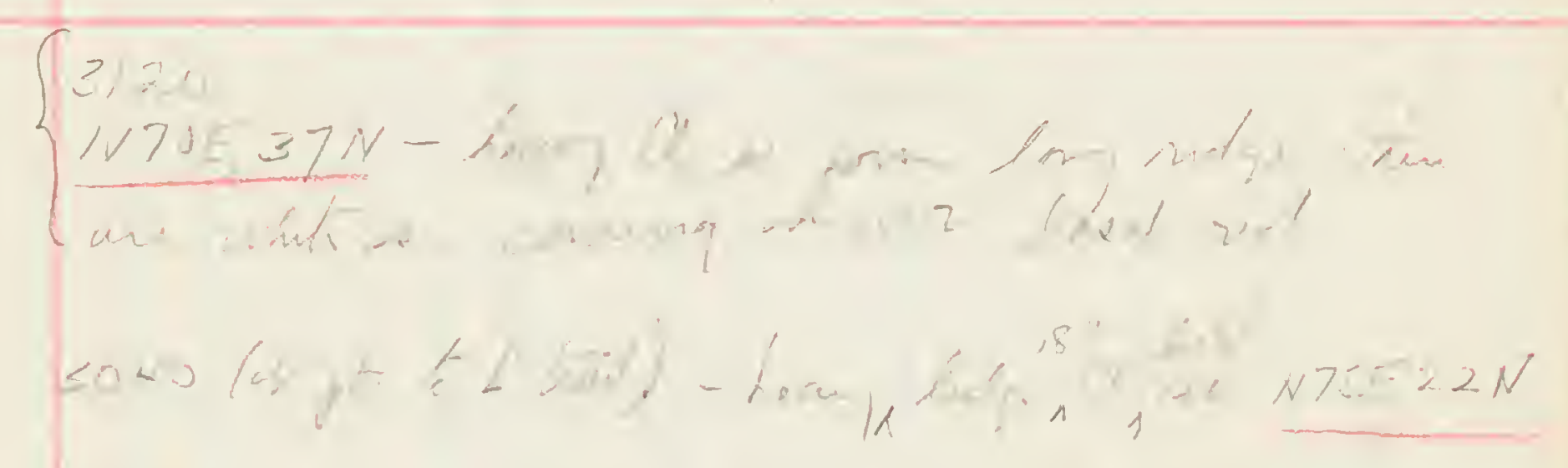

$2 \times 19$

$2860-81+200$

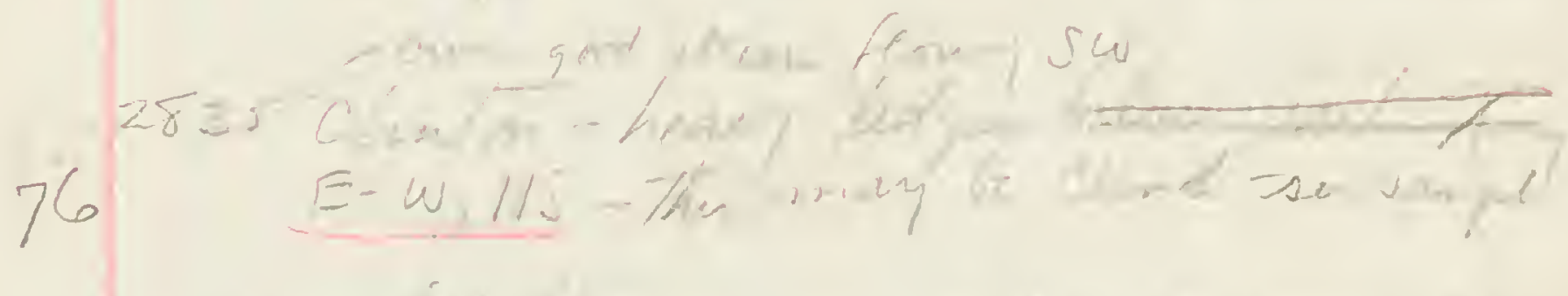

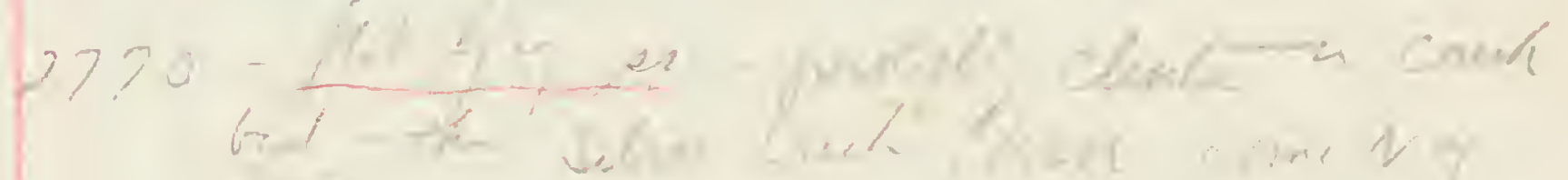

ind

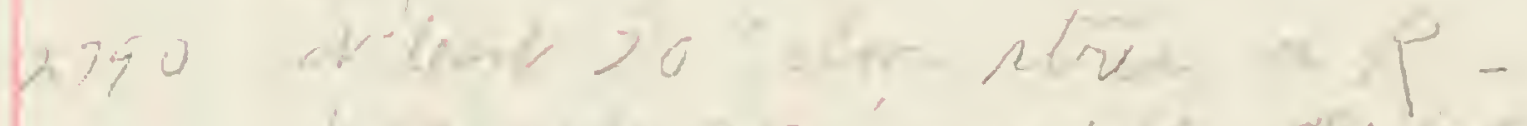

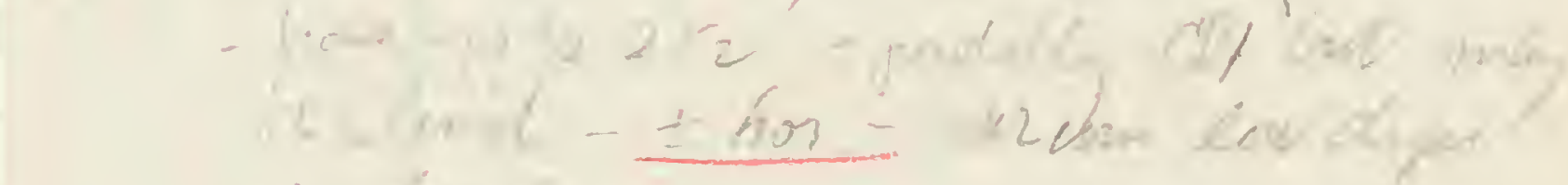

$$
\text { der th diven }
$$

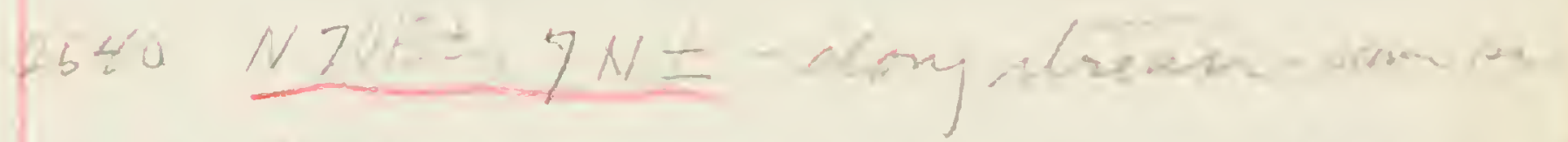

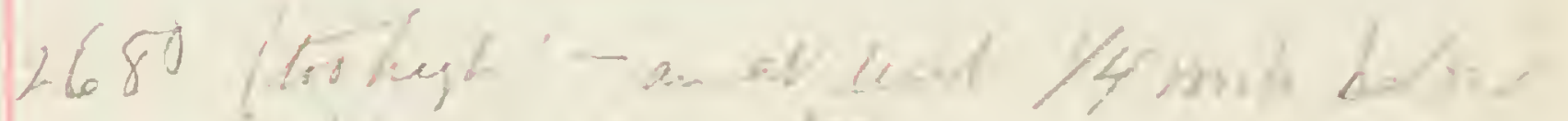

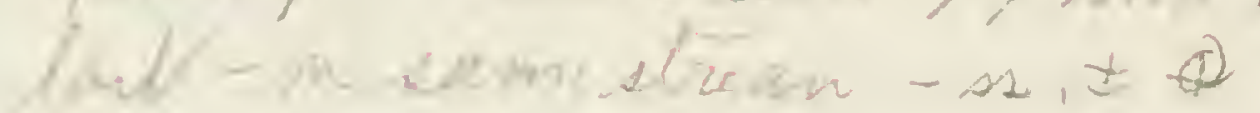

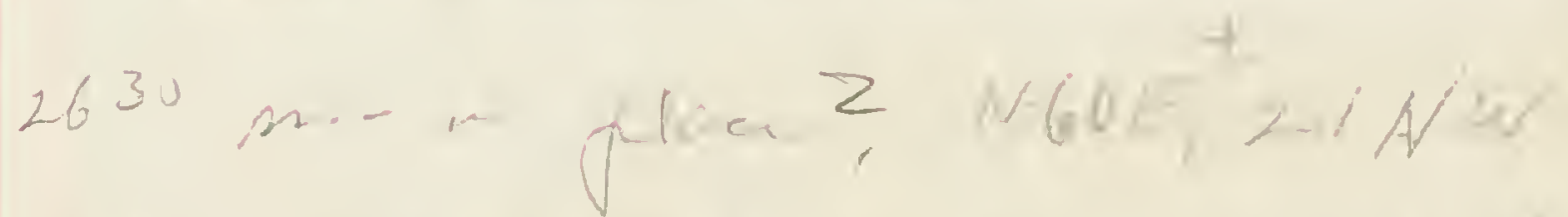

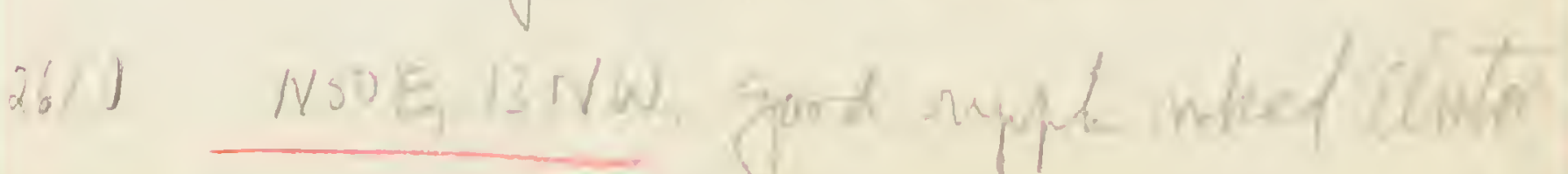




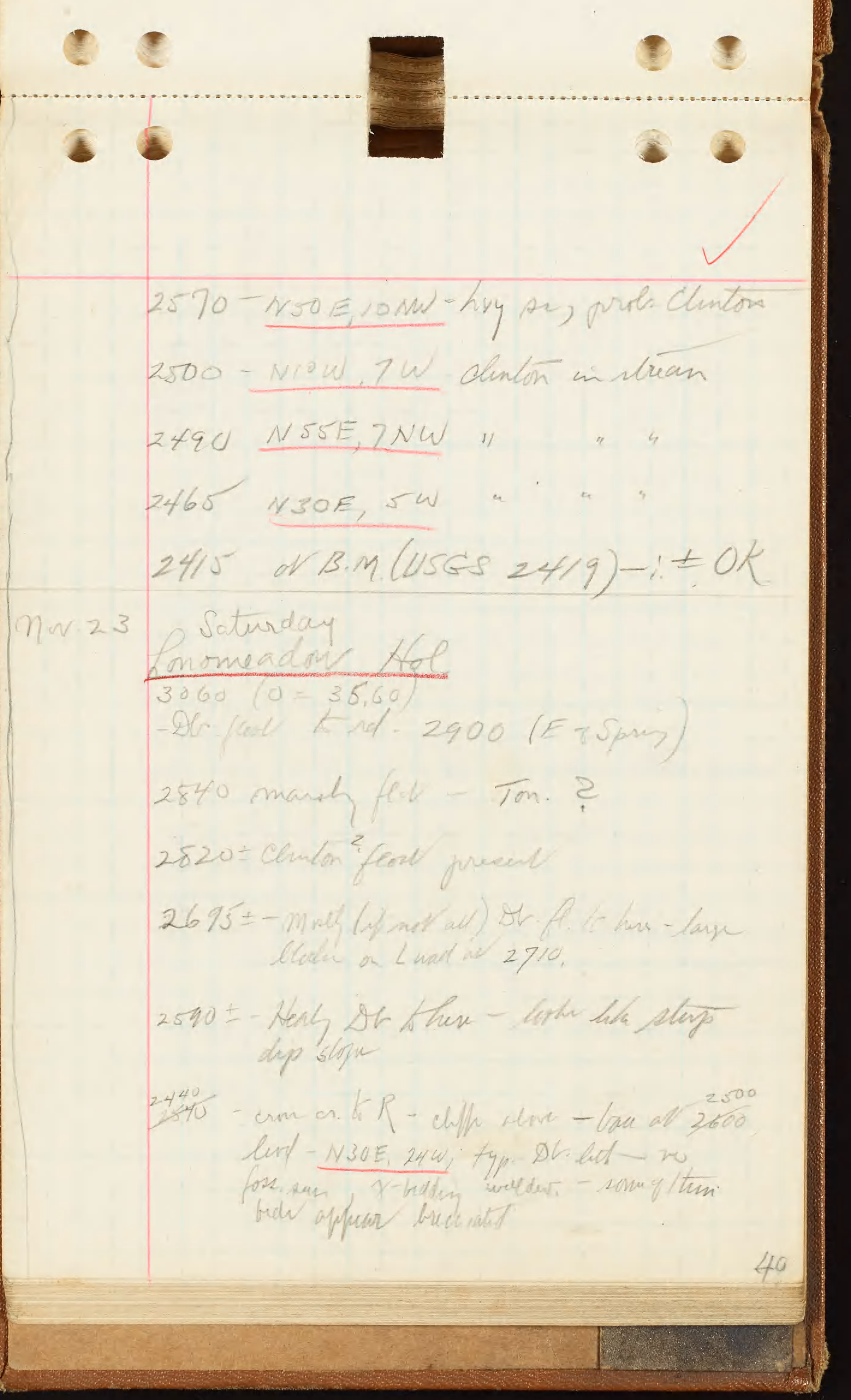




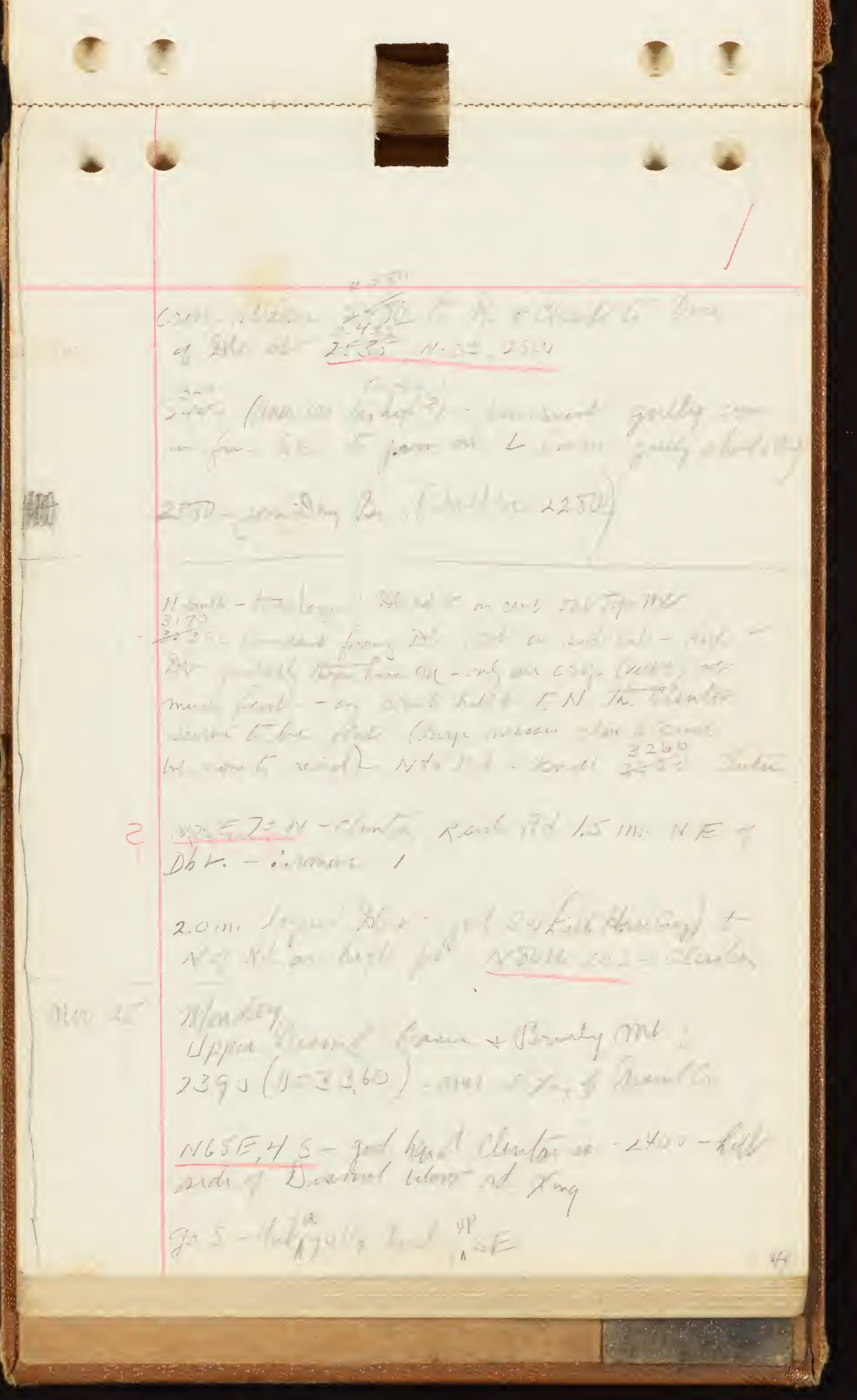





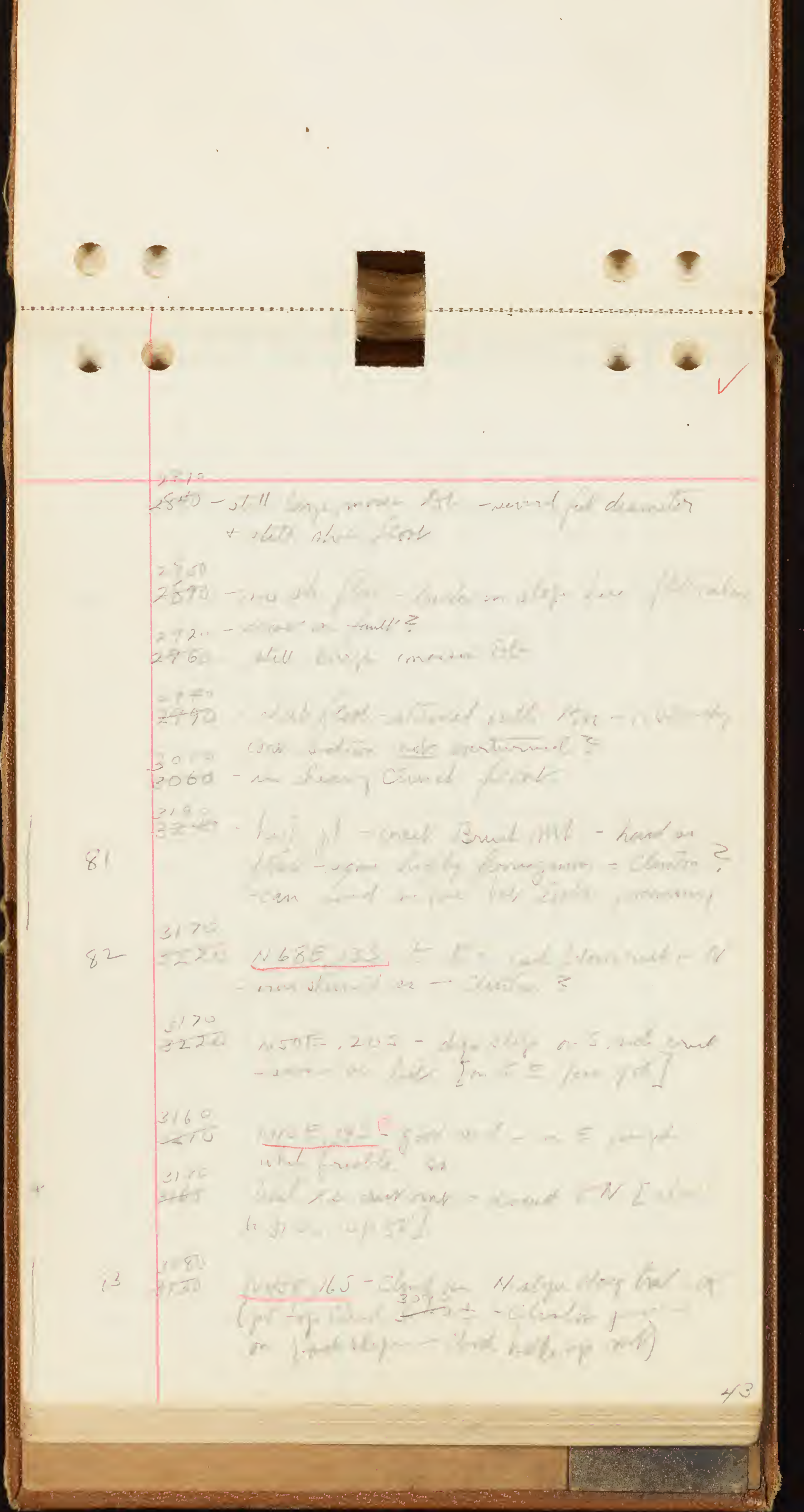



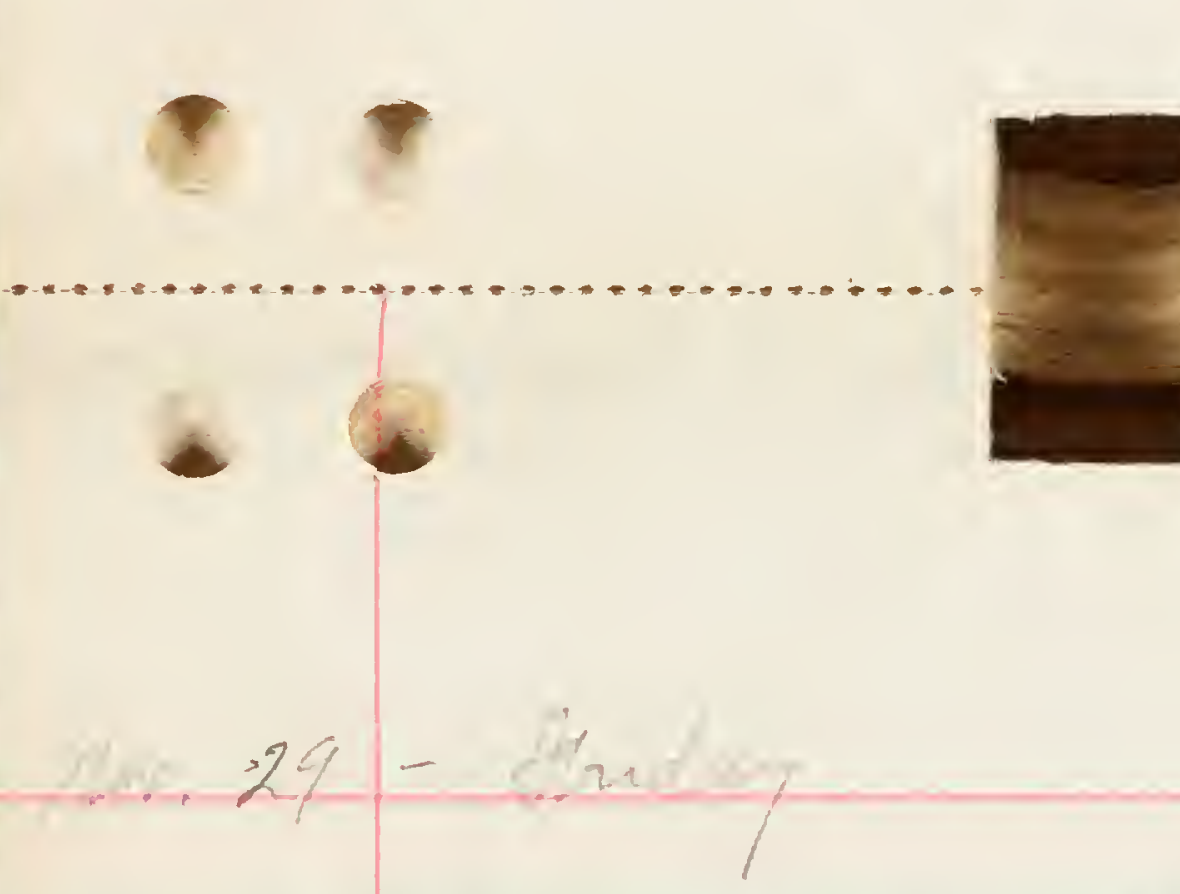
3. 5

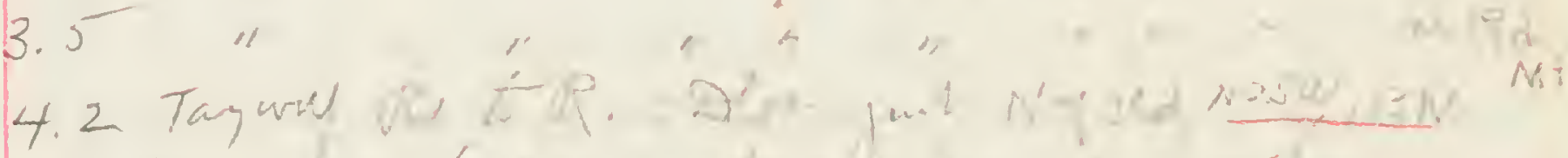

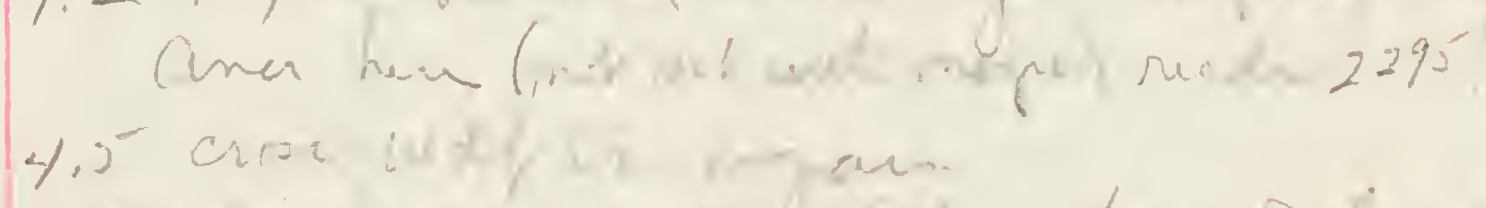

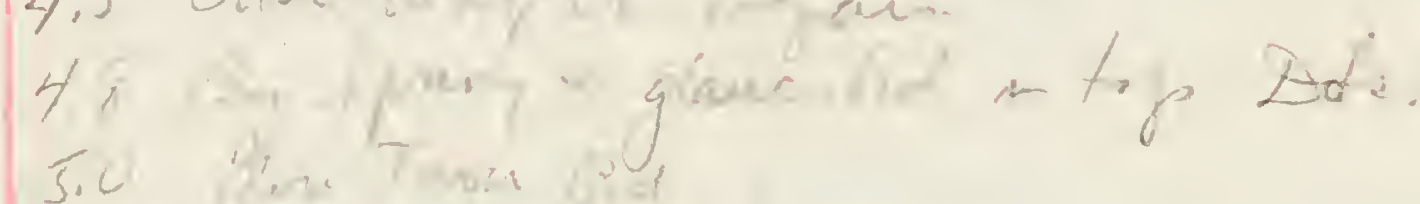

\section{5,15 Dh No EN SE}

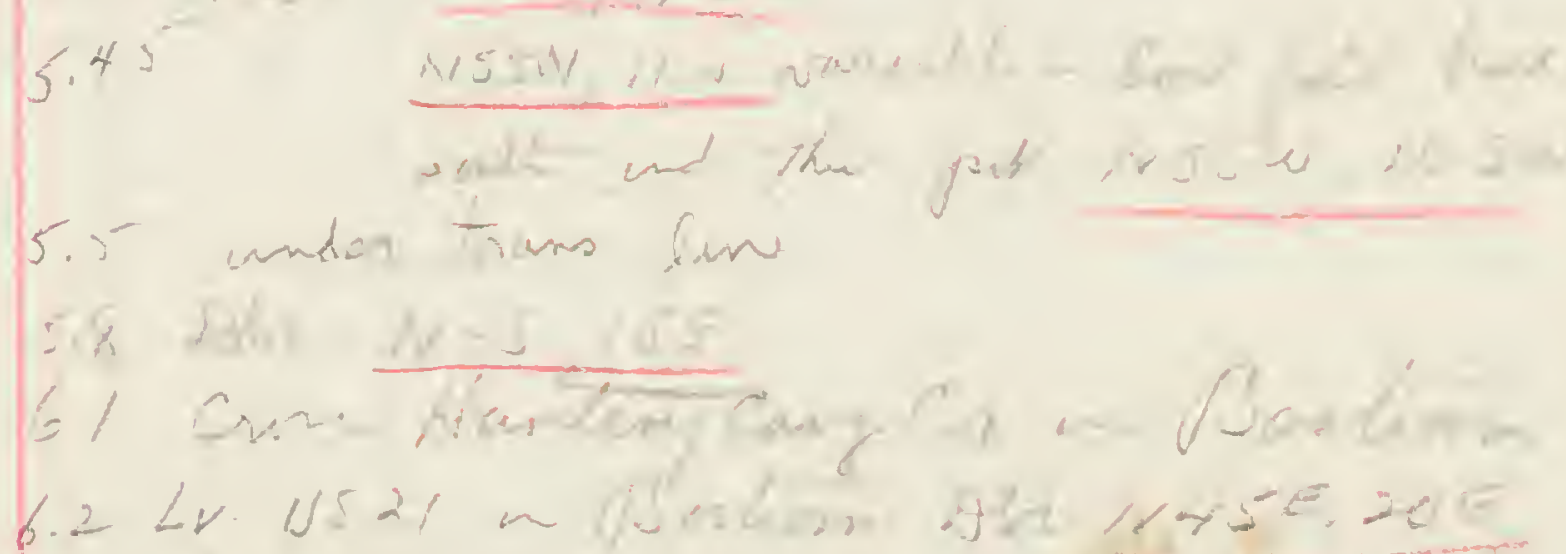

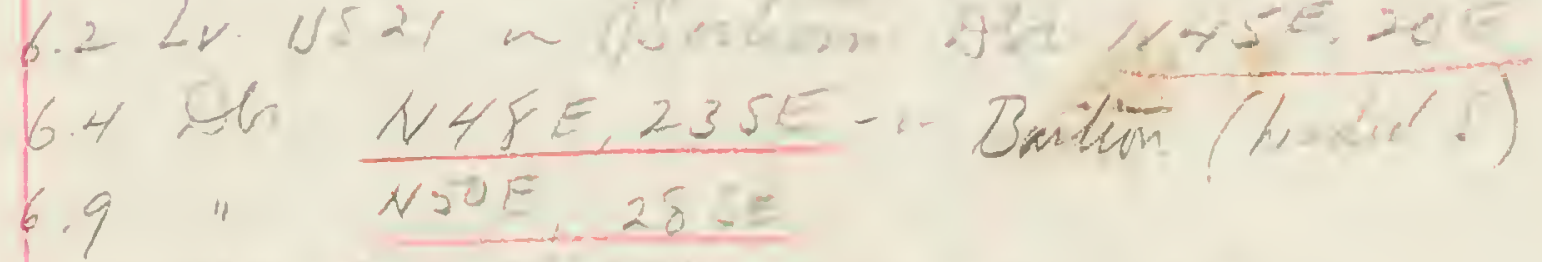

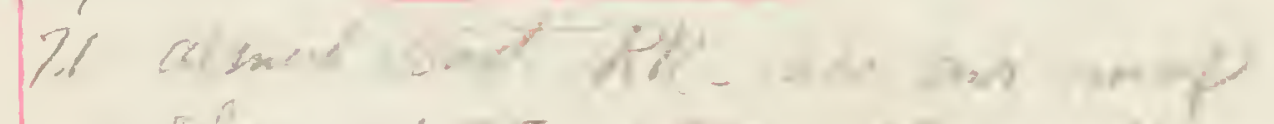

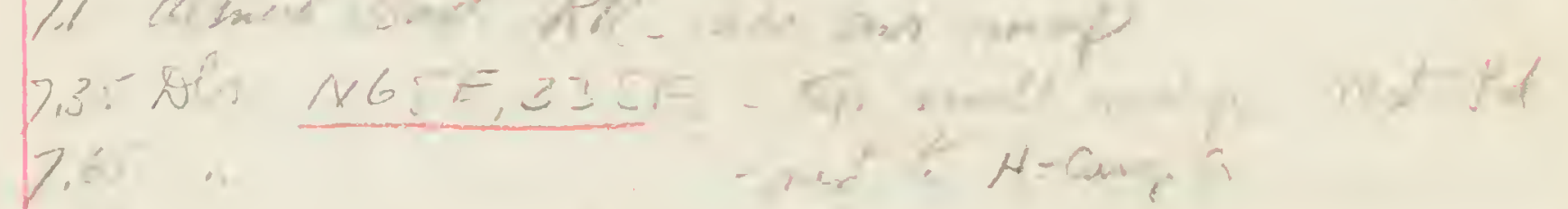

7.9 "NSE, 25-E
59 "NGSE, 20SE

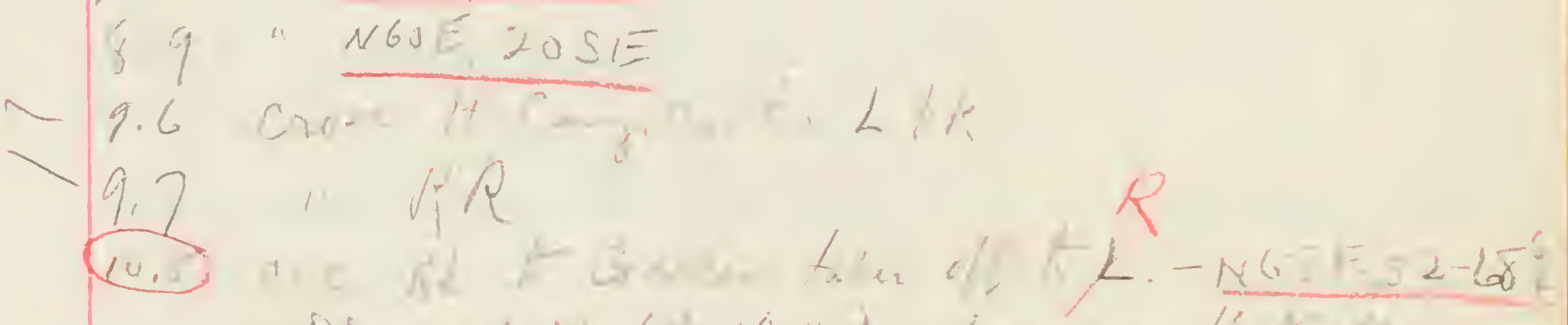

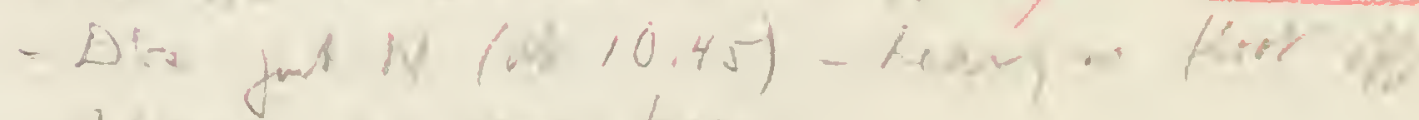

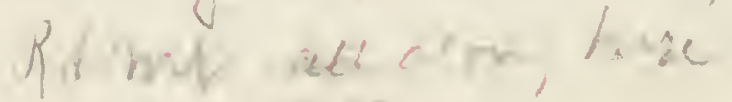

10.6 Wase RR

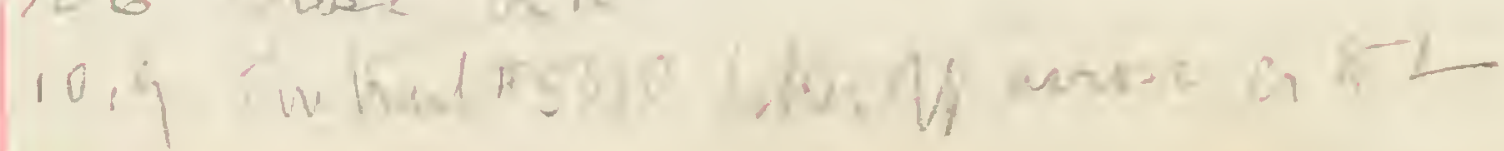



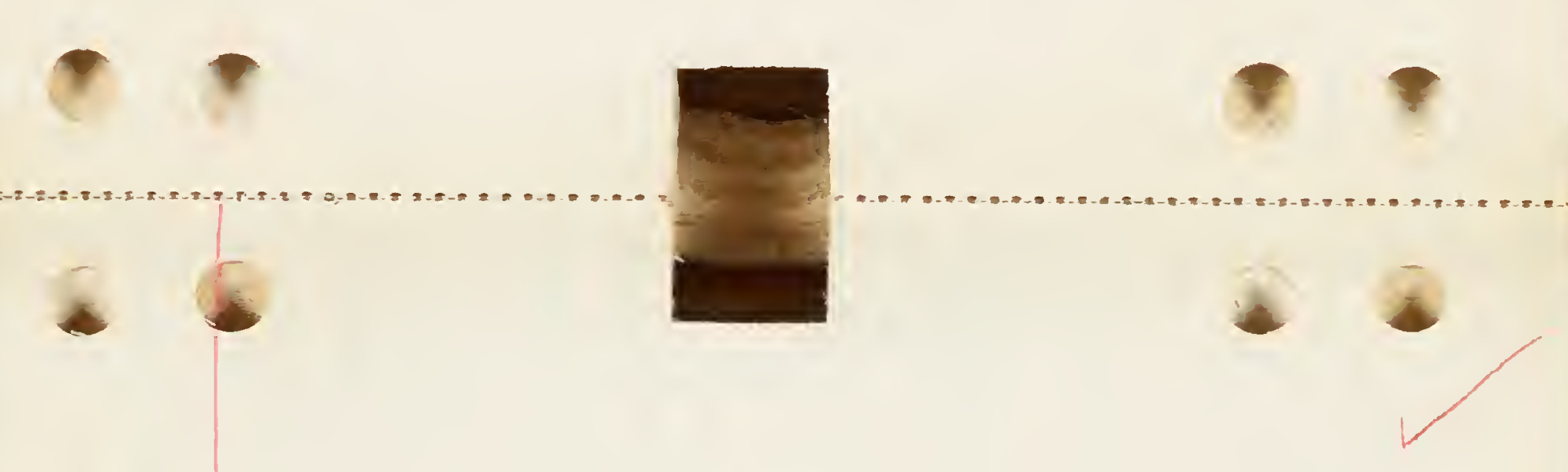

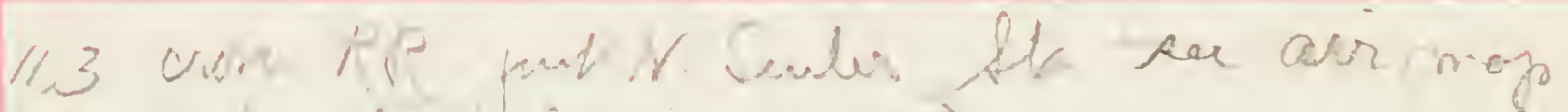
pew diule gto 2480

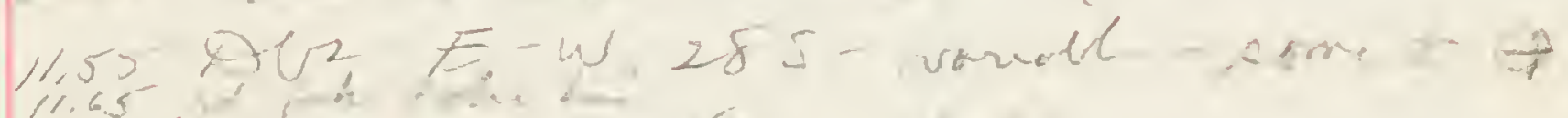

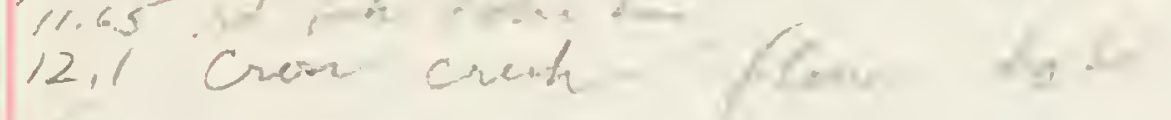

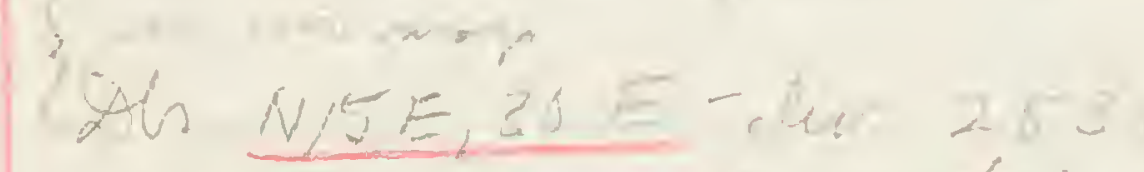

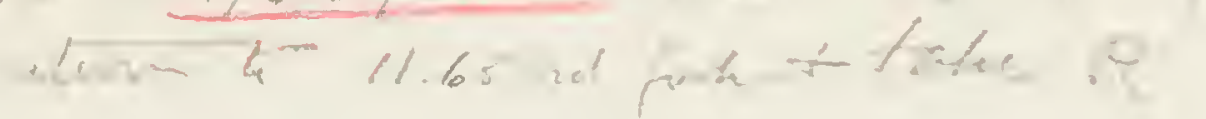

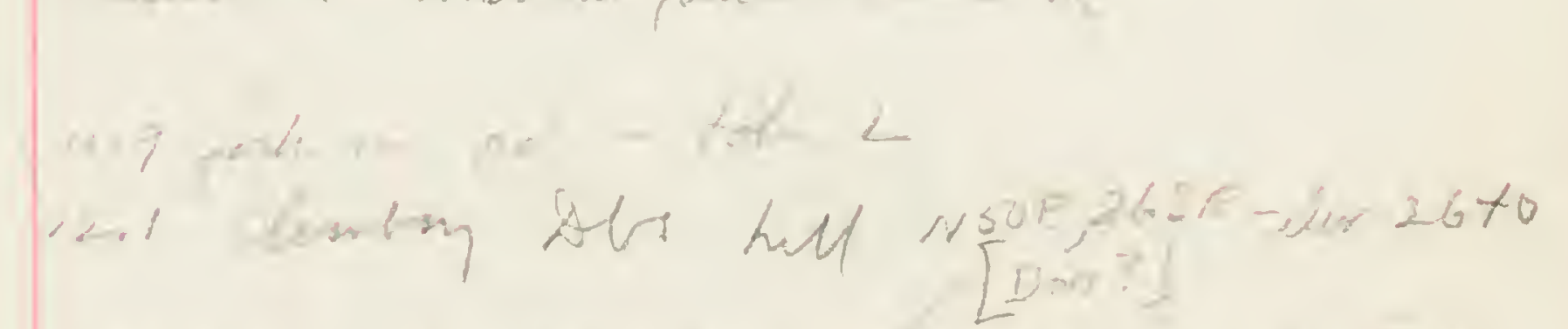

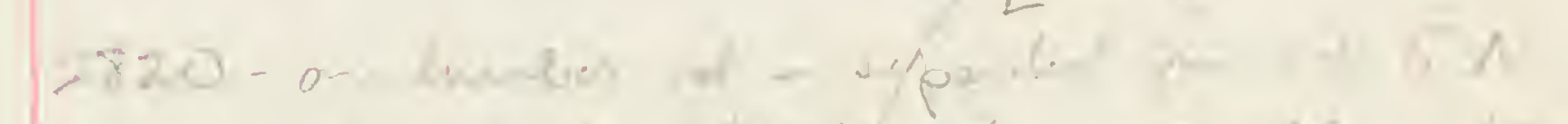

(n)

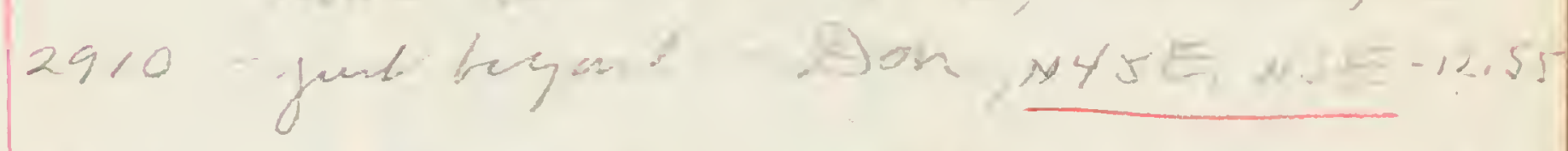

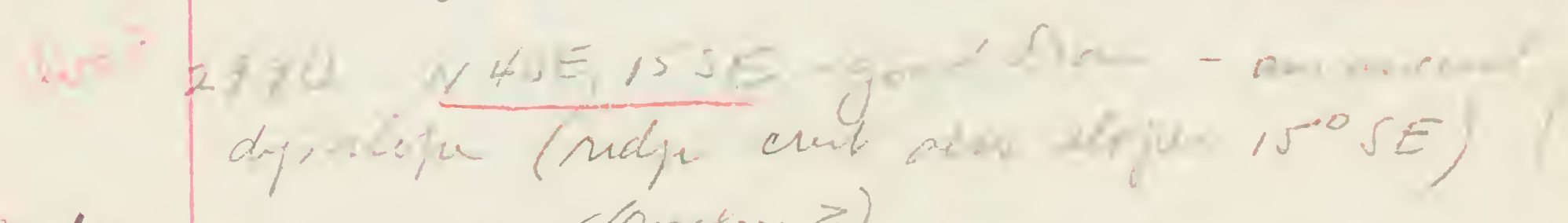

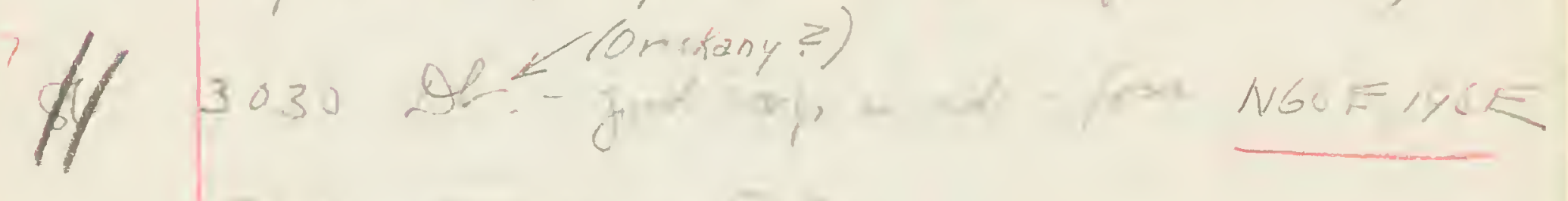

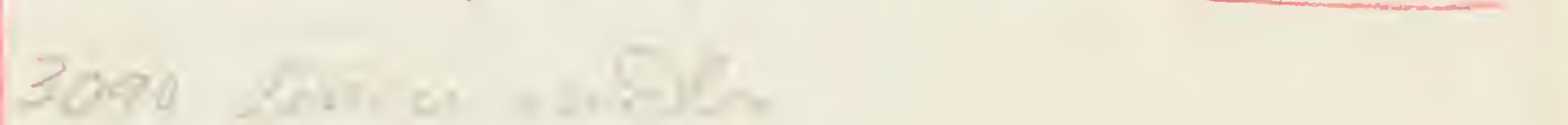

Pans

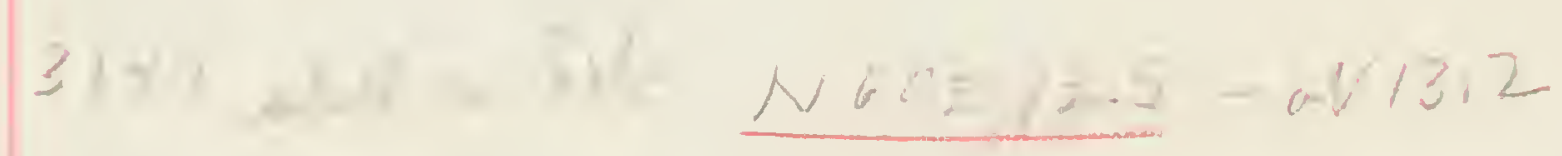

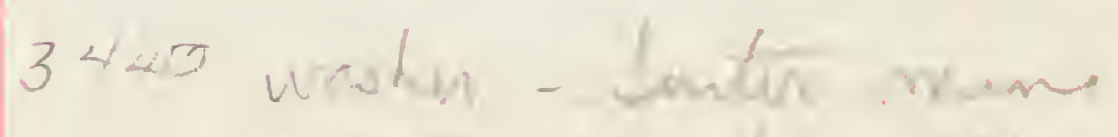

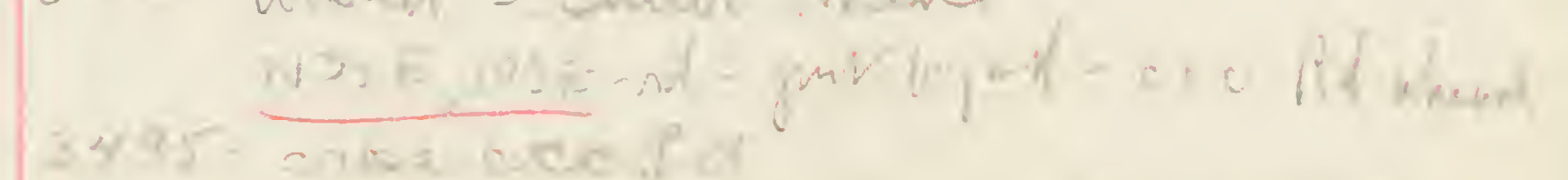

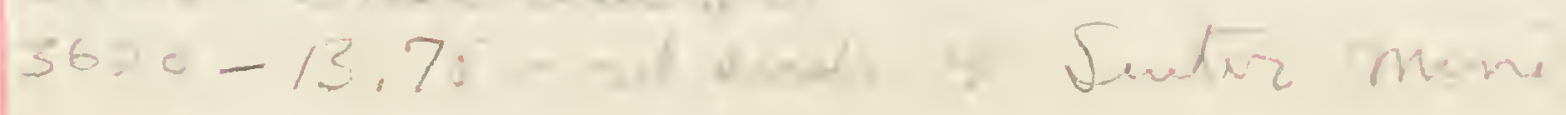




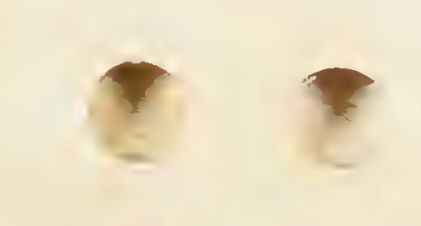

-
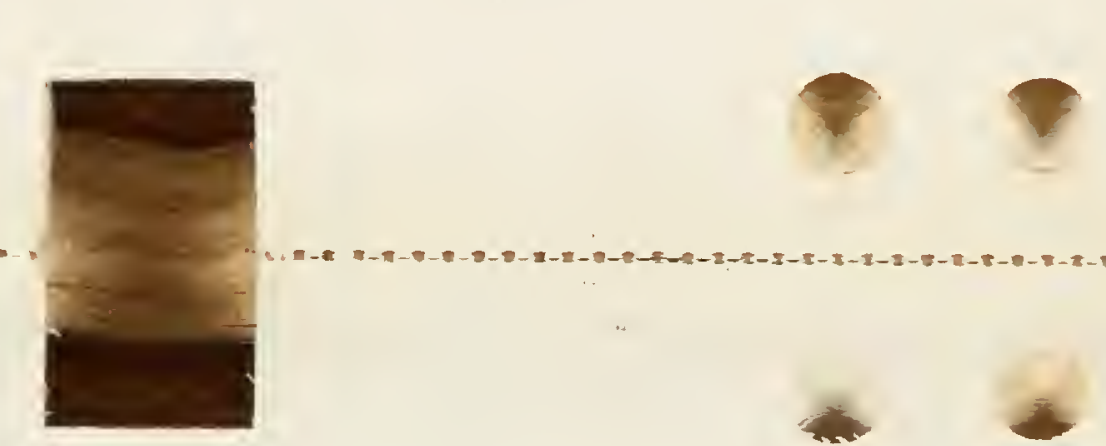

$+$

Brat is burotherieare

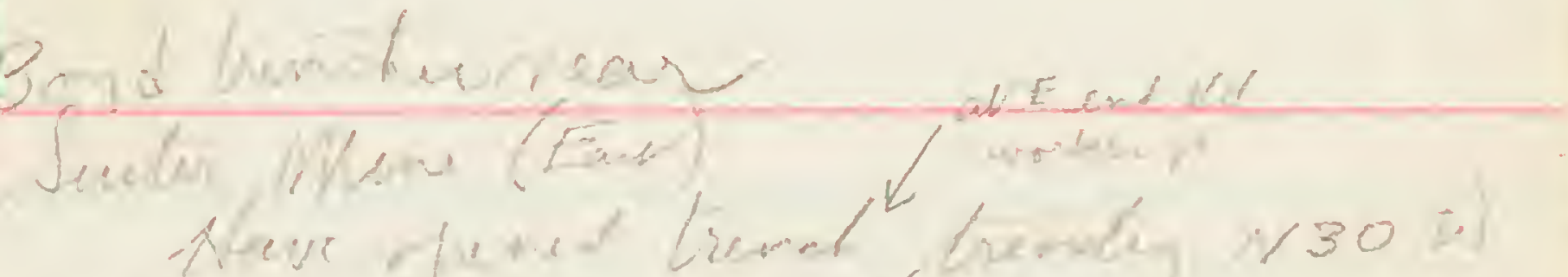

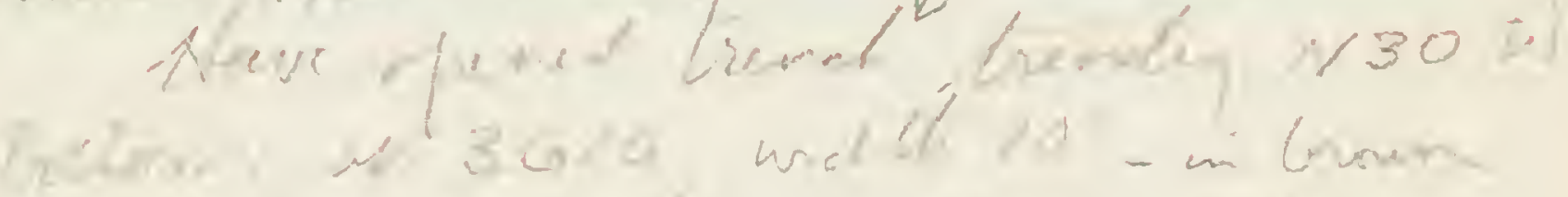

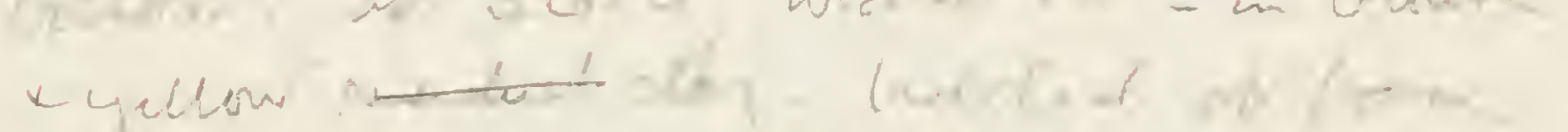

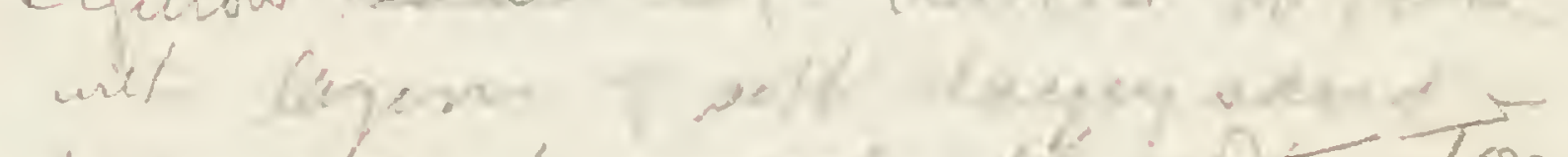

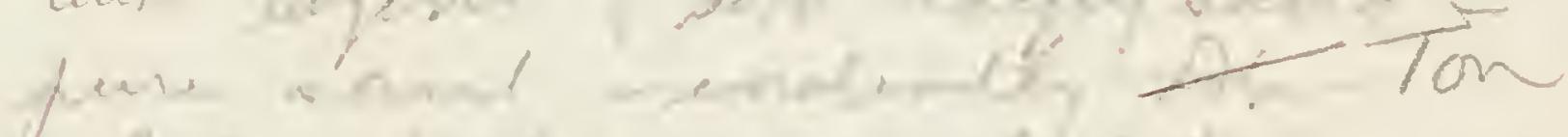

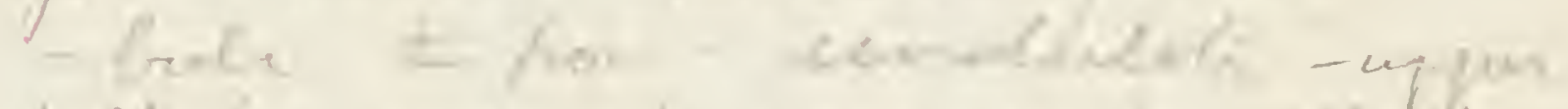

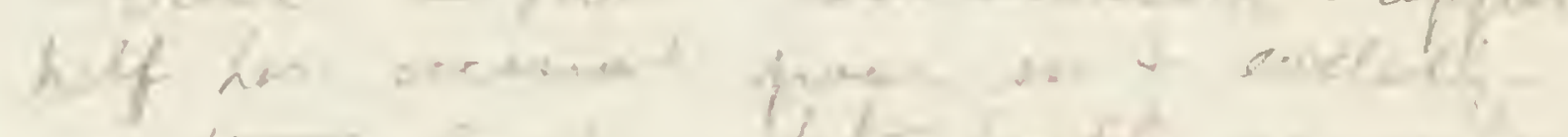

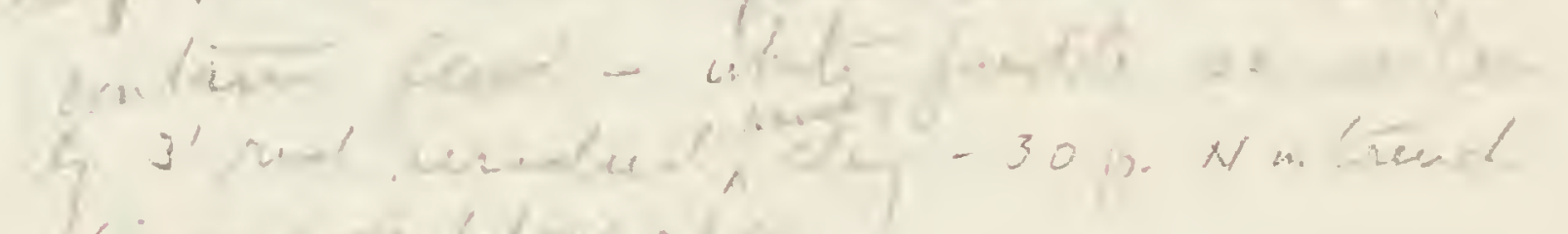

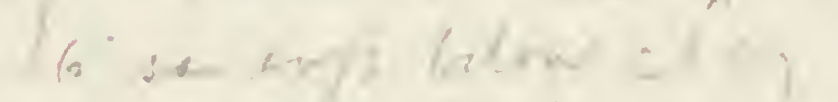

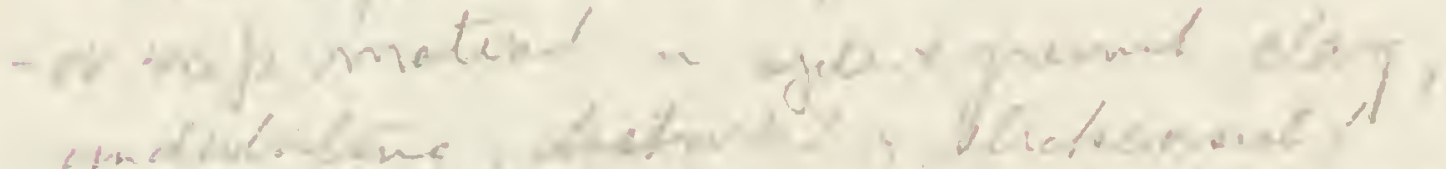

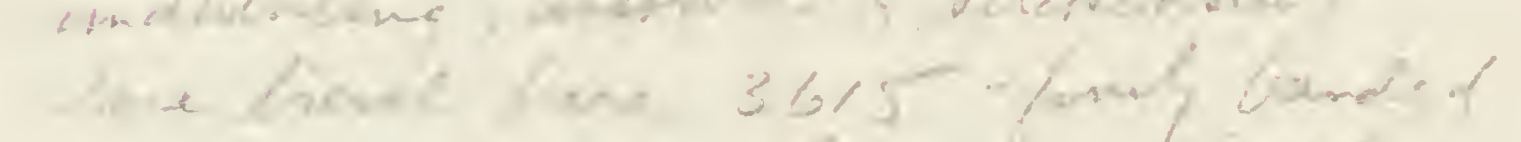

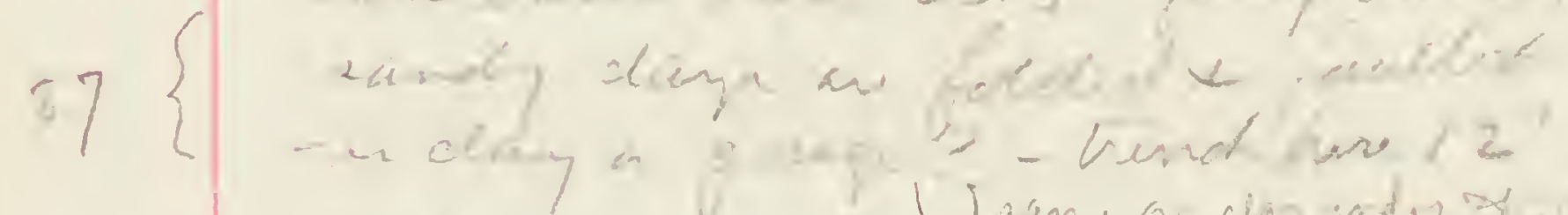

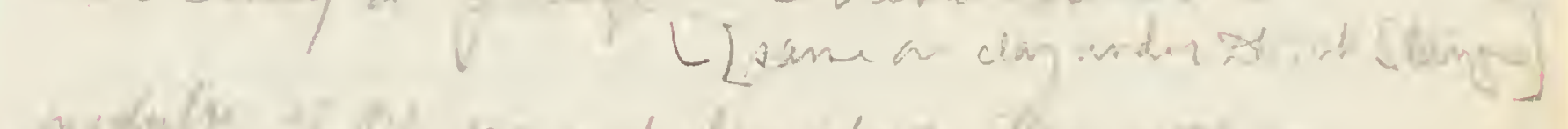

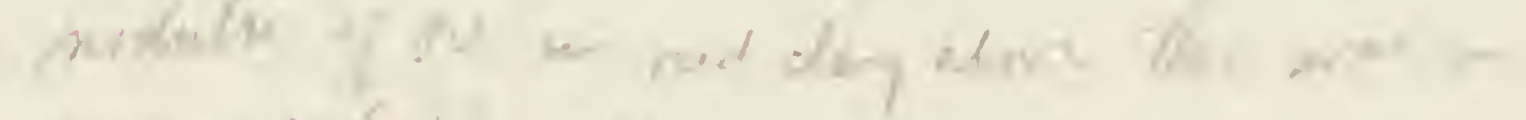
applith $(w+\ldots)$

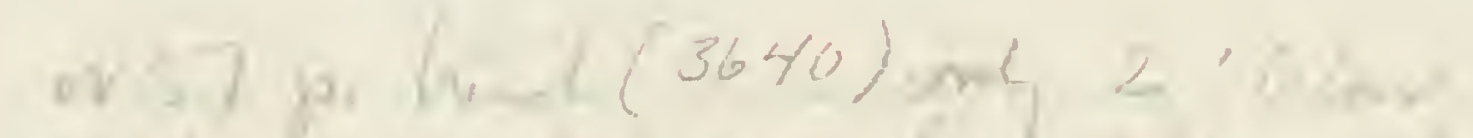

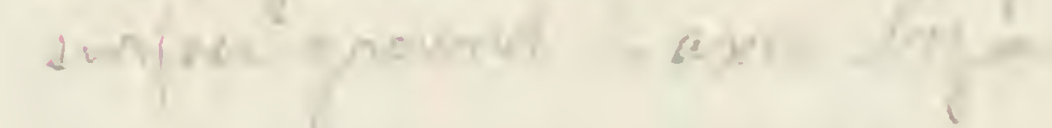

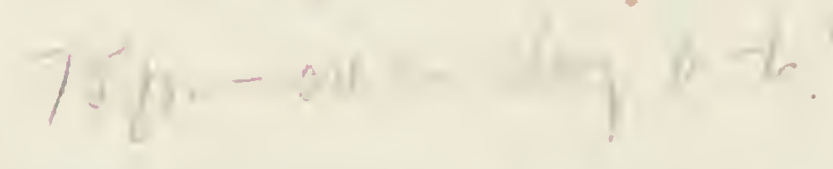

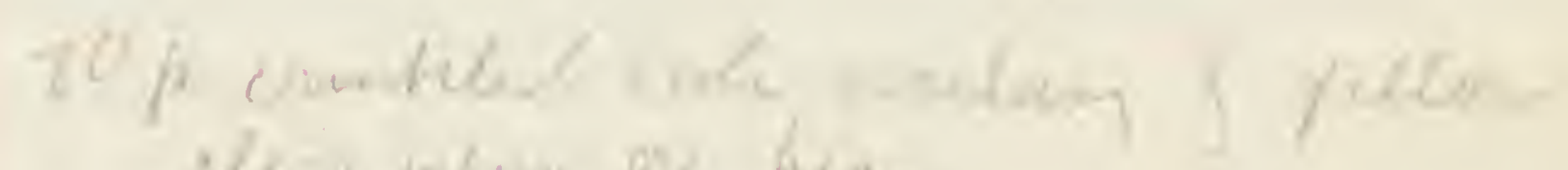
Uey wibue ou Man. 



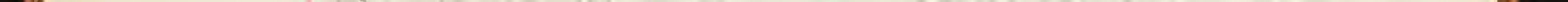




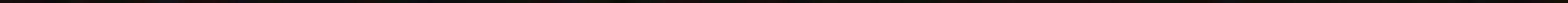




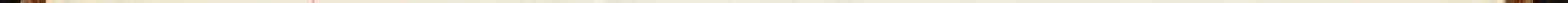




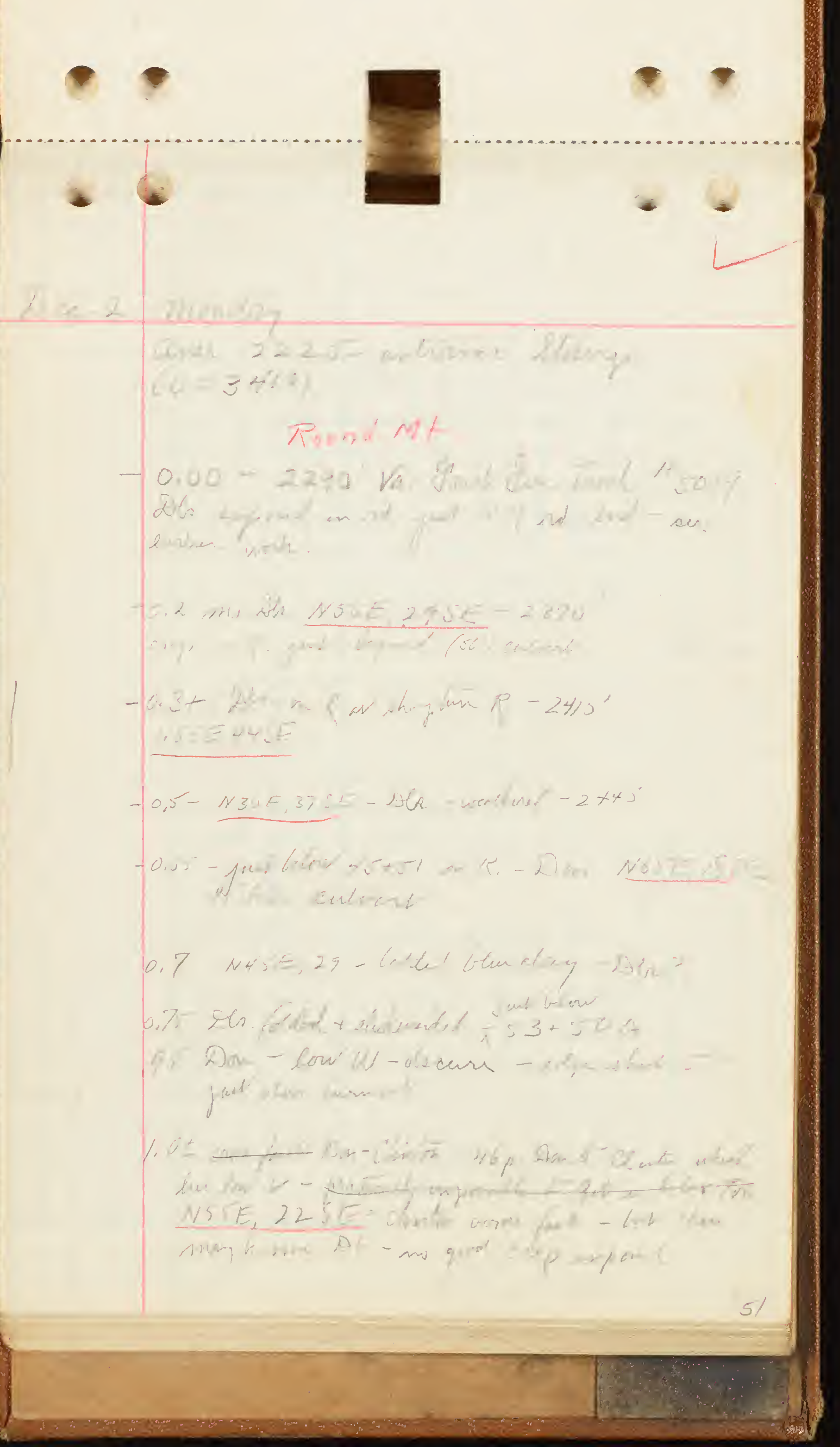




\section{$\rightarrow$}
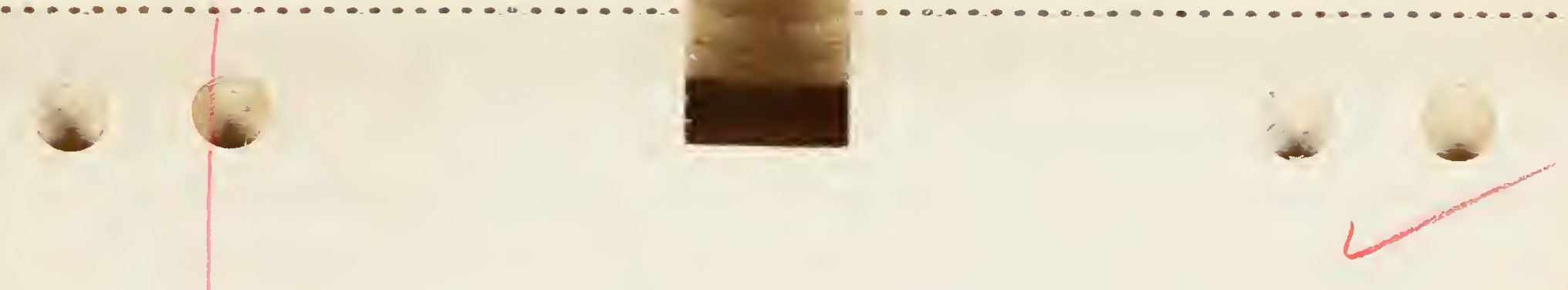

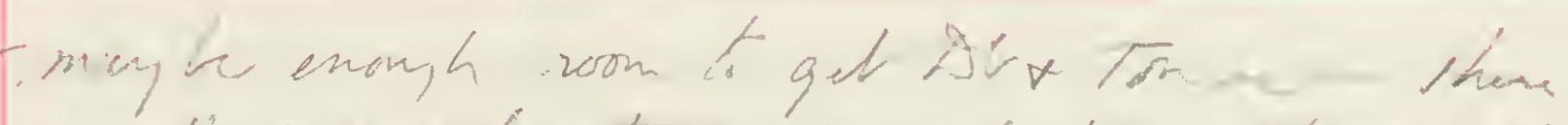

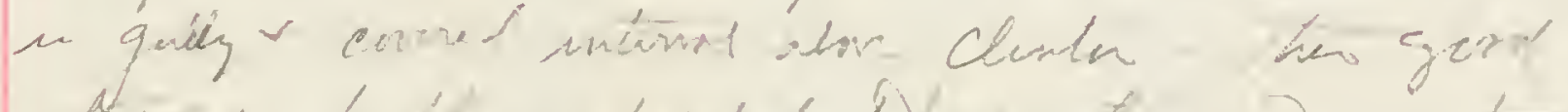

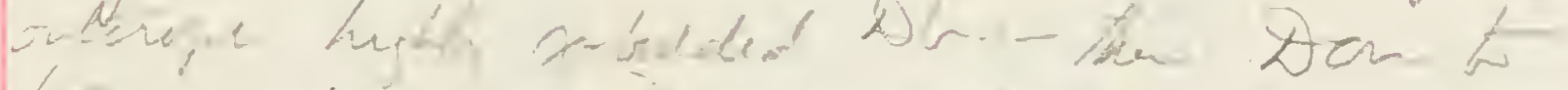

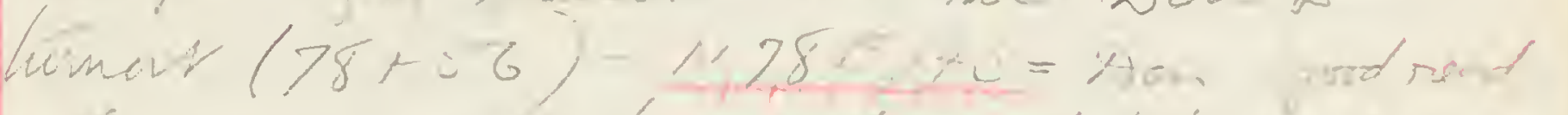

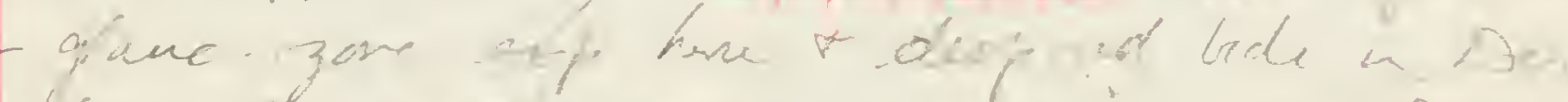

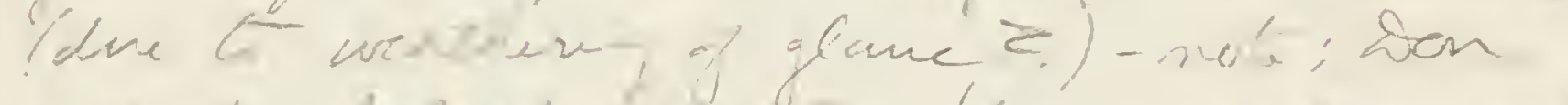

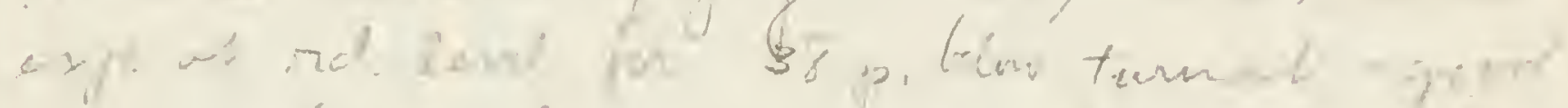

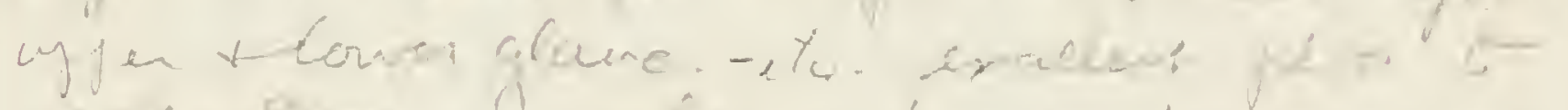

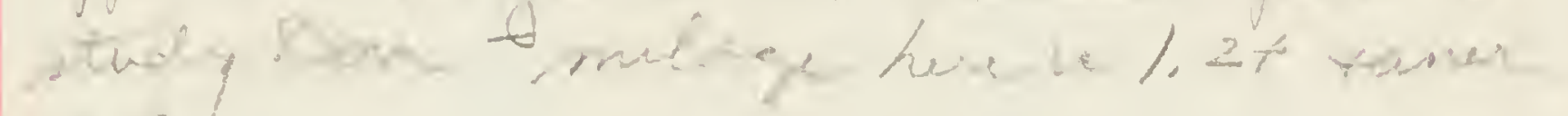
2650

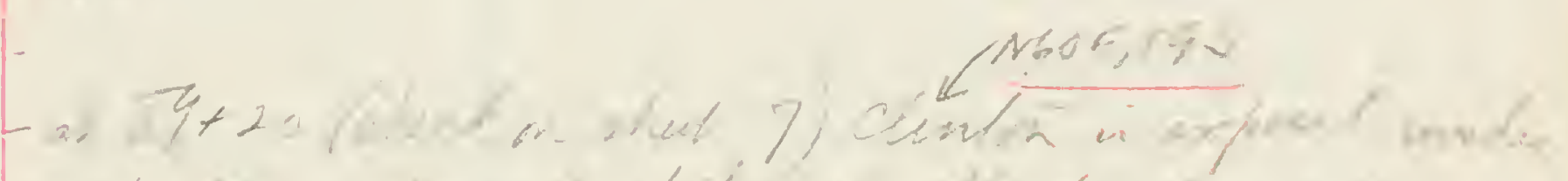

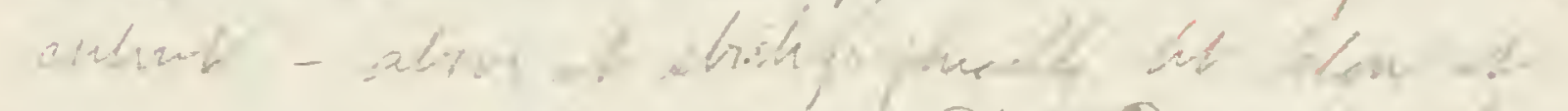

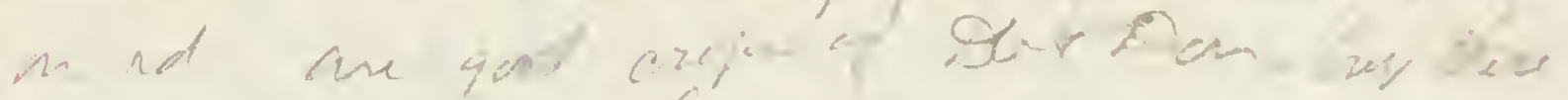
seem deth sorac for mists Ton.

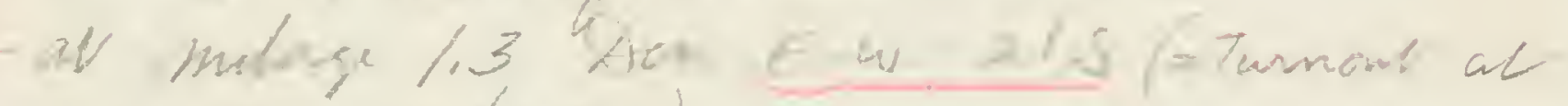
$82+93$ an sieft i)

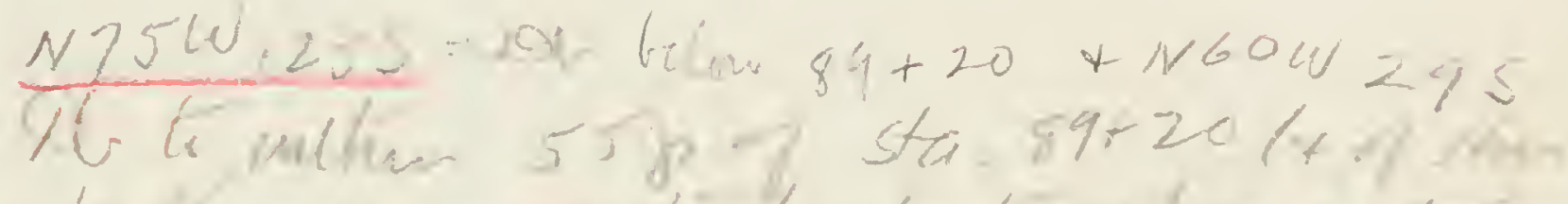

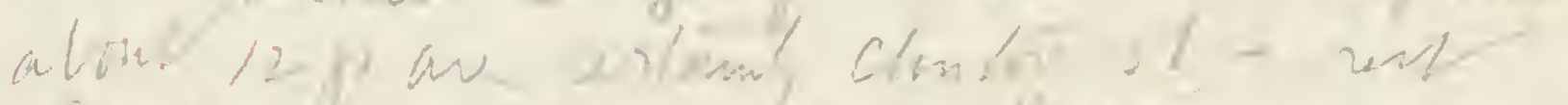

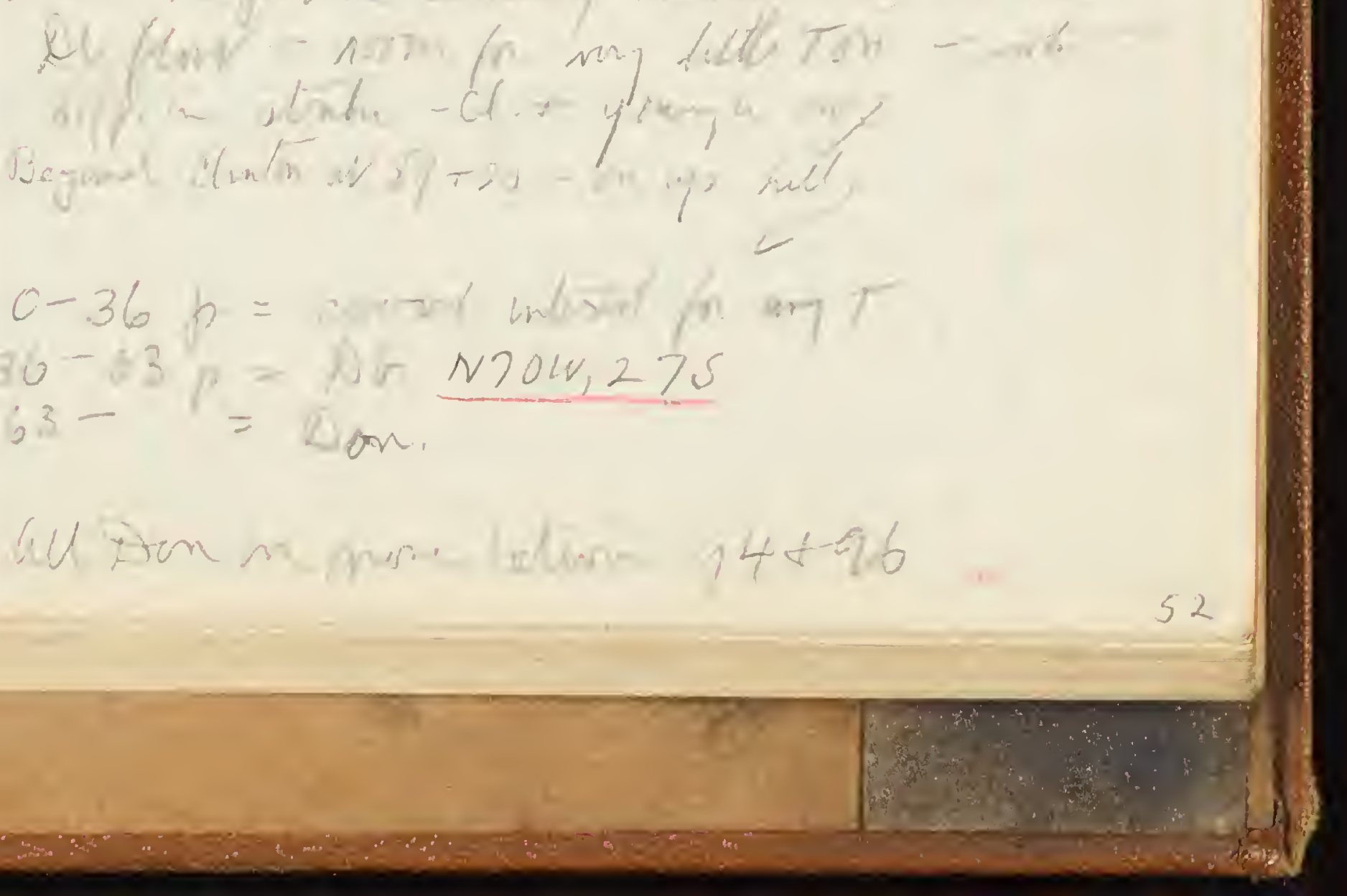




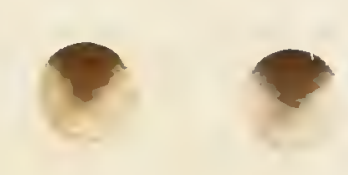

$\therefore$

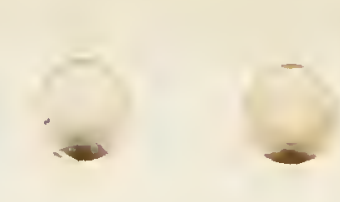

gull a $199+19$ w between fant 74

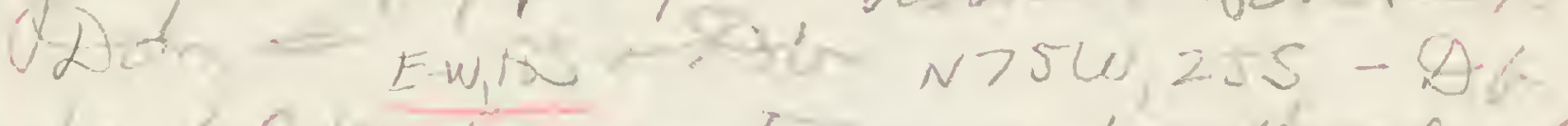

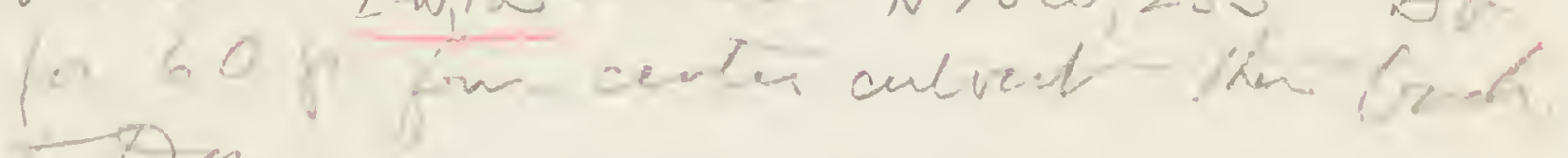
$7 x \sin$

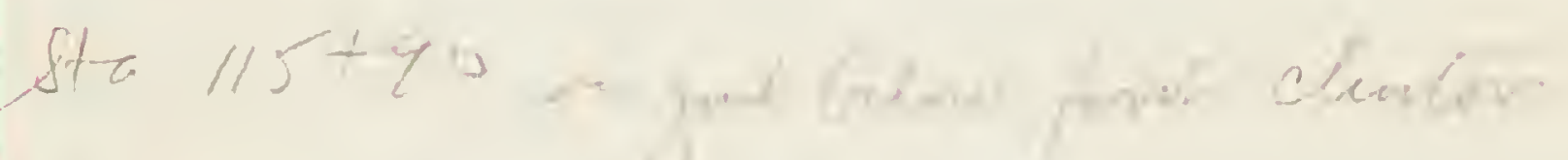

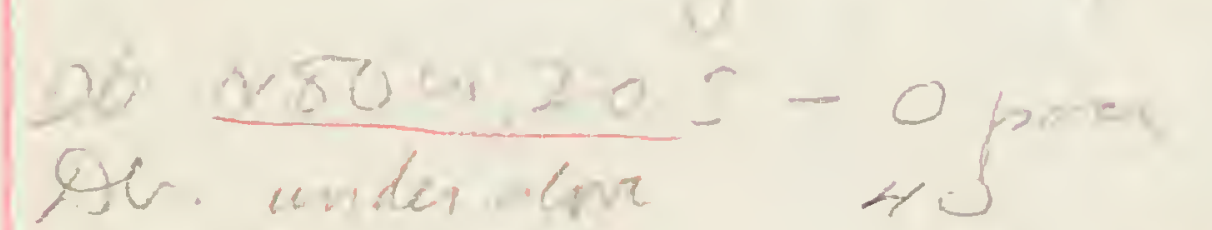

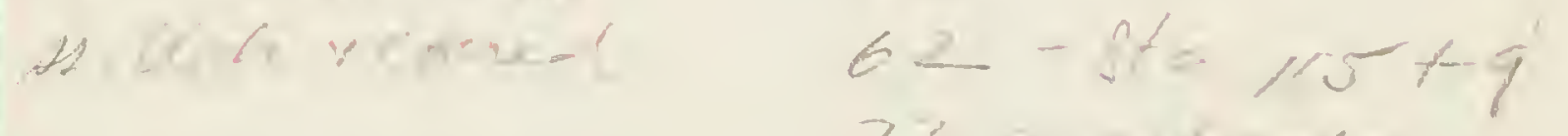

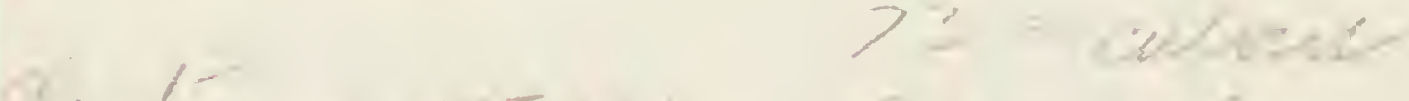

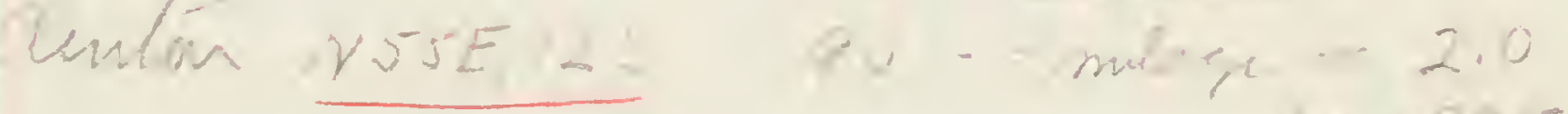

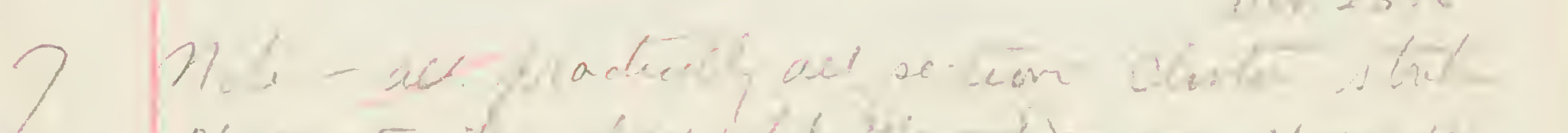

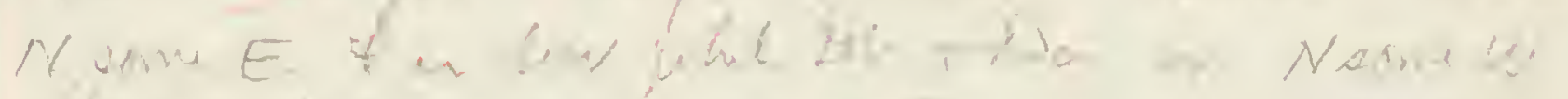

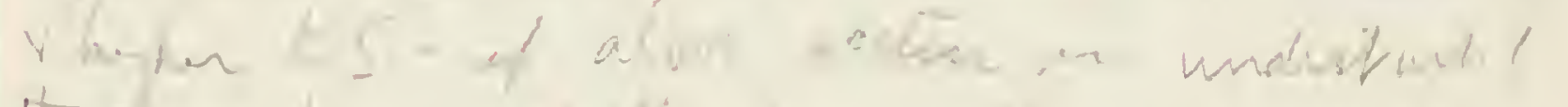

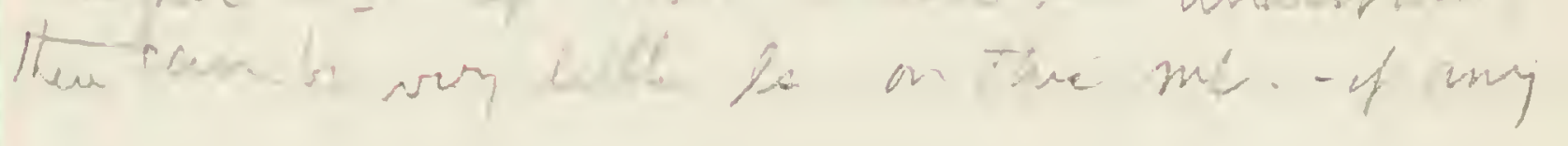

-2.2 canter NiSE, 155

$2.5-2 \quad 1455+213$

$2.65+\quad$ NGOE, 165

$5 y+75=m 11 / 2962,8 x$ and 3140

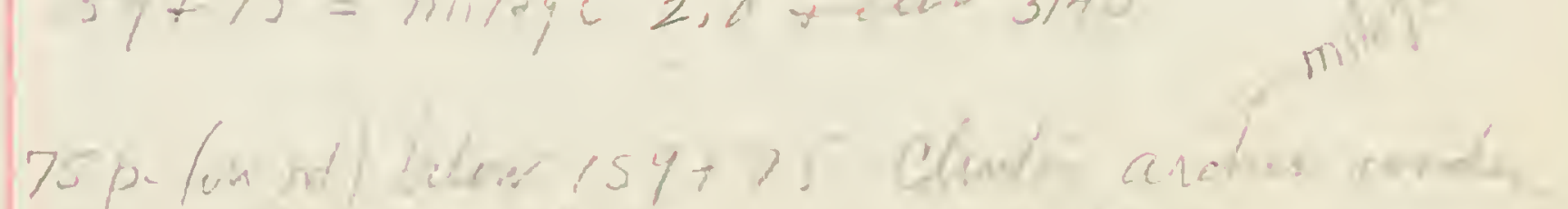

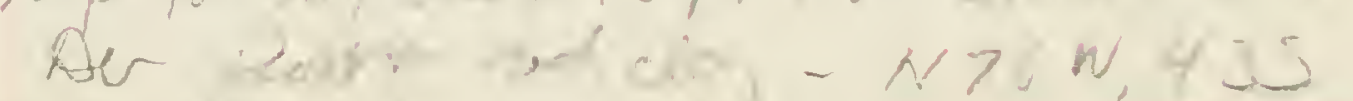

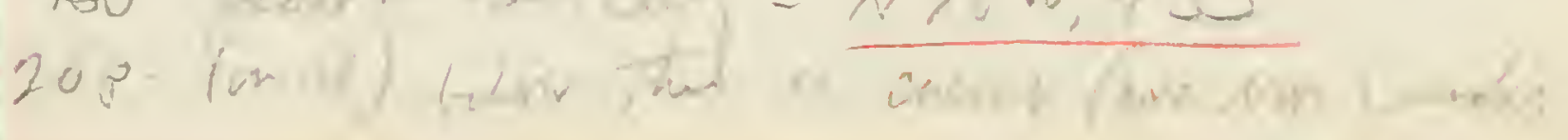




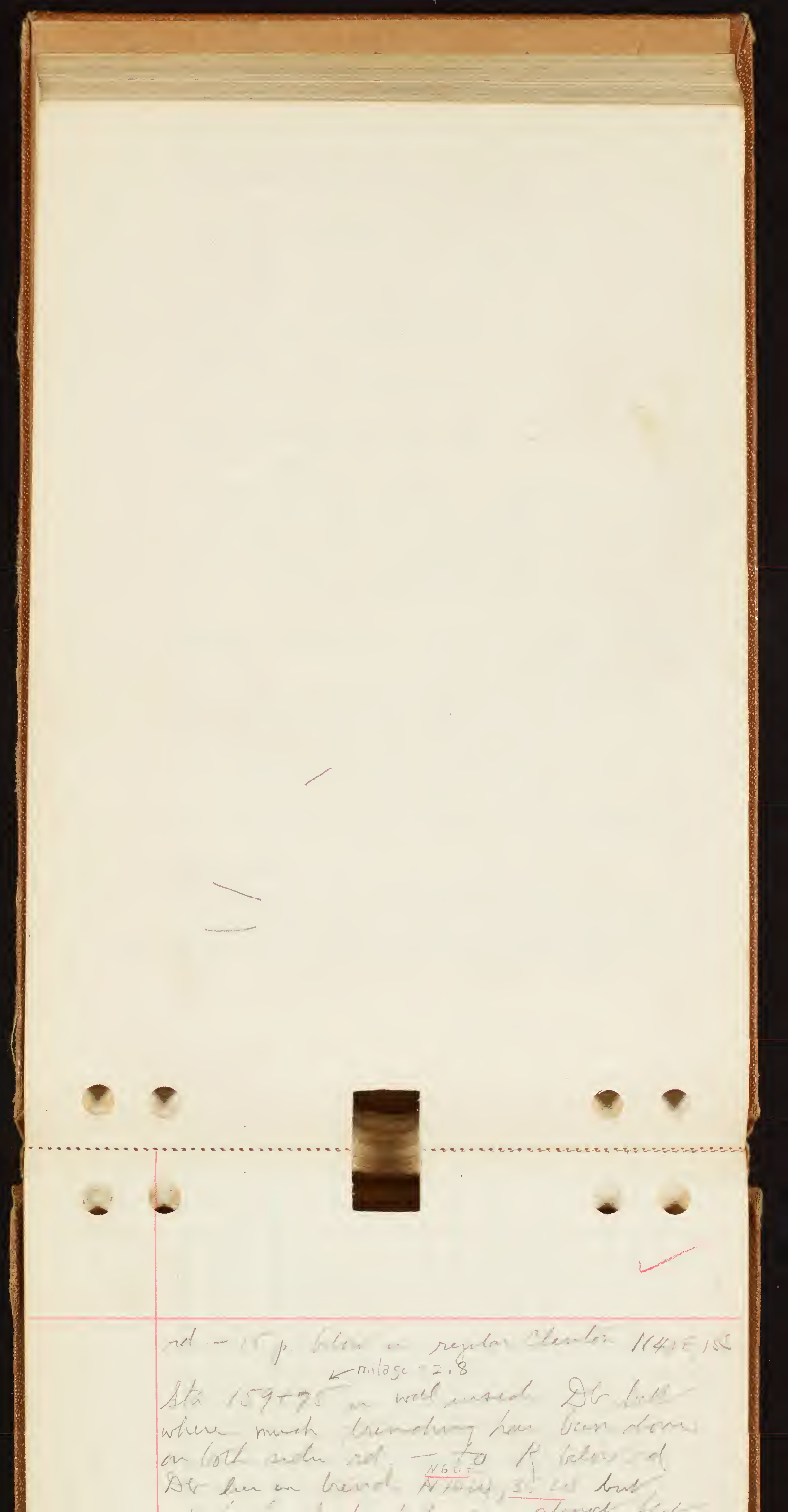




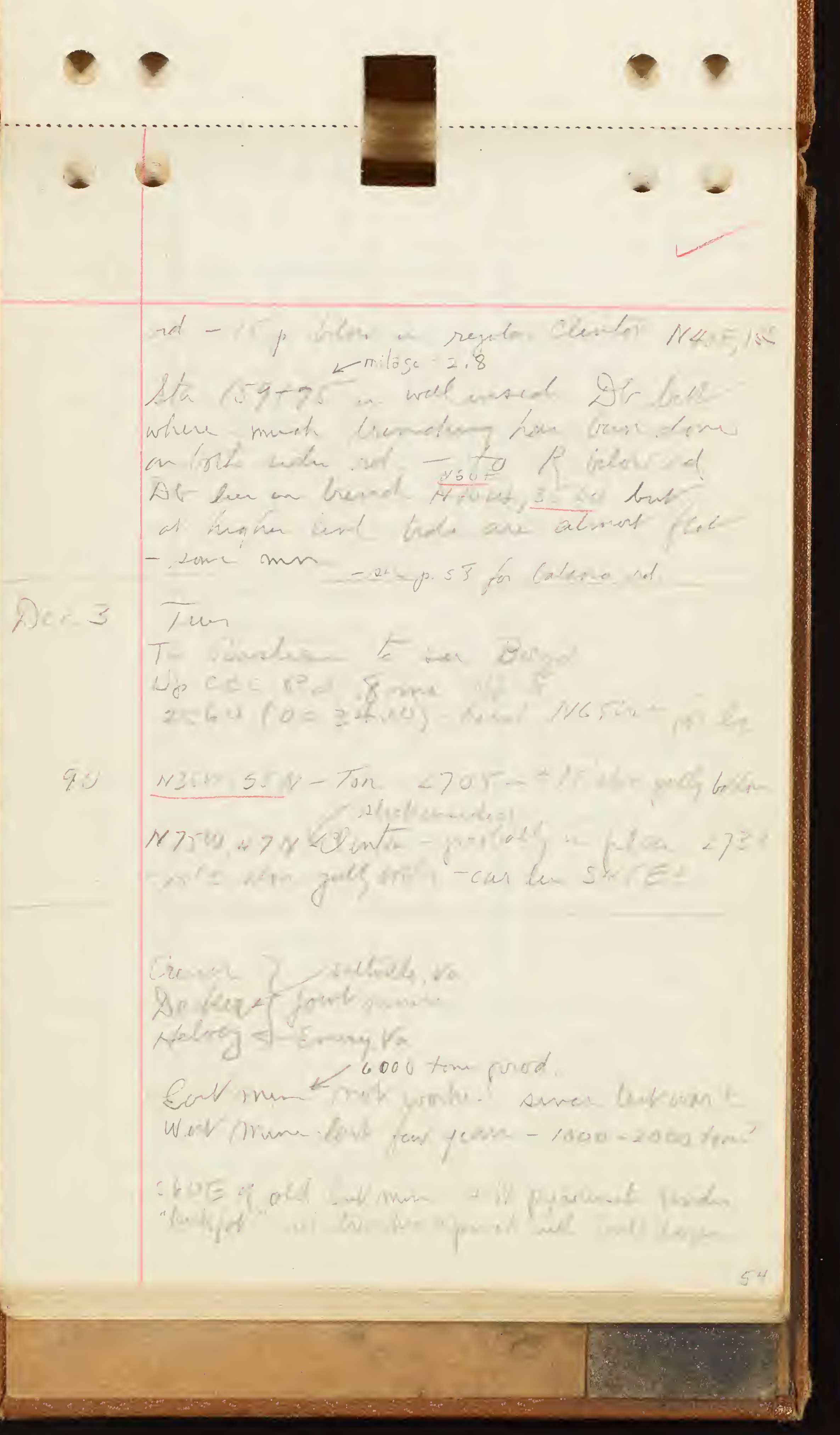




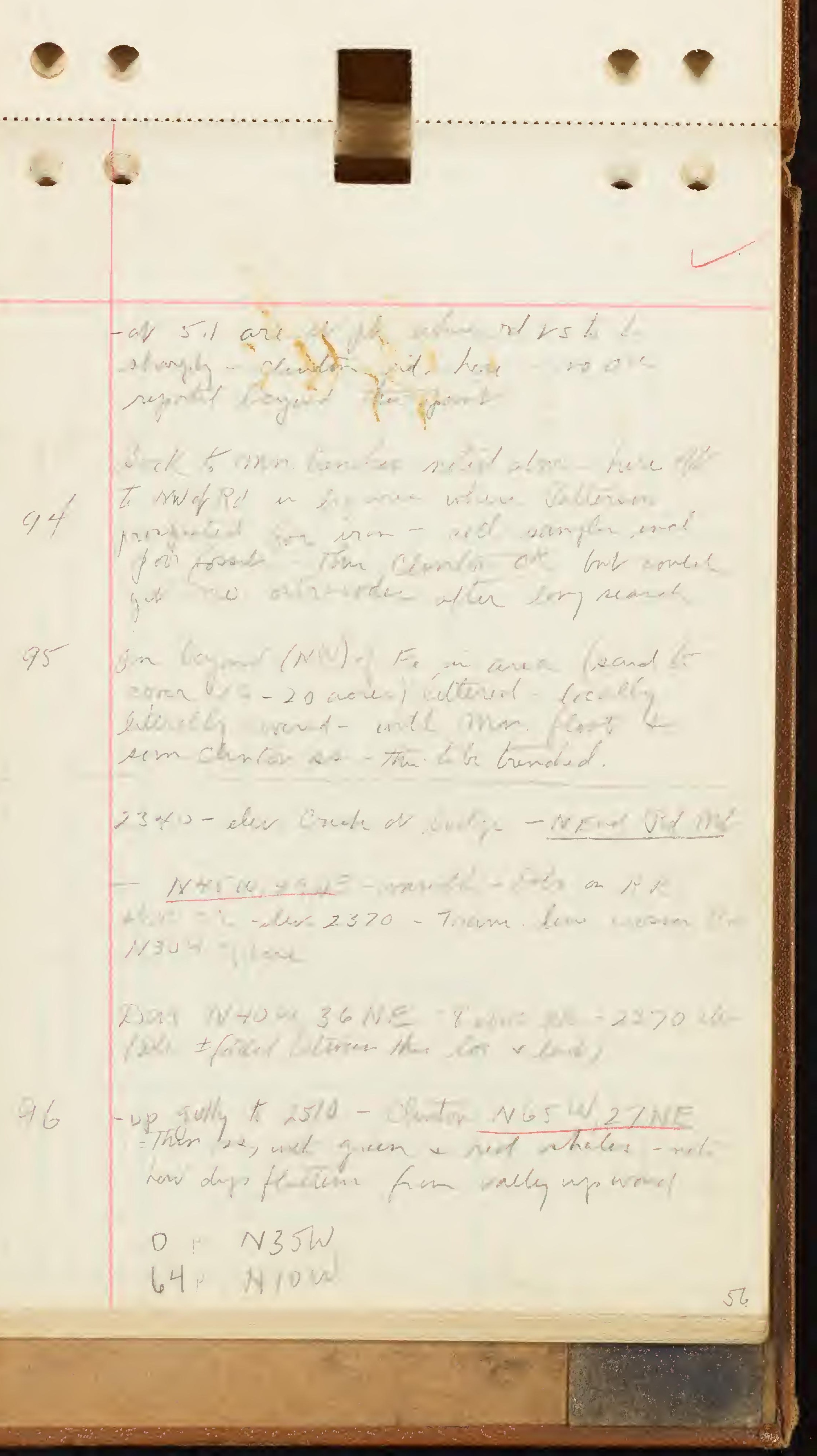




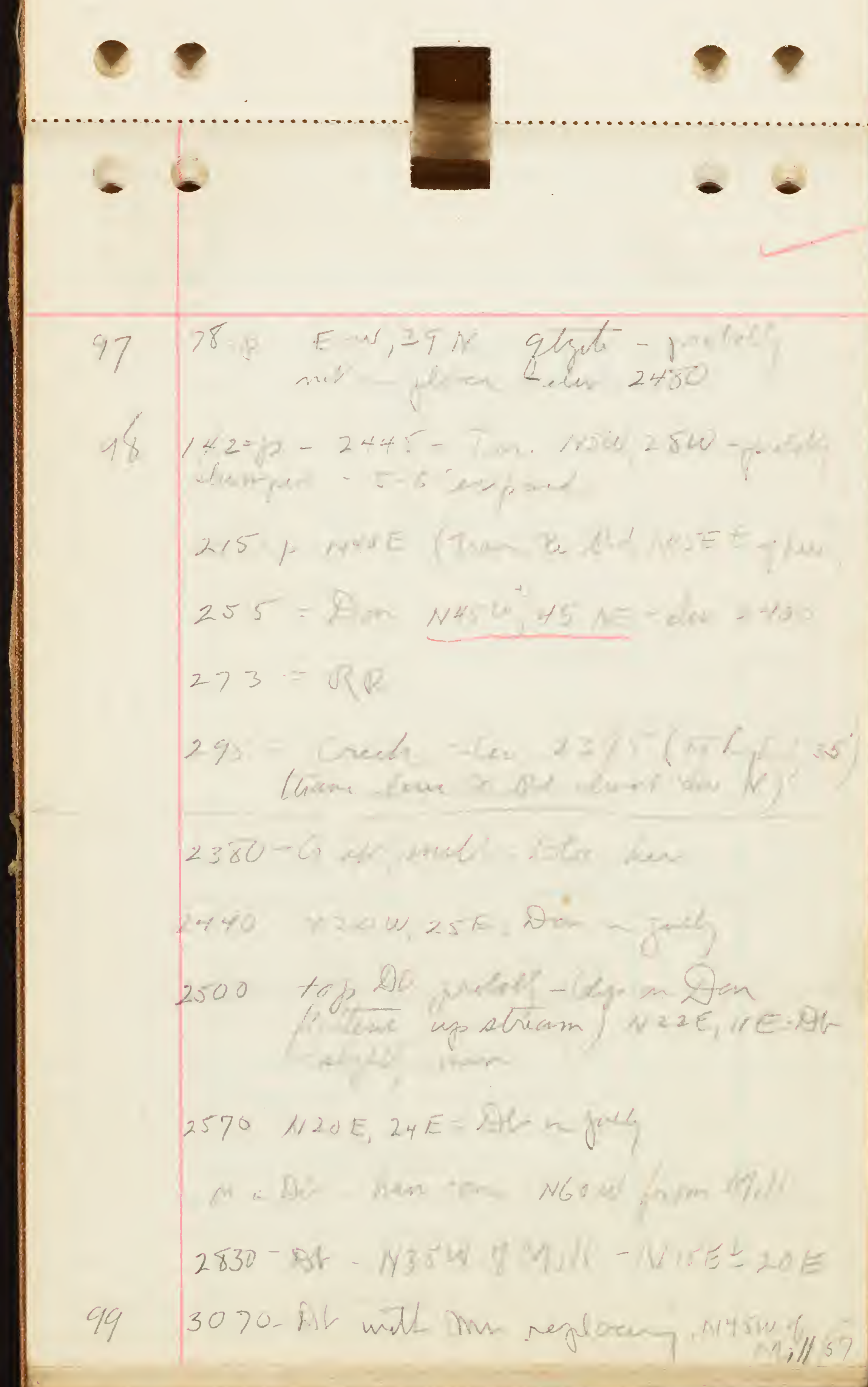




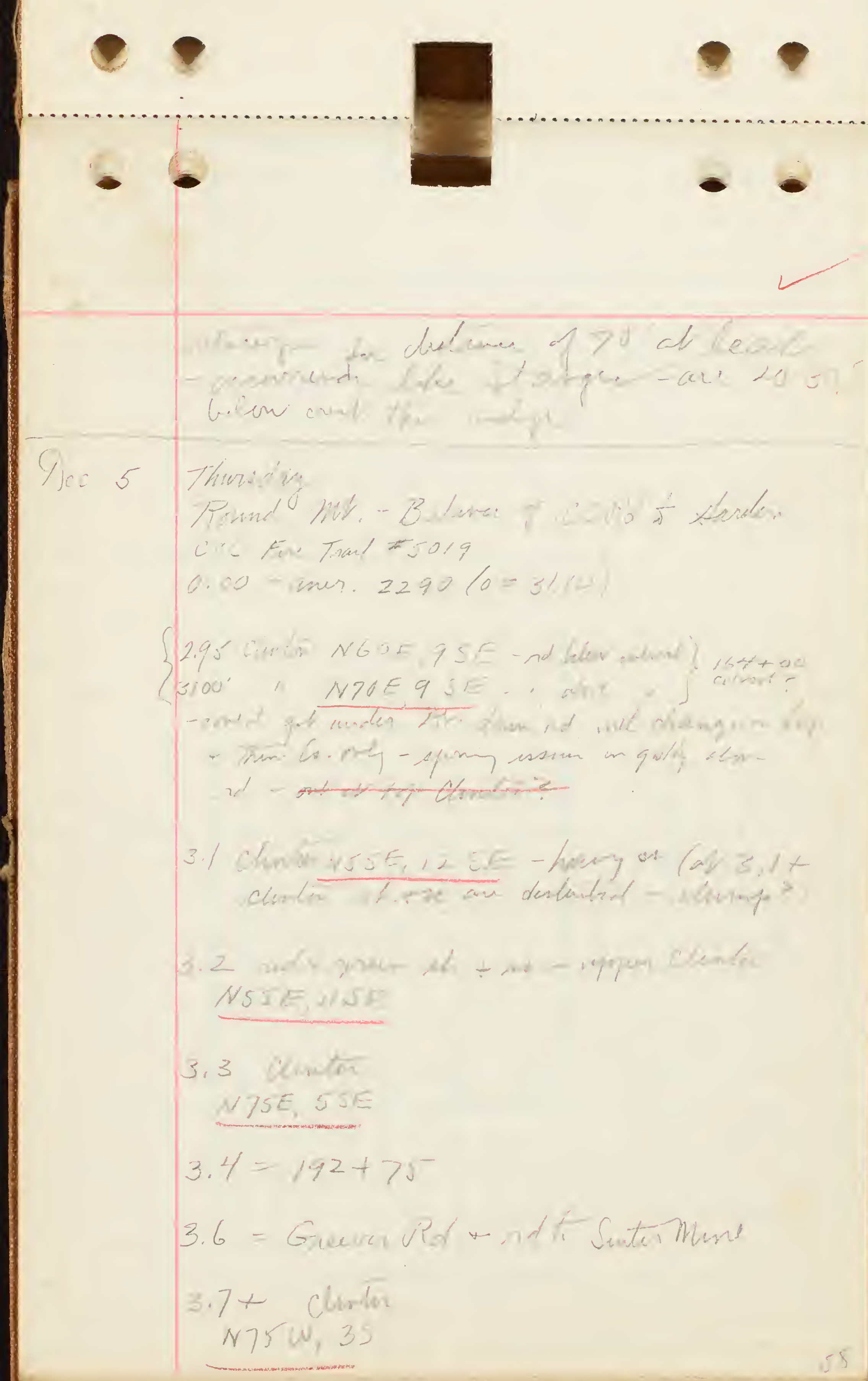


?
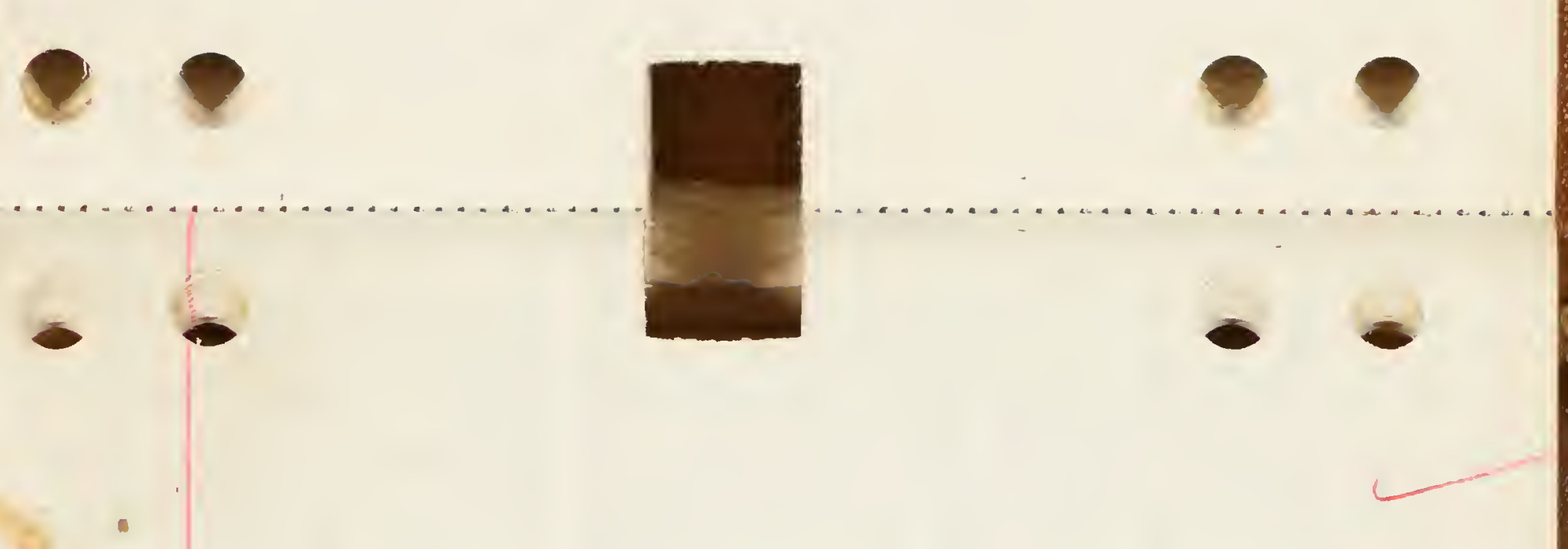

$?$

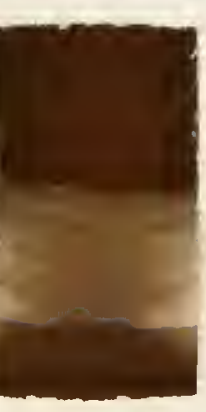

4,05 cliuber

$x+5 x$ if $-20=0 x+24+20$

4.2 Cimber

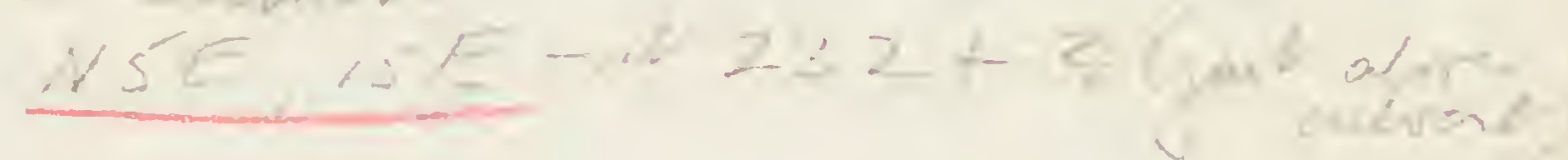

H. S cints:

N2suy ws -qualed th ned!

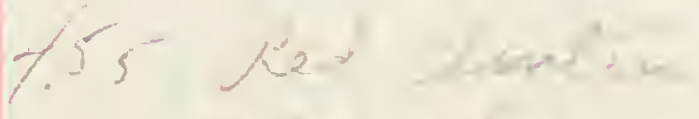

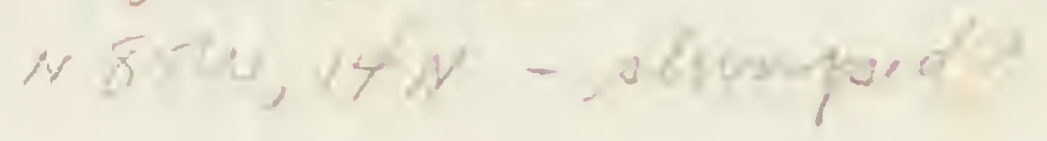

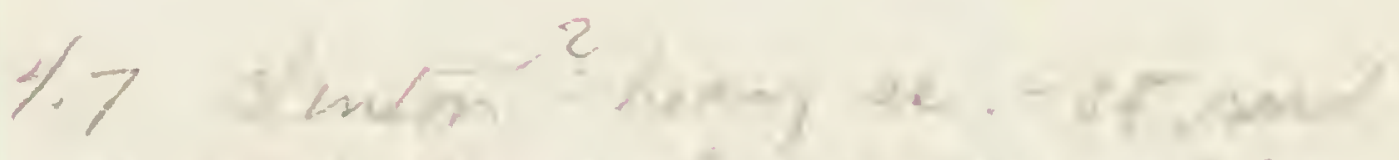

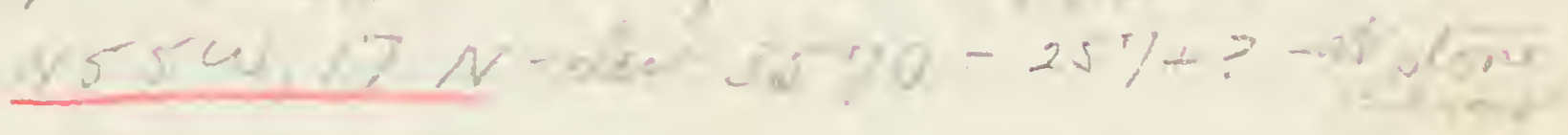

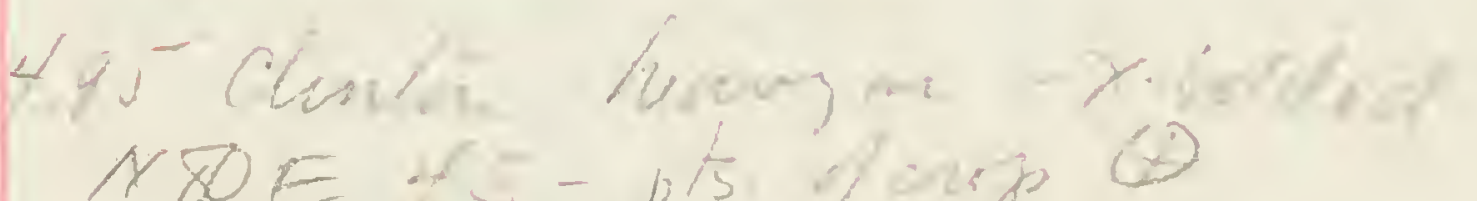

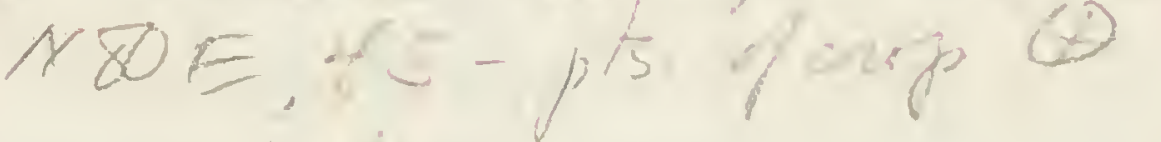

100

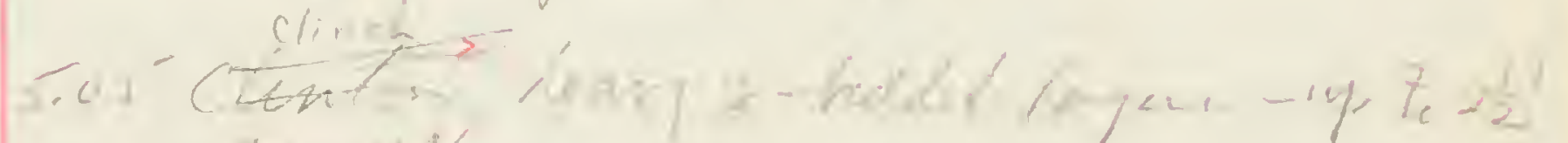
$\times 2520$ we

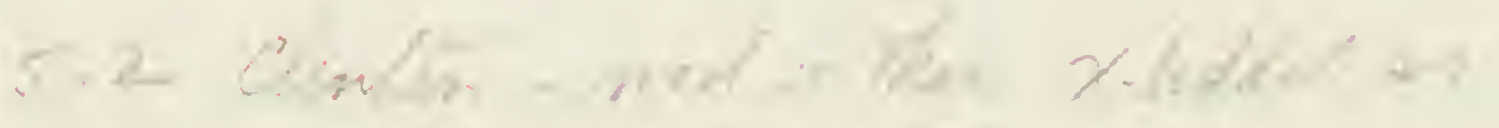

f $-45,251 \mathrm{~N}=255+20$

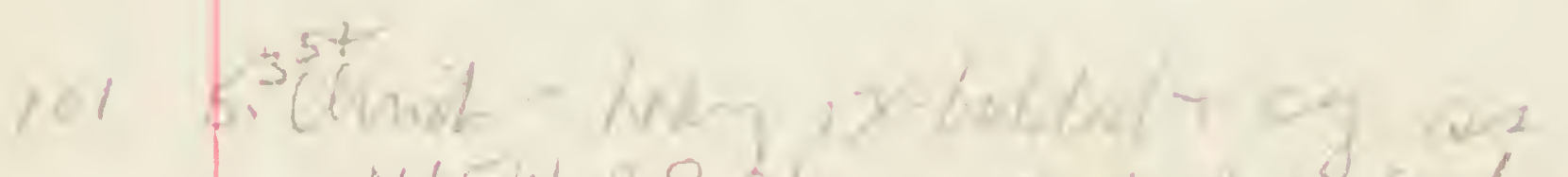
N $15 \mathrm{~W} I S N=292+50+$ brok an

$$
5.5 \text { - curb sts } 298-\text { chen } 3755
$$

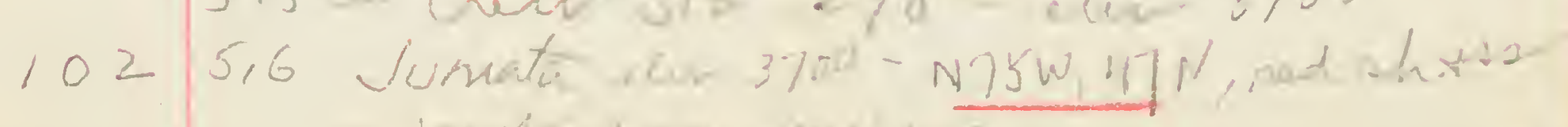

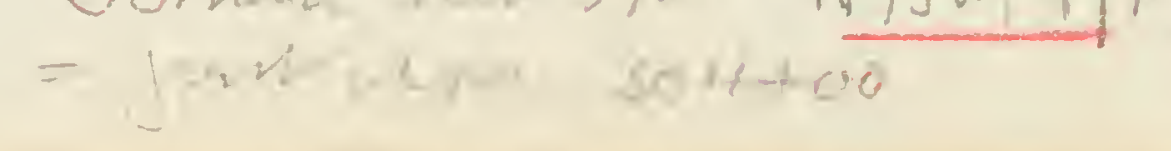




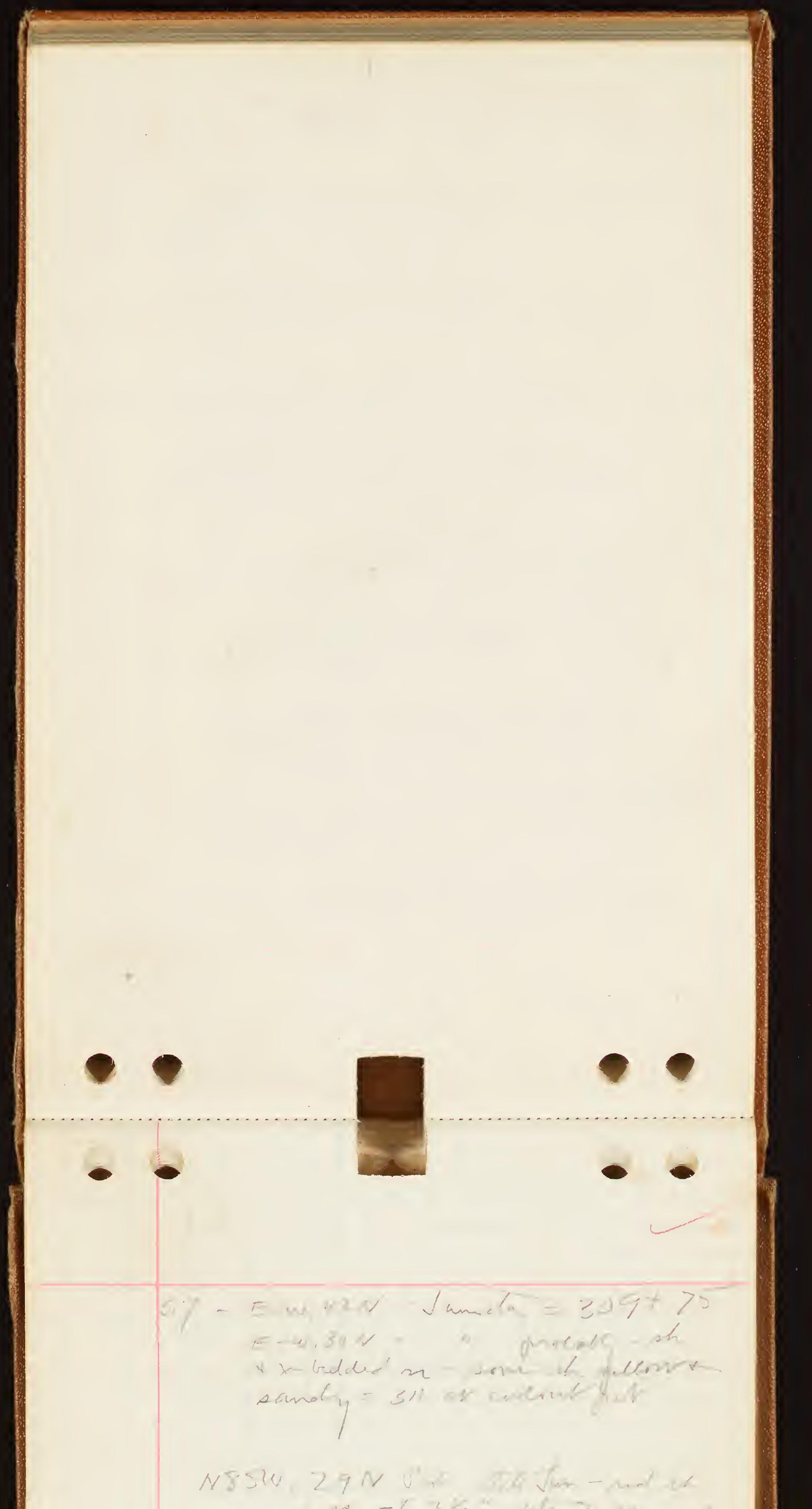



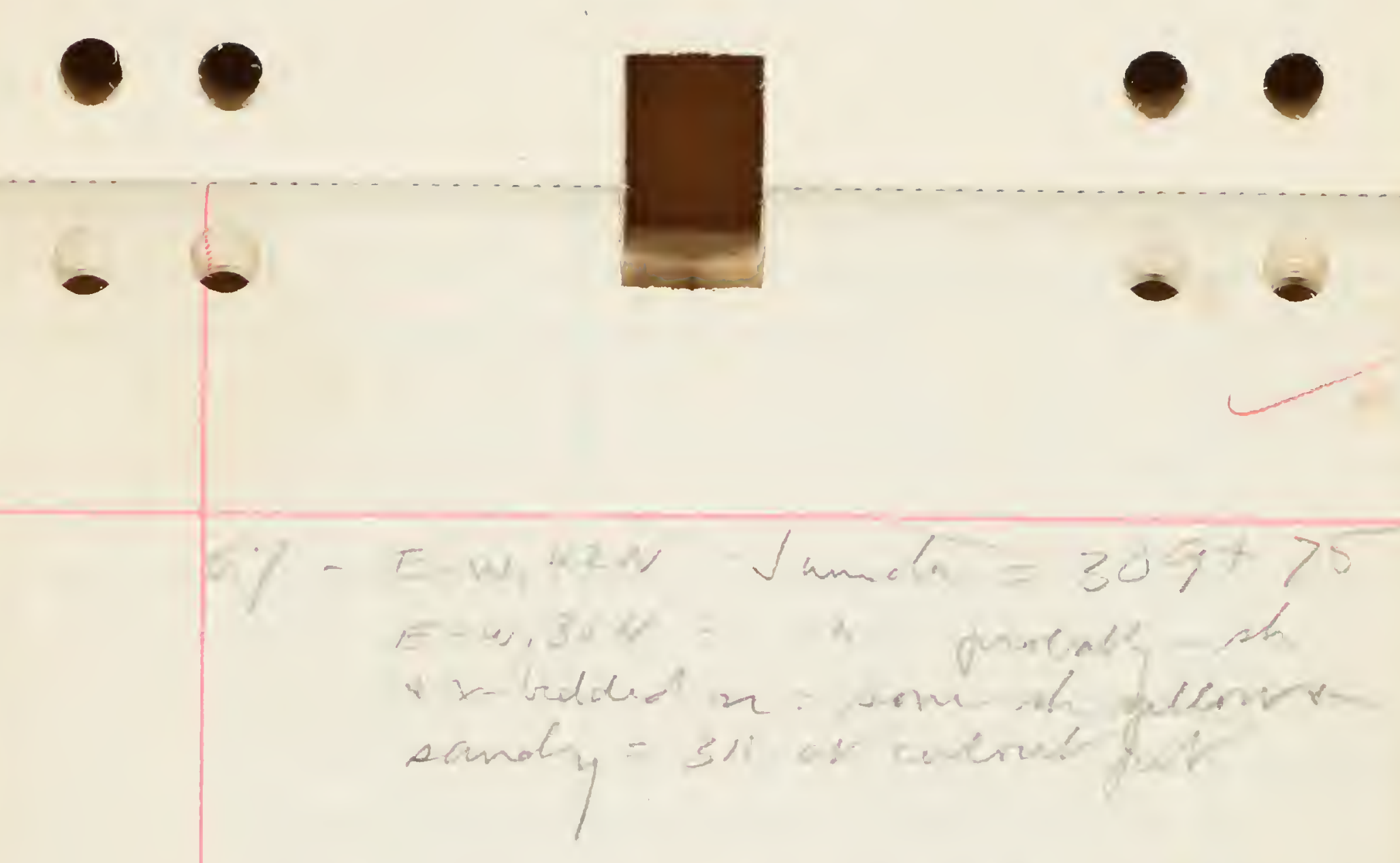

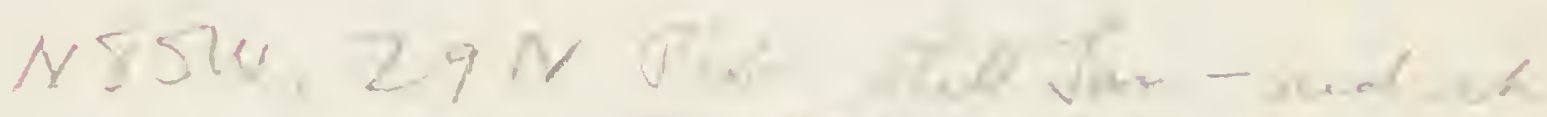

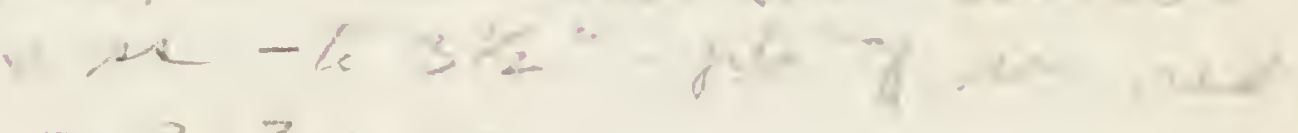

$$
\begin{aligned}
& =313+00
\end{aligned}
$$

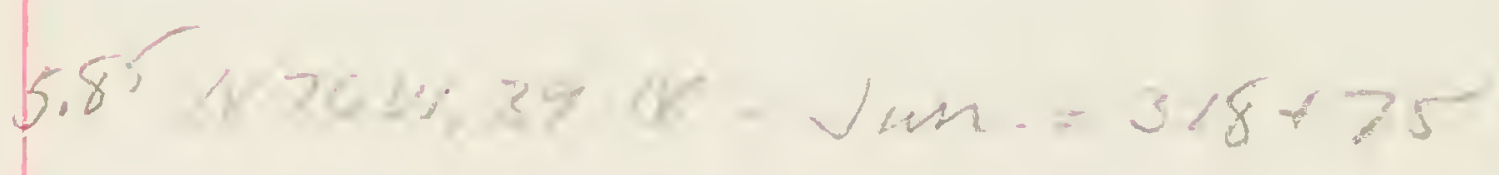

Fonkeat Jun WE-Margunch

E-AT you-yist th

103

E-M $x>5$ ye

N>5 $w, 32 M, E_{0}-M m=322+50$

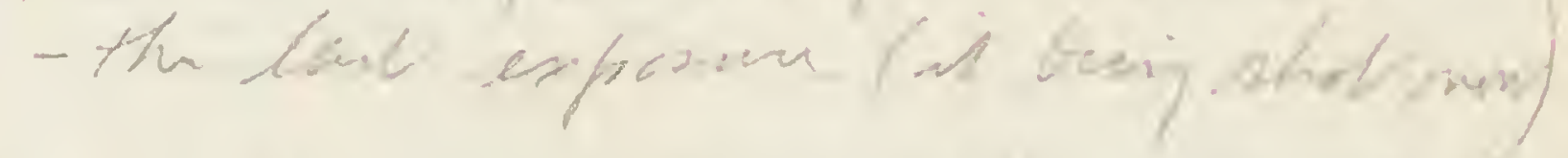

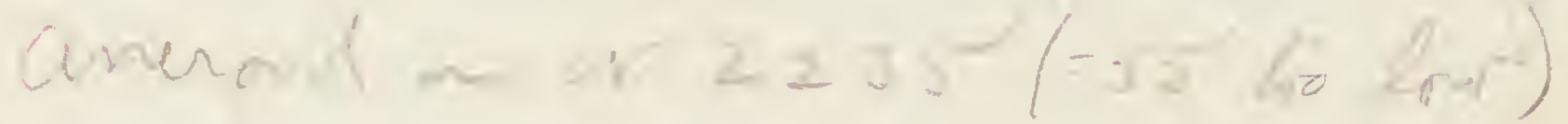




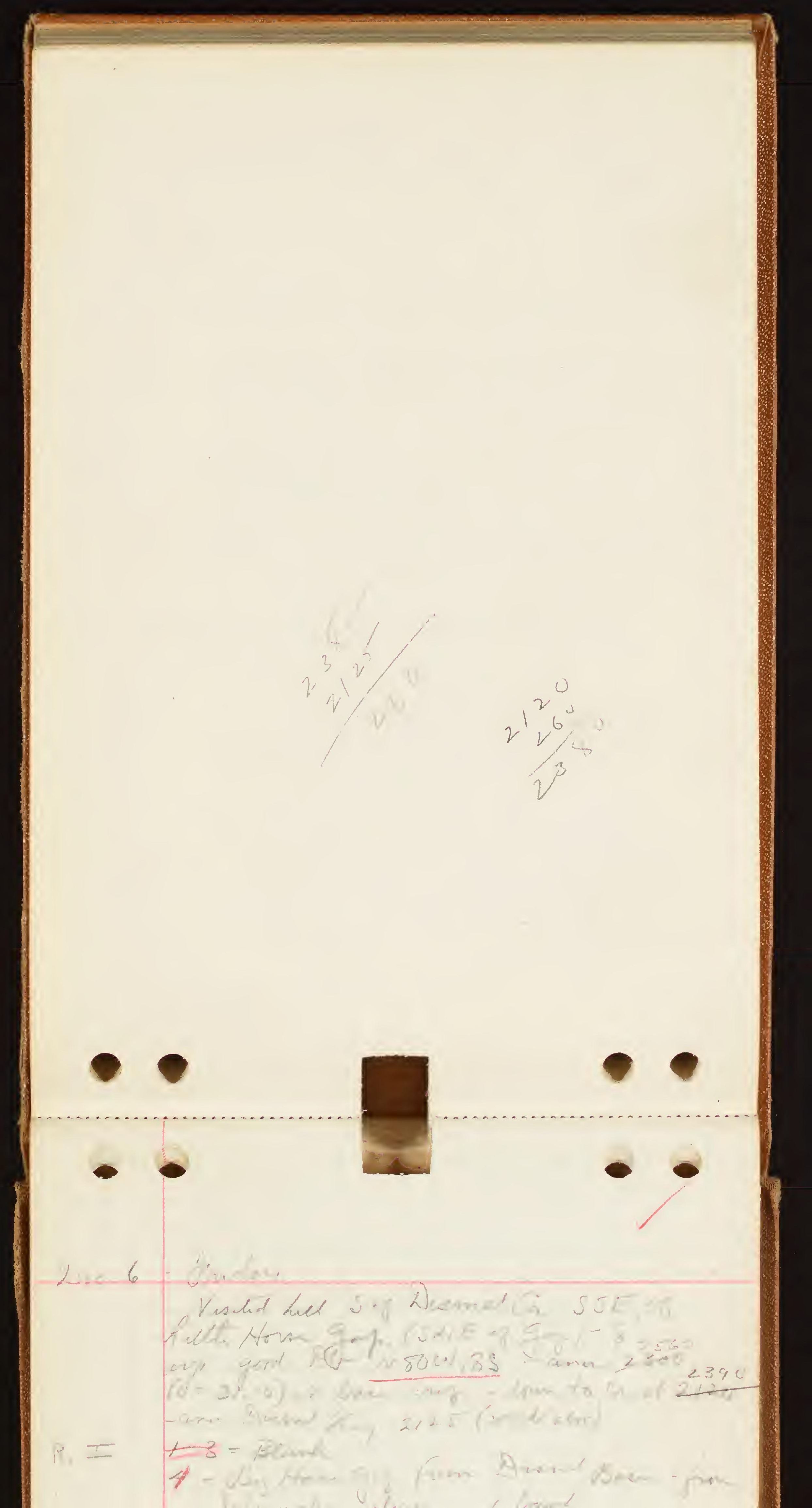




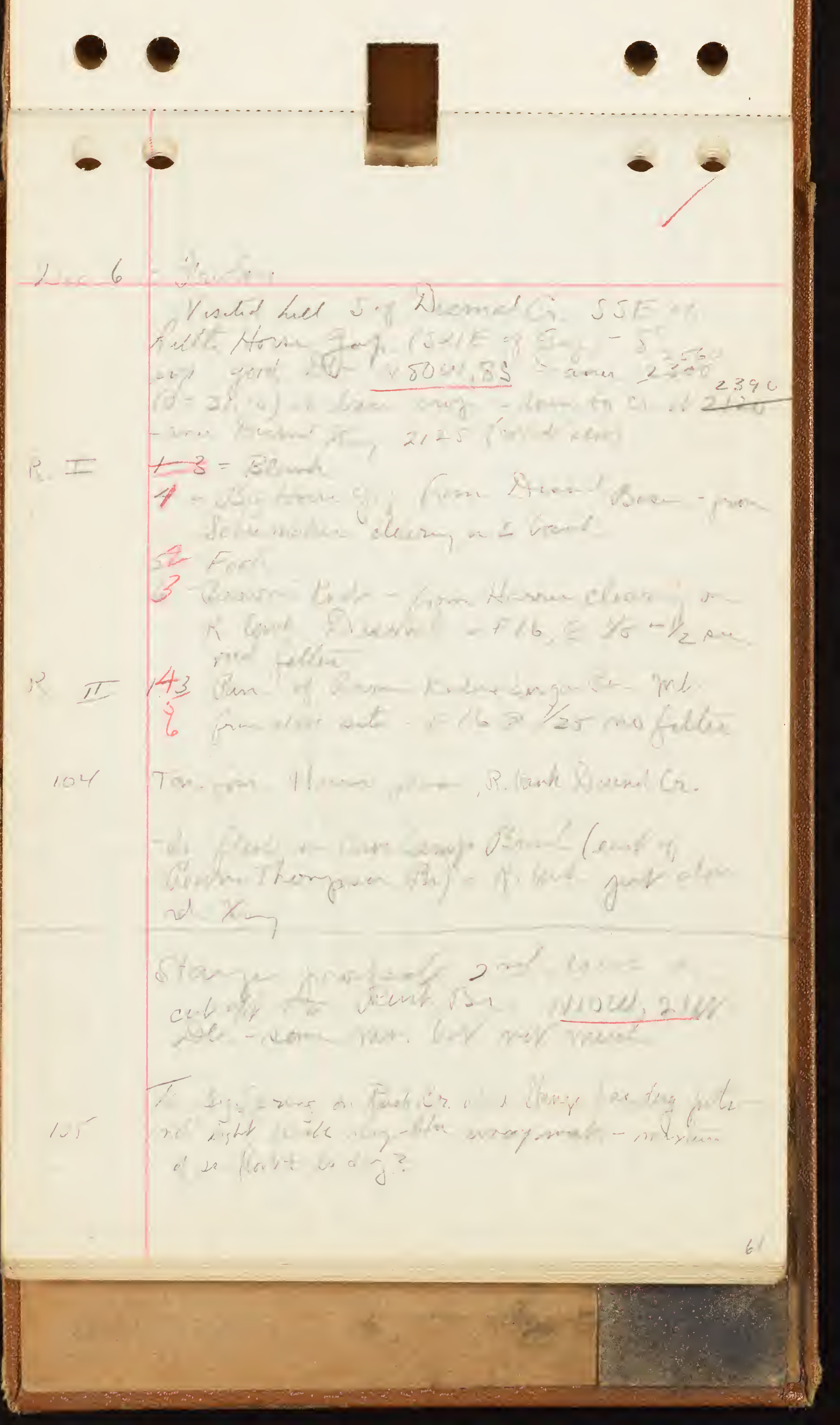




\section{-}

$\cdots$

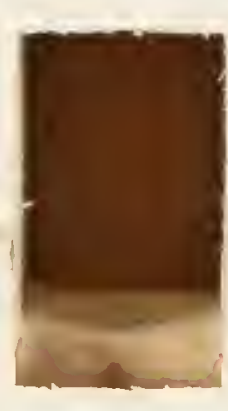

-

-

2 G. Tnatan

Whe hom Gor, $3-80(0=31.72)$

106

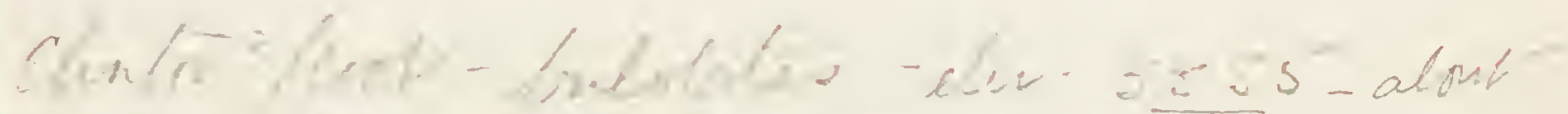

$r_{4}$ ime ECE

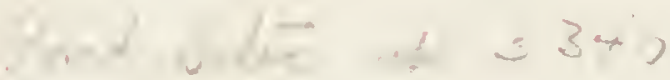

Q/bess

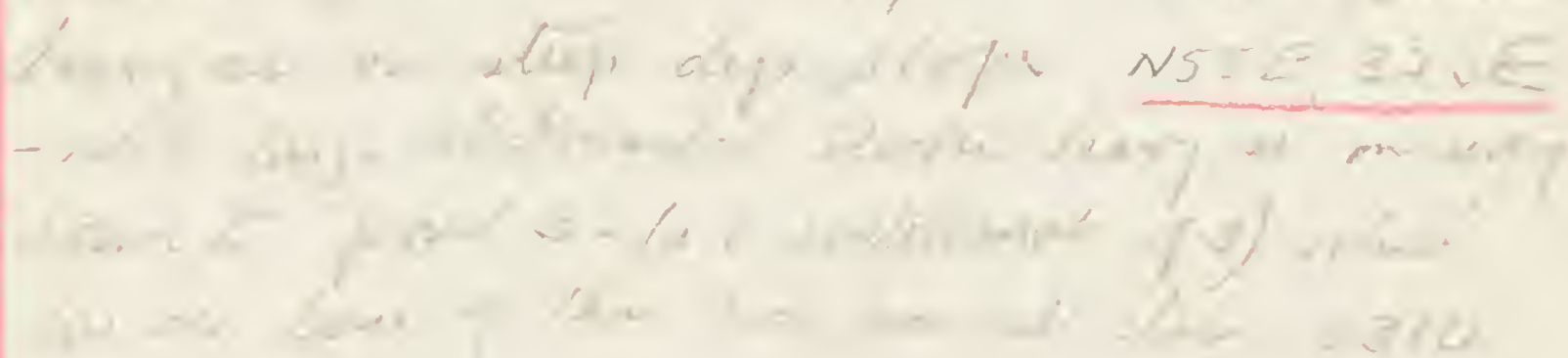

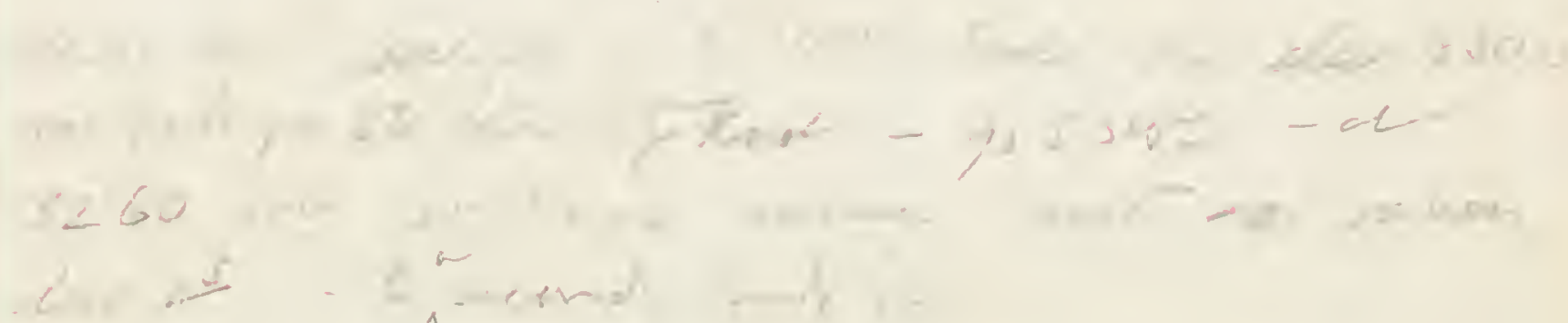

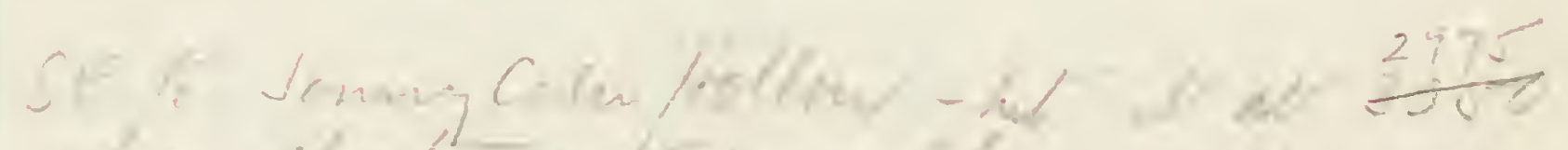

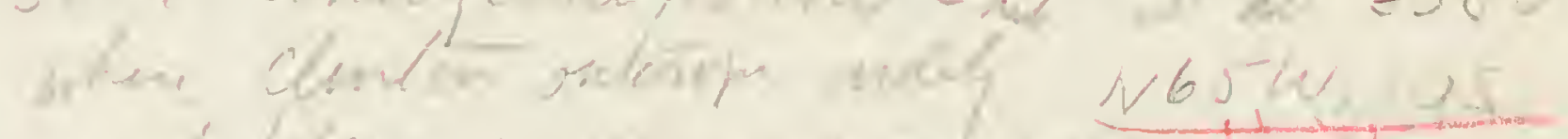

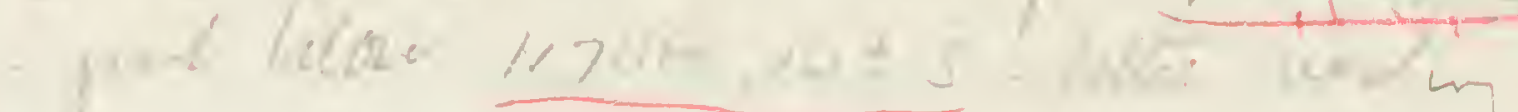
$255=$

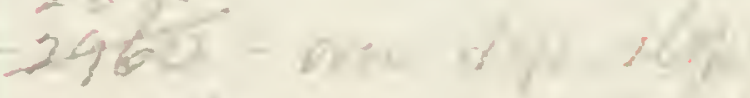

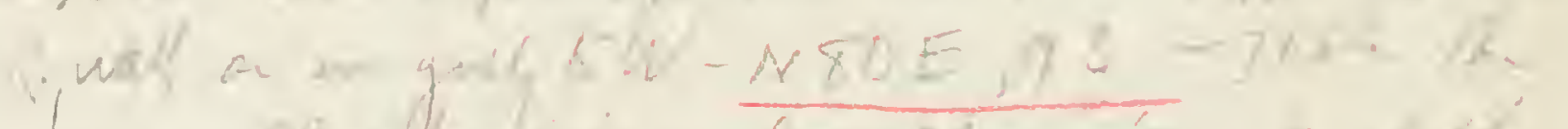

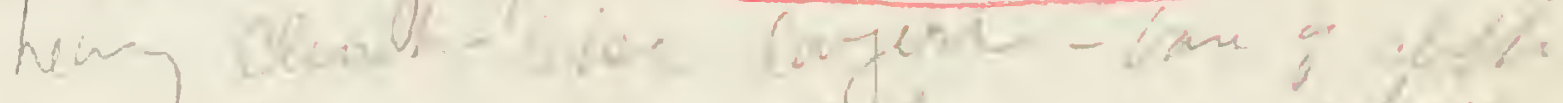

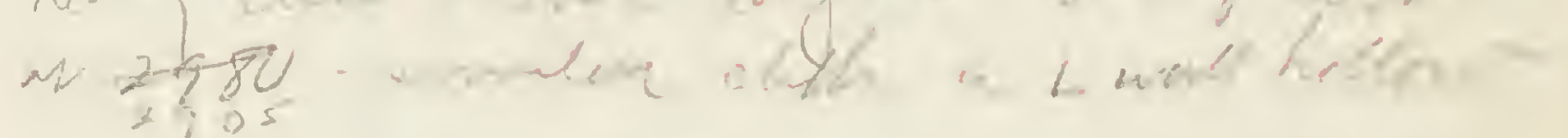

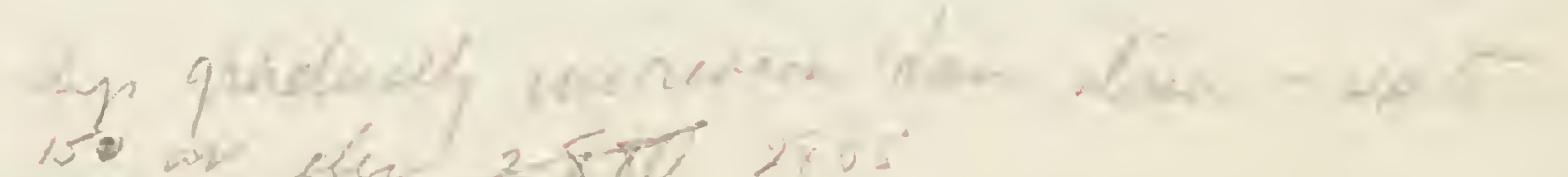

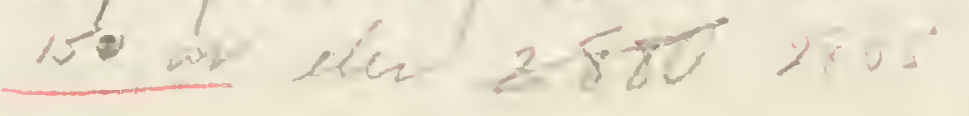




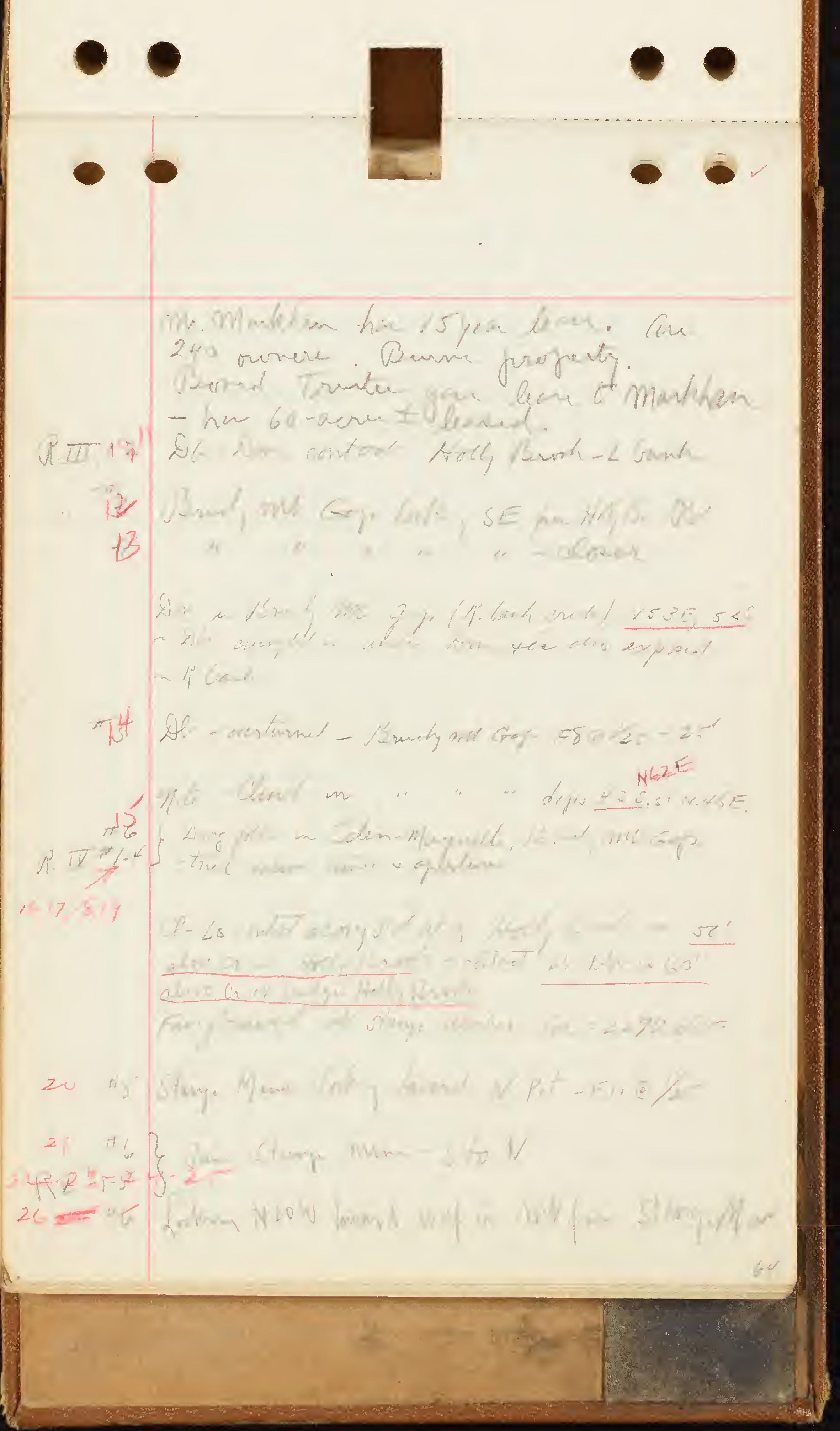



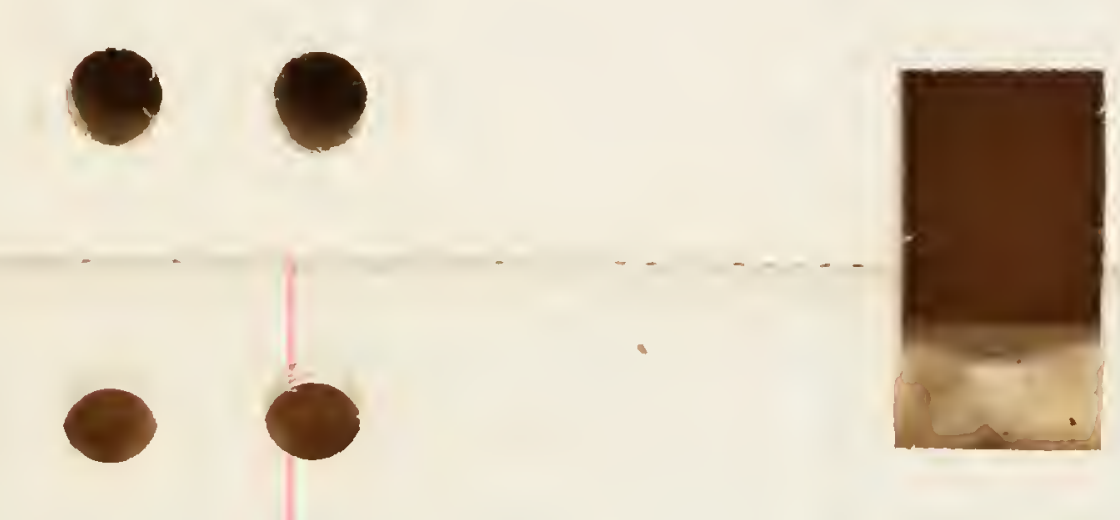

-

-

$3 \pi 27$

7293

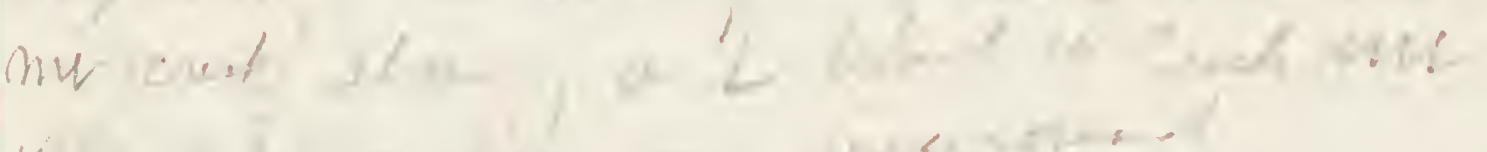

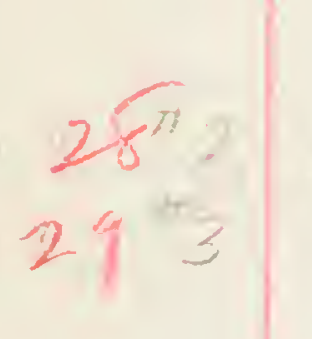

300

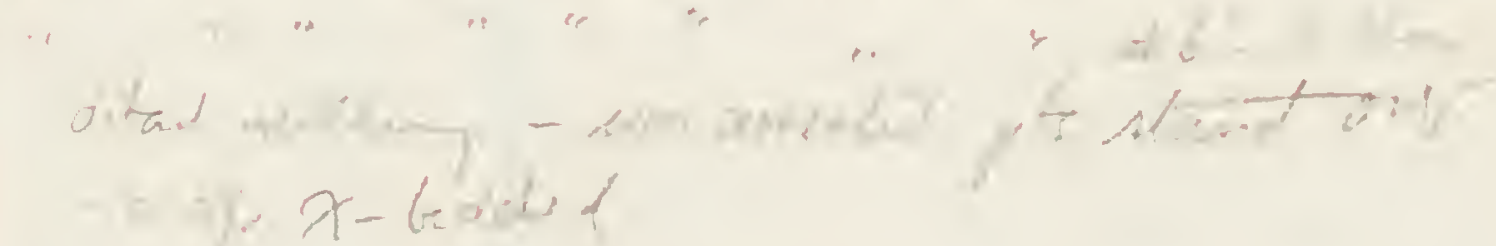

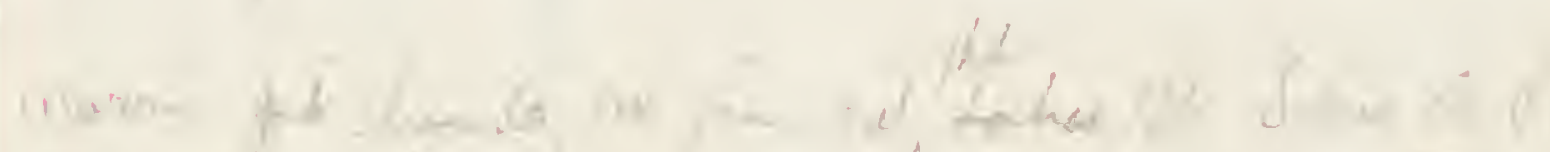

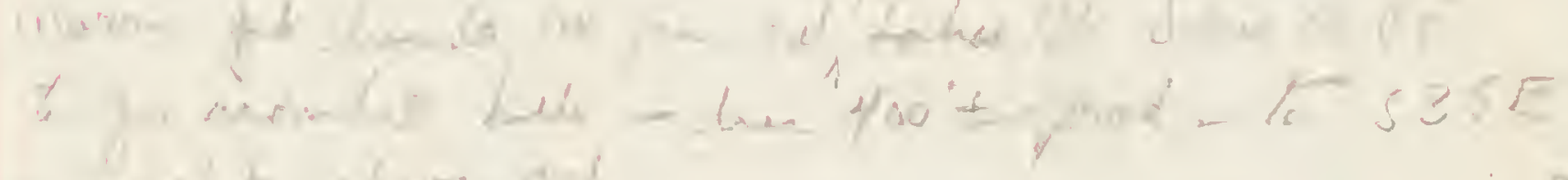

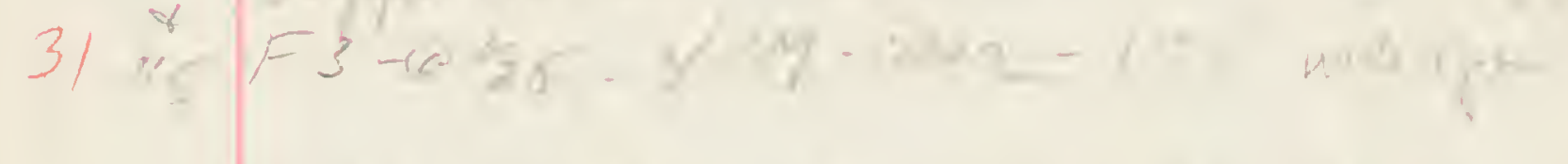

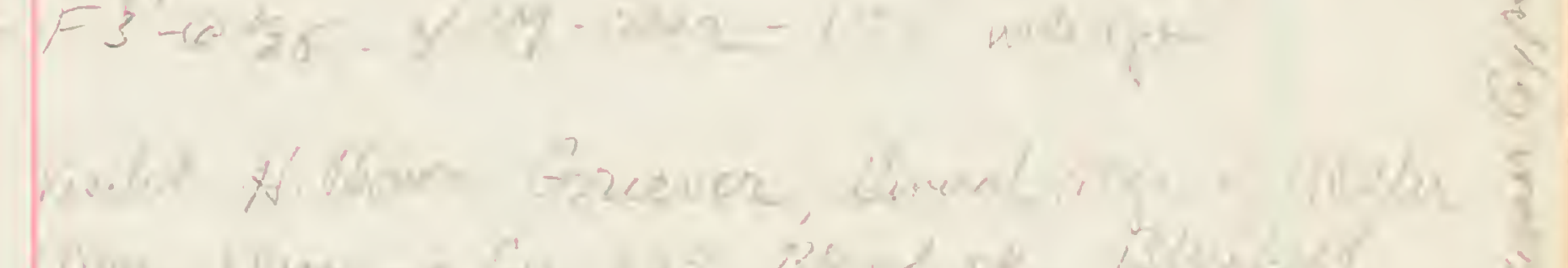

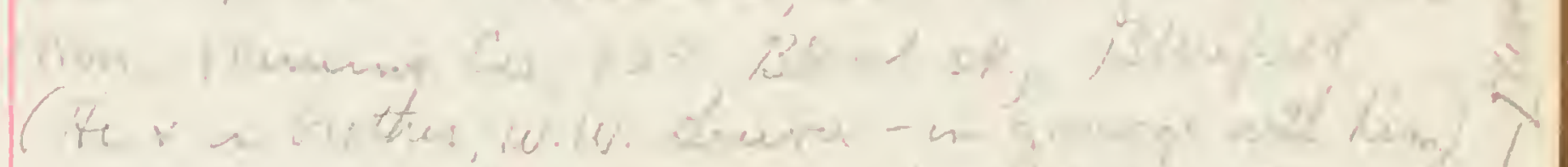

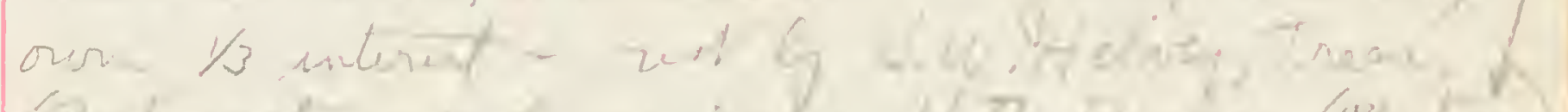

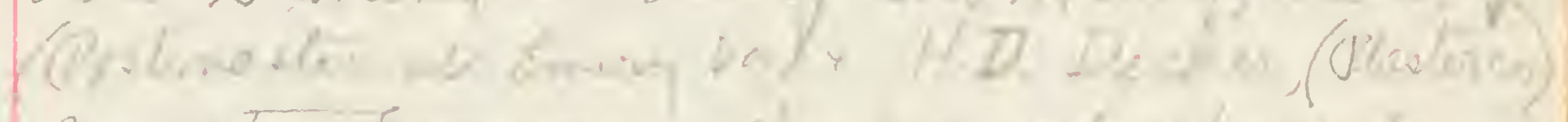

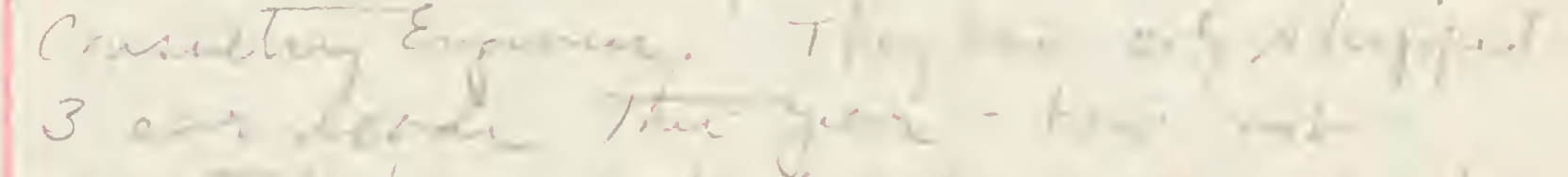

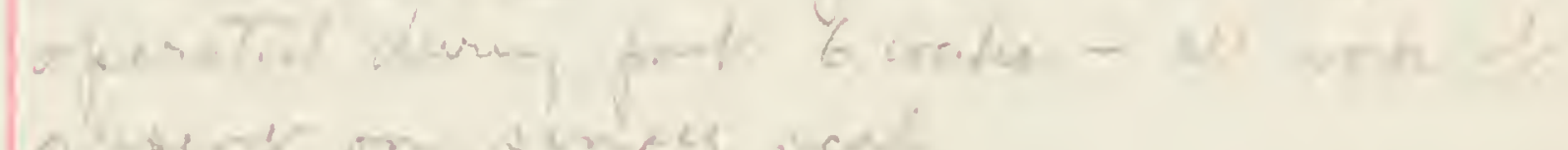

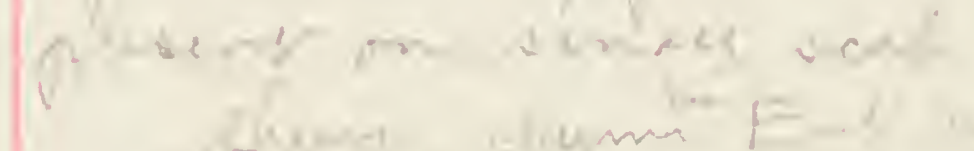

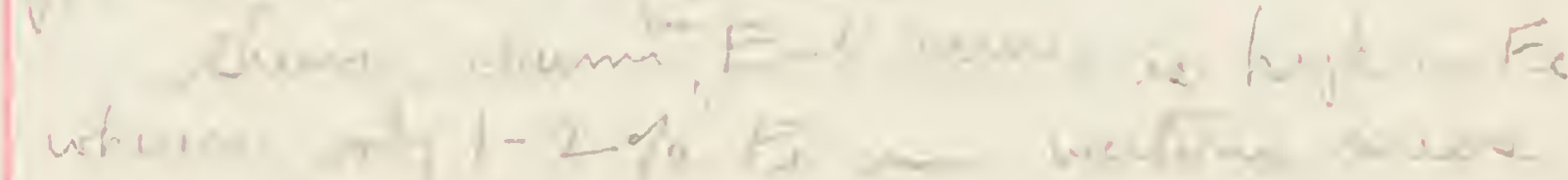

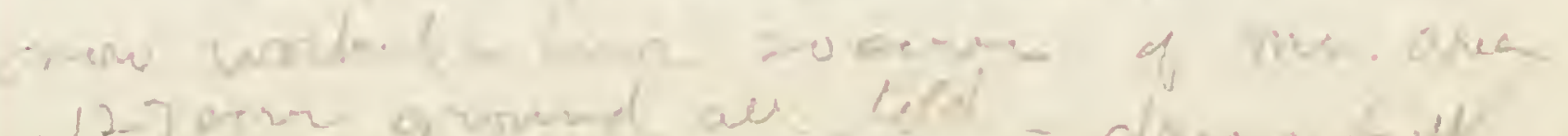

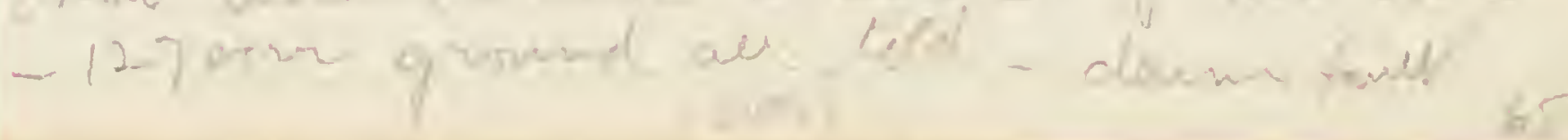




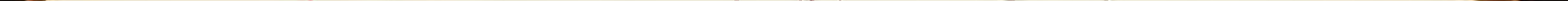




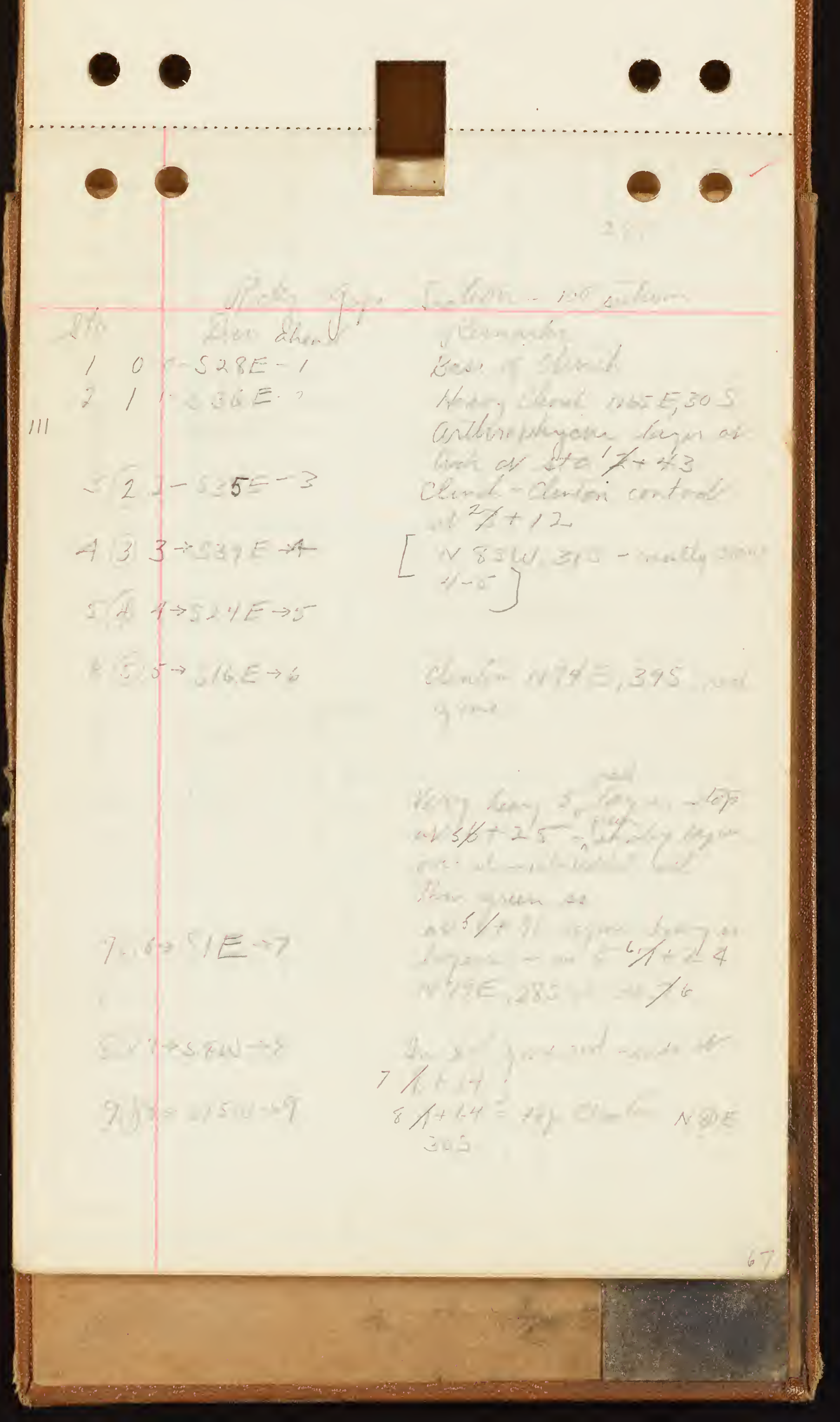




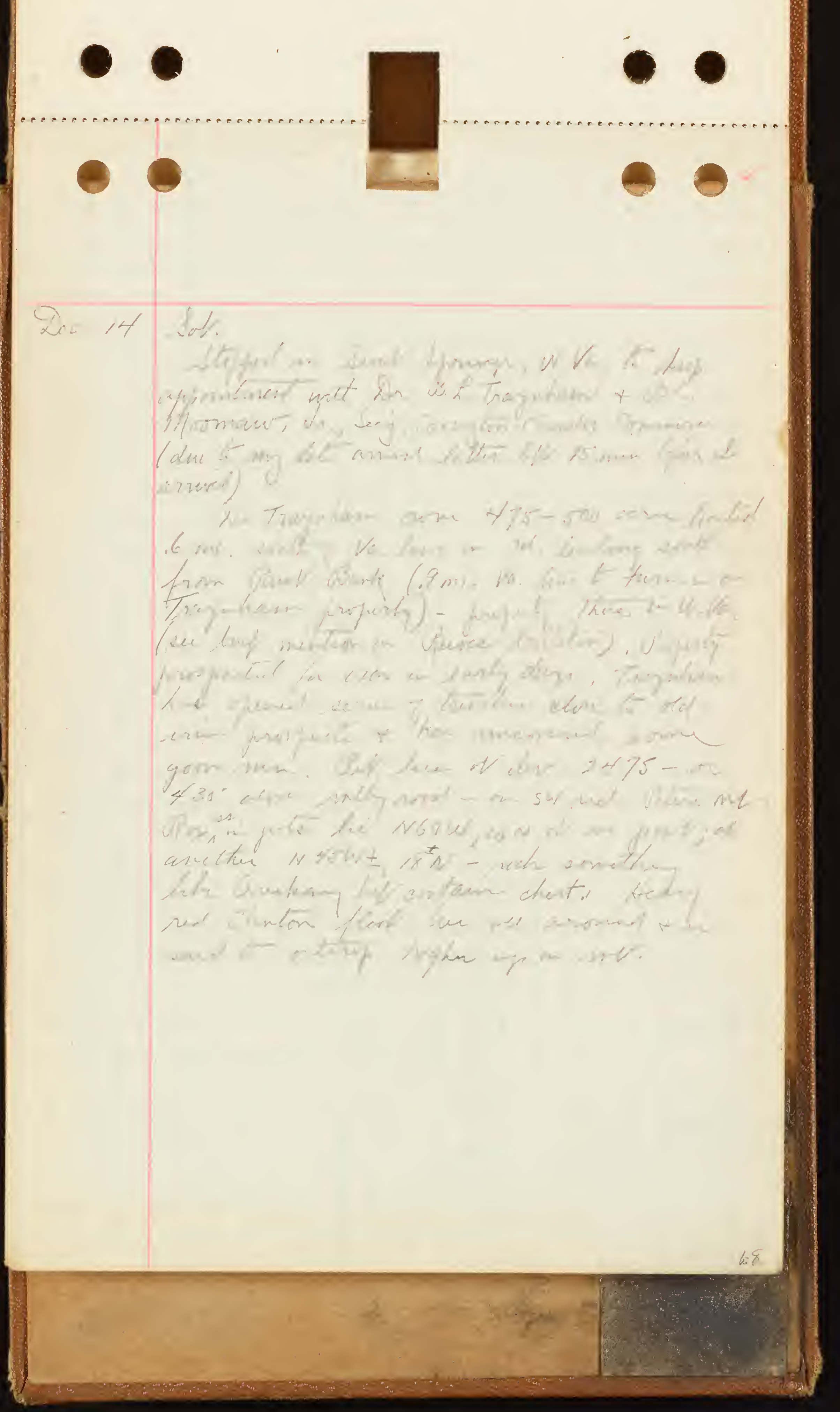


-

-

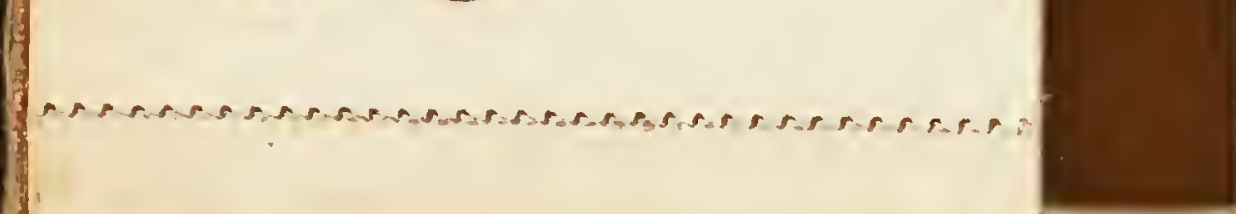

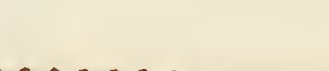




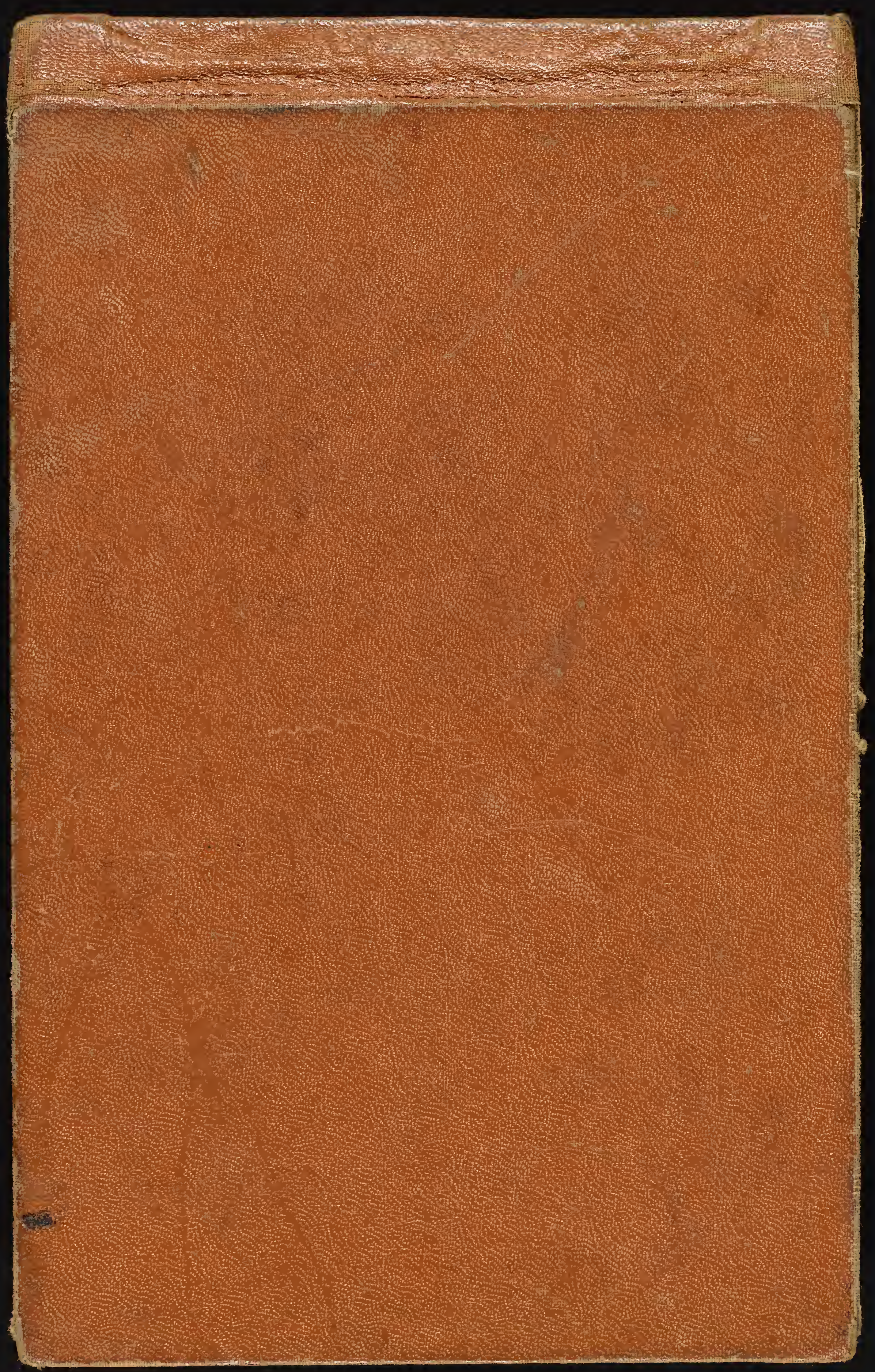

